Flood and Coastal Storm Damage Reduction Research and Development Program

\title{
STWAVE: Steady-State Spectral Wave Model User's Manual for STWAVE, Version 6.0
}

Thomas C. Massey, Mary E. Anderson, Jane McKee Smith, September 2011 Julieta Gomez, and Rusty Jones

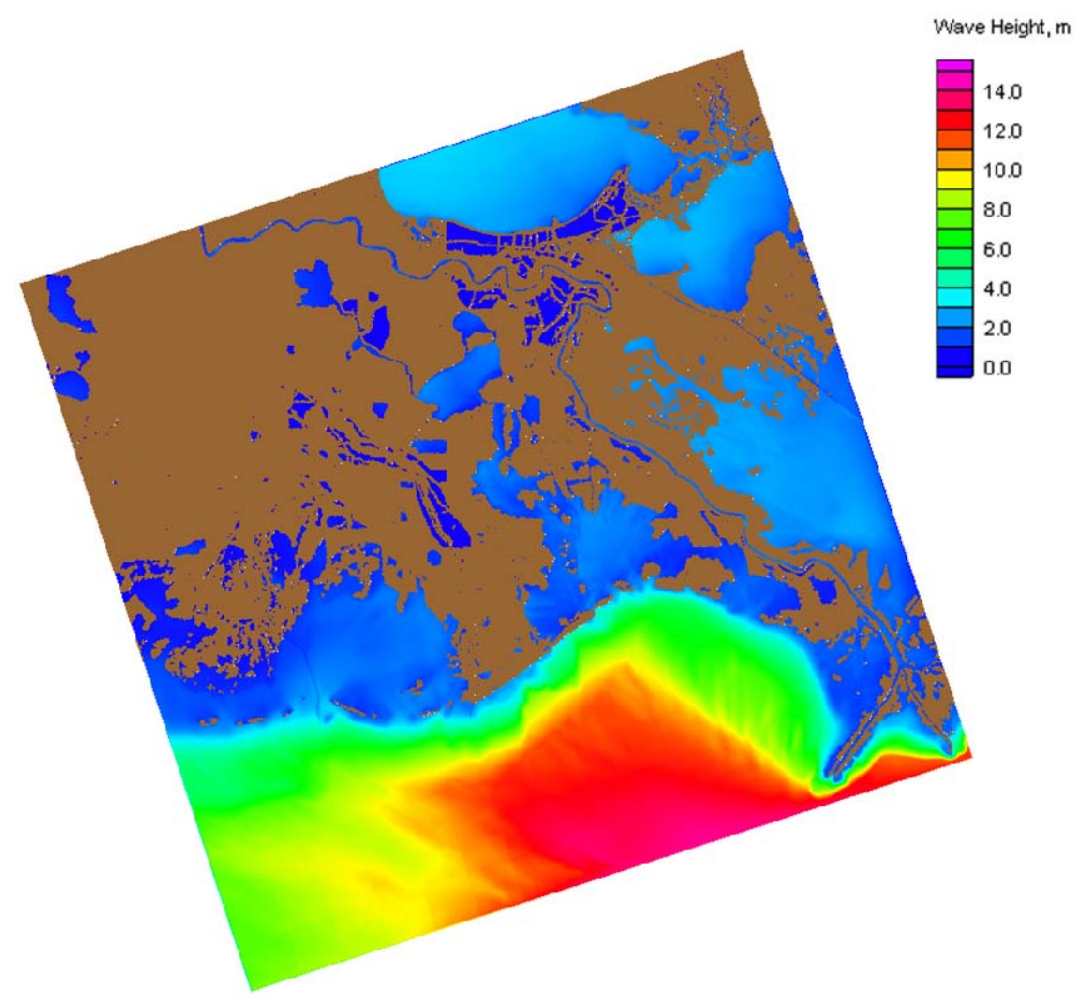




\section{STWAVE: Steady-State Spectral Wave Model User's Manual for STWAVE, Version 6.0}

Thomas C. Massey, Mary E. Anderson, and Jane McKee Smith

Coastal and Hydraulics Laboratory

U.S. Army Engineer Research and Development Center

3909 Halls Ferry Road

Vicksburg, MS 39180-6133

Julieta Gomez

University of Puerto Rico at Mayagüez

Mayagüez, Puerto Rico

Rusty Jones

Aquaveo, LLC.

3210 North Canyon Road

Suite 300

Provo, UT 84604-6508

Final report

Approved for public release; distribution is unlimited.

Prepared for U.S. Army Corps of Engineers

Washington, DC 20314-1000

Monitored by Coastal and Hydraulics Laboratory

U.S. Army Engineer Research and Development Center

3909 Halls Ferry Road, Vicksburg, MS 39180-6199 


\begin{abstract}
Estimating nearshore wave transformation and wind-wave growth is a critical component of many coastal engineering projects, e.g., predicting shoreline change, designing and maintaining coastal structures, and simulating coastal storm events. Performing physical model studies or gathering field data is not always a feasible option, and, as a result, the use of numerical models for simulating these complex coastal hydrodynamics has become a universal practice.
\end{abstract}

STWAVE (STeady-state spectral WAVE), a nearshore spectral wave model, was developed by the U.S. Army Engineer Research and Development Center (ERDC), Coastal and Hydraulics Laboratory (CHL) to accurately simulate nearshore wave propagation and transformation including refraction, shoaling, breaking, and wind-wave generation. Recently, CHL has further enhanced STWAVE to include both half-plane and full-plane capabilities within a single executable; improved and streamlined file formats; and made it Earth System Modeling Framework (ESMF) compliant, which allows for easier coupling to other models. STWAVE now runs in serial mode as well as parallel in time or space on both personal computing (PC) and high-performance computing (HPC) systems. This report describes STWAVE version 6.o capabilities, features, theory, and implementation. In depth descriptions of model parameters and examples of the new file formats are also provided.

DISCLAIMER: The contents of this report are not to be used for advertising, publication, or promotional purposes. Citation of trade names does not constitute an official endorsement or approval of the use of such commercial products. All product names and trademarks cited are the property of their respective owners. The findings of this report are not to be construed as an official Department of the Army position unless so designated by other authorized documents. 


\section{Contents}

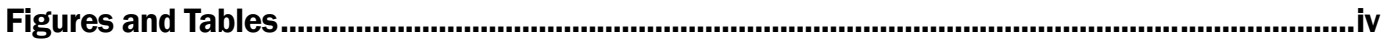

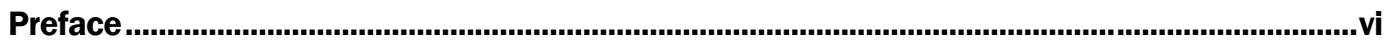

1 Introduction

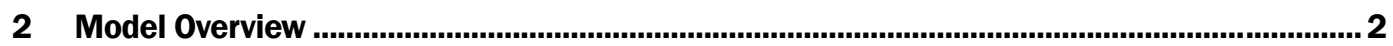

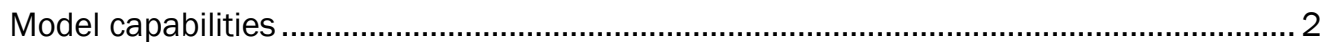

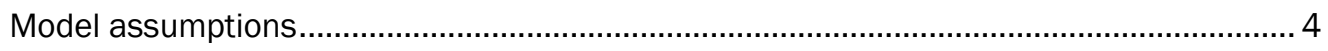

3 Governing Equations and Numerical Discretization......................................................... 5

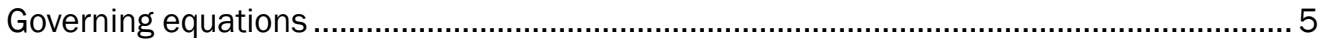

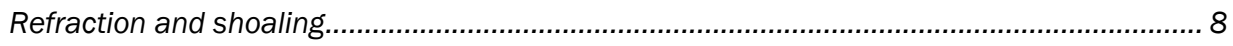

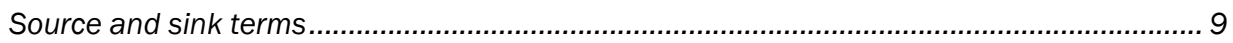

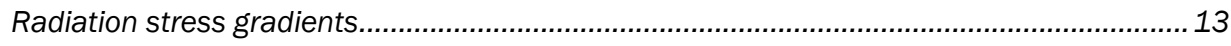

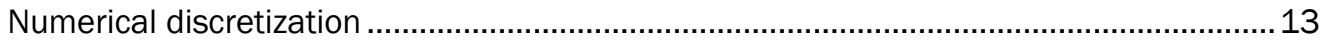

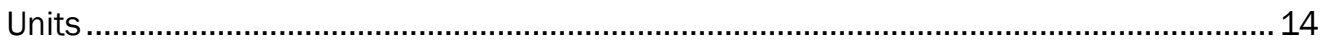

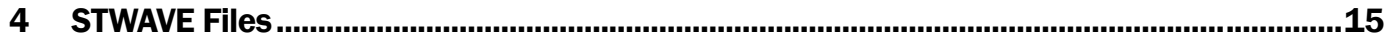

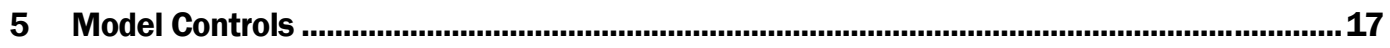

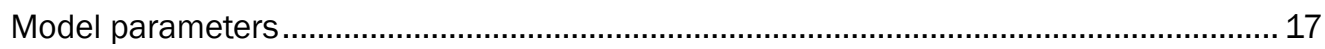

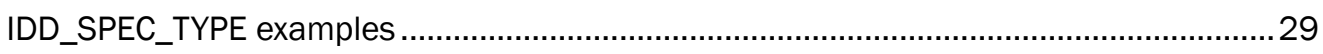

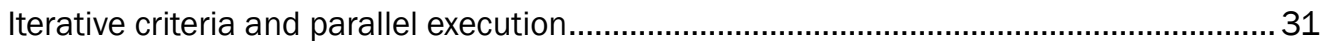

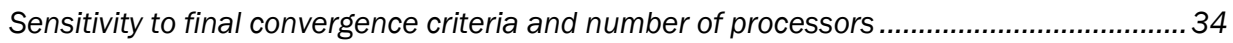

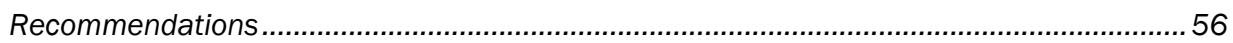

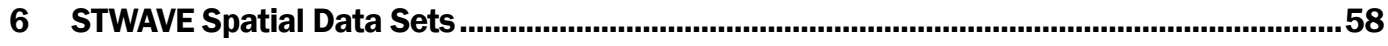

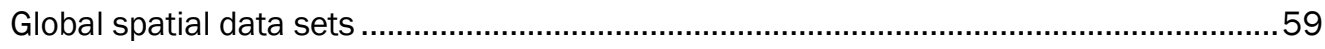

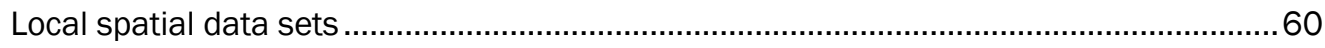

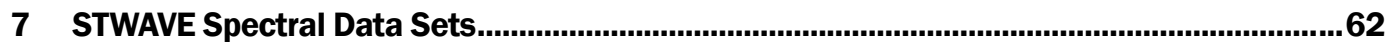

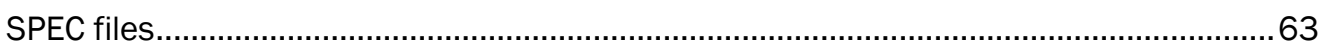

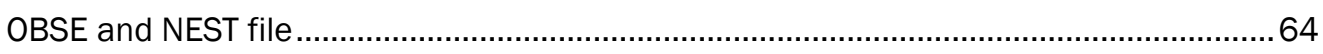

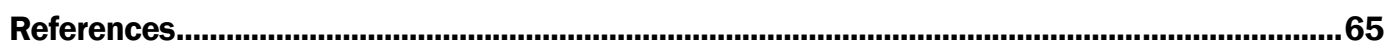

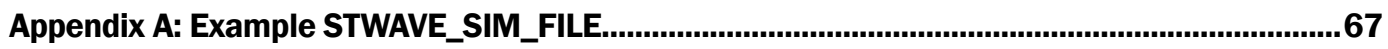

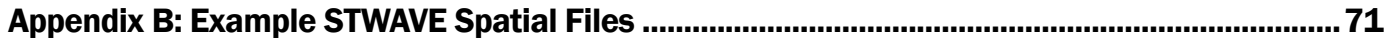

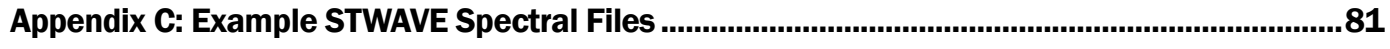

Report Documentation Page 


\section{Figures and Tables}

\section{Figures}

Figure 1. Example full-plane and half-plane domain decompositions for parallel applications

Figure 2. Definition sketch of wave and current vectors, from Smith et al. 2001. ............................ 7

Figure 3. A schematic of a STWAVE grid. ................................................................................ 14

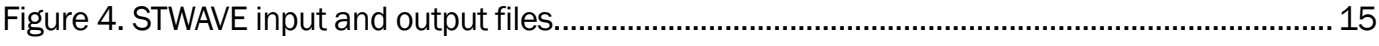

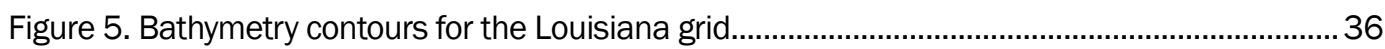

Figure 6. Percentage of wet cells (active) for each snap for the Louisiana grid.....................................36

Figure 7. Maximum surge levels (meters) over the grid for each snap in the Louisiana grid.................36

Figure 8. Maximum wind speed (meters/second) over the grid for each snap in the

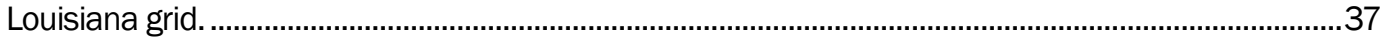

Figure 9. Mean wind direction (degrees) over the grid for each snap in the Louisiana grid. ..................37

Figure 10. Average wave height for each snap for the Louisiana grid....................................................37

Figure 11. Wall clock time for computing 97 snaps on the Louisiana grid..........................................38

Figure 12. Average time per iteration versus the number of processor for the Louisiana grid. .............39

Figure 13. Iteration counts per snap for different run conditions for the Louisiana grid........................42

Figure 14. Wave heights (meters) for snap 97 from the serial mode runs for the Louisiana grid.

Figure 15. Contours of wave height for snap 97 on the Louisiana grid for different EF values for 132 processors and 210 processors.

Figure 16. Contours of wave height for snap 97 on the Louisiana grid for different EF values for 323 processors and 528 processors.

Figure 17. Comparisons of difference in average wave height (meters) for the Louisiana grid.............46

Figure 18. Bathymetry/topography contours for the Texas grid.............................................................4

Figure 19. Percent of wet (active) cells for each snap for the Texas case. …….......................................4

Figure 20. Maximum surge levels (meters) over the grid for each snap in the Texas case. ...................47

Figure 21. Maximum wind speed (meters/second) over the grid for each snap in the Texas

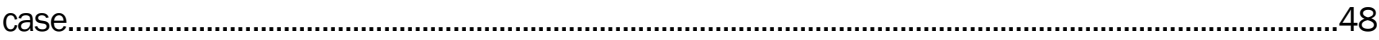

Figure 22. Mean wind direction (degrees) over the grid for each snap in the Texas case. .....................48

Figure 23. Total wall clock time (minutes) for different run parameters for the Texas grid....................50

Figure 24. Wave height (meters) for snap 36 of the Texas case, using the serial base case of $\mathrm{EF}=(0.1,99.8)$.

Figure 25. Difference in wave height (meters) for 6 and 24 processors of the same EF criteria.

Figure 26. Difference in wave height (meters) for 54 and 88 processors of the same EF criteria.

Figure 27. Difference in wave height (meters) for 204 processors of the same EF criteria...................54

Figure 28. Difference in wave height (meters) versus EF value for serial runs. 
Figure 29: Average wave height (meters) over the grid for each snap in the Texas case.

\section{Tables}

Table 1. Summary of half-plane and full-plane features. .................................................................. 2

Table 2. STWAVE simulation files........................................................................................... 16

Table 3. Ordered listing of all STWAVE *.sim file FORTRAN namelists............................................. 18

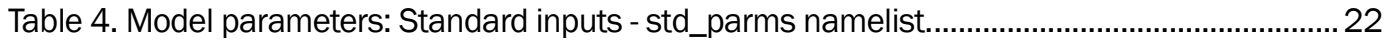

Table 5. Model parameters: Run time parameters - run_parms namelist. ...................................... 23

Table 6. Model parameters: Spatial grid parameters - spatial_grid_parms namelist. ......................2 25

Table 7. Model parameters: Input file type - input_files namelist....................................................2 25

Table 8. Model parameters: Ouput file type - output_files namelist. ...............................................26

Table 9. Model parameters: Time related parameters - time_parms namelist. ................................ 27

Table 10. Model parameters: Constant boundary spectra - const_spec namelist............................ 27

Table 11. Model parameters: Analytic depth profile - depth_fun namelist. ......................................2.

Table 12. Model parameters: Constant bottom friction - const_fric namelist...................................28

Table 13. Model parameters: Snap IDD's - snap_idds extra namelist.................................................2

Table 14. Model parameters: Selected points - select_pts extra namelist........................................2

Table 15. Model parameters: Nest points - nest_pts extra namelist. ..............................................28

Table 16. Model parameters: Station points - station_locations extra namelist................................ 29

Table 17. Model parameters: Spatially constant winds - const_wind extra namelist. ........................29

Table 18. Model parameters: Spatial water level adjustment - const_surge extra namelist..............29

Table 19. Model parameters: TMA boundary spectra - const_tma_spec extra namelist. ................. 29

Table 20. Parameters used for sensitivity tests on the Louisiana grid. ............................................38

Table 21. Parameters used for sensitivity tests on the Texas grid......................................................49

Table 22. STWAVE spatial data sets - datadims namelist. ...............................................................58

Table 23. STWAVE spatial data sets - data set namelist. ................................................................ 59

Table 24. STWAVE spectral data sets - Datadims namelist. ............................................................ 62 


\section{Preface}

This study was conducted for the Flood and Coastal Storm Damage Reduction Research and Development (FCSDR R\&D) Program under the project entitled, "Transition to Field of ERDC's Coastal Storm-Modeling System.” The technical monitor was Dr. Thomas C. Massey.

The work was performed by the Coastal Process Branch of the Flood and Storm Protection Division, U.S. Army Engineer Research and Development Center - Coastal and Hydraulics Laboratory (ERDC-CHL). The publication was prepared under the overall supervision of Dr. Ty V. Wamsley, Branch Chief, Coastal Process Branch; Bruce Ebersole, Division Director, Coastal Process Branch; William R. Curtis, Technical Director for Flood and Coastal Storm Damage Reduction; Dr. Cary Talbot, Program Manager of the FCSDR R\&D Program; Jose E. Sanchez, Deputy Director of CHL; and Dr. William D. Martin, Director of CHL.

COL Kevin J. Wilson was the Commander and Executive Director of ERDC, and Dr. Jeffery P. Holland was the Director. 


\section{Introduction}

The purpose of applying nearshore wave transformation models is to describe quantitatively the change in wave parameters (wave height, period, direction, and spectral shape) of waves propagating from offshore to nearshore regions. Unlike offshore waves, which are fairly homogenous on the scale of kilometers, nearshore waves are highly influenced by bathymetric features, currents, and fluctuating water levels, and may vary on the scale of tens of meters. Offshore wave information obtained from wave gauges or global- or regional-scale wave hindcasts or forecasts is transformed to the nearshore coastal region using these models. Nearshore wave information is required for the design of nearly all coastal engineering projects, and using numerical models to estimate these parameters is becoming extensive due to their increasing complexity and economy of application relative to field or physical model studies.

The purpose of STWAVE (STeady-state spectral WAVE model) is to provide a simple, robust numerical model for simulating nearshore windwave growth, propagation, and transformation (Smith et al. 2001; Smith 2001; Smith 2007). STWAVE is a finite-difference, phase-averaged spectral wave model based on the wave action balance equation. This report describes version 6.0 of STWAVE, which uses an improved file format and is able to operate in half-plane or full-plane mode with a single executable.

This report presents the general features, governing equations, capabilities, and guidelines for using STWAVE version 6.o. In Chapter 2, model capabilities and assumptions are given. An overview of the governing equations and numerical discretization of STWAVE are provided in Chapter 3. Chapter 4 describes STWAVE input and output files with a further description of the model parameters presented in Chapter 5. Descriptions of STWAVE spatial and spectral data sets are in Chapters 6 and 7, respectively. Sample input and output files are given in Appendices A-C. 


\section{Model Overview}

\section{Model capabilities}

STWAVE computes nearshore wave transformation including refraction, shoaling, and breaking, as well as wind-wave generation. STWAVE has two modes available, half-plane and full-plane. Half-plane mode allows wave energy to propagate only from the offshore towards the nearshore ( $\pm 87.5 \mathrm{deg}$ from the $x$-axis of the grid, which is typically the approximate shore-normal direction). All waves traveling in the negative $x$-direction, such as those reflected from the shoreline, steep bottom features, and structures, as well as those generated by offshore-blowing winds, are neglected in half-plane simulations. The full-plane mode allows wave transformation and generation on the full 360-deg plane.

The full-plane option of STWAVE is not intended to be a replacement for the half-plane version, but an addition. The half-plane version requires considerably lower memory requirements, executes faster, and is generally appropriate for most nearshore coastal applications with the exception of semi-enclosed bays and lakes where there is no obvious offshore direction. For these cases, the full-plane version should be applied since it allows wave transformation and generation in all directions. Some STWAVE model options are unique to either half-plane or full-plane mode. Table 1 summarizes these features. Previously mentioned features that are not listed in this table are available in both modes.

Table 1. Summary of half-plane and full-plane features.

\begin{tabular}{|l|l|l|}
\hline Feature & HP & FP \\
\hline Wave transformation and generation on full 360-deg plane & & $\mathrm{x}$ \\
\hline Option for wave-current interaction & $\mathrm{x}$ & \\
\hline Option for direct input of wave parameters to create TMA spectrum & & $\mathrm{x}$ \\
\hline Direction bins restricted to 5 deg & $\mathrm{x}$ & \\
\hline DX and DY grid cell spacing must be the same & $\mathrm{x}$ & \\
\hline Requires iterative criteria & & $\mathrm{x}$ \\
\hline
\end{tabular}

Additionally, both the half-plane and full-plane modes of STWAVE can be executed in serial, and parallel in time or space. Serial execution utilizes one processor, allowing STWAVE to run on a personal computer. Parallel in 
time indicates time decomposition. Time decomposition is essentially serial execution with multiple processors whereby each wave instance, referred to as a wave snap and identified by a snap identification (snap IDD), is completed using its own processor (e.g., 93 wave instances could use 93 processors). The parallel in space execution uses domain decomposition where the computational grid is broken into different sections with each section residing on a different computer processor. This allows for larger modeling domains and finer resolution. An example schematic of the domain decomposition for half-plane and full-plane grids is shown below in Figure 1. While a full-plane grid can be separated in both the I- and Jdirections, a half-plane grid can only be segmented in the J-direction (with I being the primary wave propagation direction). The domain decomposition does not require any pre-processing and is performed automatically when the model begins execution. Additional information regarding grid orientation is provided in the Numerical Discretization section.

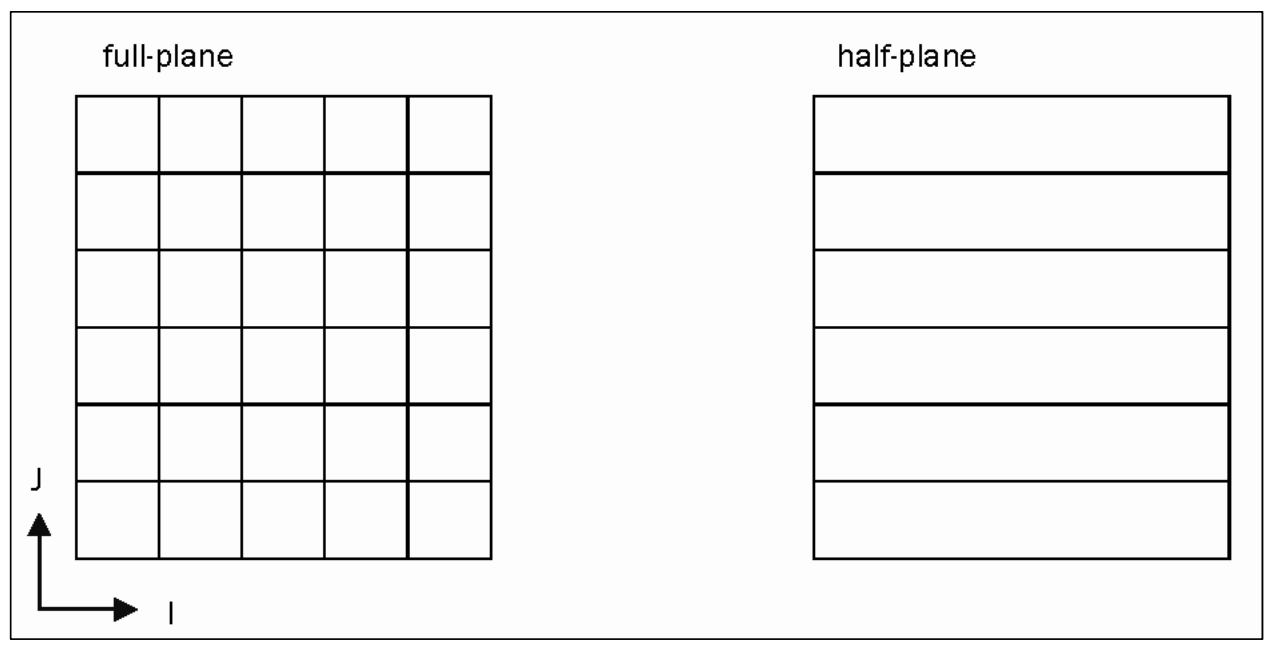

Figure 1. Example full-plane and half-plane domain decompositions for parallel applications.

The parallelized in space STWAVE can be coupled to ADCIRC (Advanced CIRCulation model for shelves, coasts, and estuaries) using the ERDC Coastal Storm Modeling (CSTORM-MS) coupler that takes advantage of and is compatible with the Earth System Modeling Framework (ESMF) software. This circulation-wave coupling allows the two models to run sequentially providing feedback responses (leap-frogging through time) to each other by sharing information via memory and processors. 


\section{Model assumptions}

The assumptions made in STWAVE version 6.0 are the following:

1. Phase-averaged. STWAVE is based on the assumption that relative phases of the spectral components are random, and phase information is not tracked. In order to resolve detailed near-field reflection and diffraction patterns near coastal structures, a phase-resolving model should be applied.

2. Mild bottom slope and negligible wave reflection. Waves reflected from the shoreline or from steep bottom features are neglected.

3. Steady-state waves, currents, and winds. STWAVE is formulated as a steady-state model, which reduces computation time and is appropriate for wave conditions that vary more slowly than the time it takes for waves to transit the domain. For wave generation, the steady-state assumption means that the winds have remained steady sufficiently long for the waves to attain fetch-limited or full-developed conditions (waves are not limited by the duration of the winds).

4. Linear refraction and shoaling. STWAVE incorporates linear wave refraction, shoaling, and propagation, and thus, does not represent wave asymmetry or other nonlinear wave features. Model accuracy is reduced (e.g., underestimated wave heights) at large Ursell numbers.

5. Depth-uniform current. The wave-current interaction in the model is based on a current that is constant throughout the water column; the modification of refraction and shoaling due to strong vertical gradients is not represented.

6. Linear radiation stress. Radiation stress is calculated based on linear wave theory. 


\section{Governing Equations and Numerical Discretization}

\section{Governing equations}

STWAVE simulates depth-induced wave refraction and shoaling, currentinduced refraction and shoaling, depth-and steepness-induced wave breaking, wind-wave growth, and wave-wave interaction and whitecapping that redistribute and dissipate energy in a growing wave field.

The governing equations are similar between the half-plane and full-plane modes. Governing equations for half-plane mode will be discussed first since this option includes the interaction of waves with currents by considering a reference frame moving with the current. Wave parameters in this frame are denoted with the subscript $r$ as being "relative" to the current and parameters in the nonmoving reference frame are denoted with the subscript $a$ for "absolute."

The wave dispersion relation is given in the moving reference frame as (Jonsson 1990 and others):

$$
\omega_{r}^{2}=g k \tanh (k d)
$$

where:

$$
\begin{aligned}
& \omega=\text { angular frequency } \\
& g=\text { gravitational acceleration }, \\
& k=\text { wave number } \\
& d=\text { water depth. }
\end{aligned}
$$

In the absolute frame of reference, the dispersion equation is:

$$
\omega_{a}=\omega_{r}+k U_{c} \cos (\delta-\alpha),
$$

where:

$$
U_{c}=\text { current speed, }
$$


$\delta=$ direction of the current relative to a reference frame ( $x$-axis),

$\alpha=$ wave orthogonal direction (normal to wave crest).

The wave number is solved by substituting Equation 1 into Equation 2 and iteratively solving for $k$. The wave number and wavelength $(L=2 \pi / k)$ are the same in both reference frames.

Wave celerity, $C$, and group celerity, $C_{g}$, are required to calculate shoaling and refraction solutions in both frames. In the reference frame relative to the current,

$$
\begin{gathered}
C_{r}=\frac{\omega_{r}}{k} \\
C_{g r}=0.5 C_{r}\left(1+\frac{2 k d}{\sinh (2 k d)}\right)
\end{gathered}
$$

The direction of the relative group celerity is $\alpha$, the wave orthogonal direction, see Figure 2. In the absolute reference frame,

$$
\begin{gathered}
C_{a}=C_{r}+U_{c} \cos (\delta-\alpha), \\
\left(C_{g a}\right)_{i}=\left(C_{g r}\right)_{i}+\left(U_{c}\right)_{i},
\end{gathered}
$$

where $i$ is tensor notation for the $x$ - and $y$-components. The direction of the wave ray is defined as:

$$
\mu=\tan ^{-1}\left(\frac{C_{g r} \sin \alpha+U_{c} \sin \delta}{C_{g r} \cos \alpha+U_{c} \cos \delta}\right)
$$

The distinction between the wave orthogonal (direction perpendicular to the wave crests) and the wave ray (direction of energy propagation) is important in describing wave-current interaction. Without currents, as in the full-plane mode, the wave rays and wave orthogonals are the same, but with currents, the wave energy moves along the wave rays whereas the wave direction is defined by the wave orthogonals. A definition sketch of wave and current vectors is provided in Figure 2. 


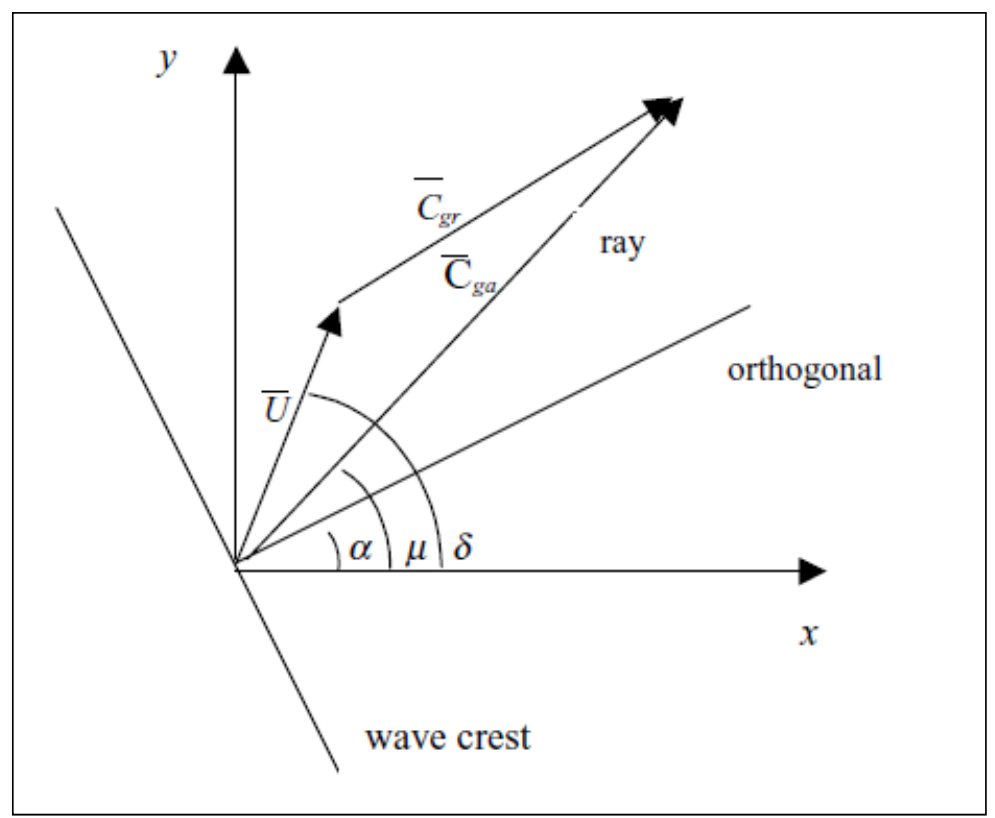

Figure 2. Definition sketch of wave and current vectors, from Smith et al. 2001.

The wave orthogonal direction for steady-state conditions in the presence of currents is given by (Mei 1989; Jonsson 1990):

$$
C_{g a} \frac{D \alpha}{D R}=-\frac{C_{r} k}{\sinh (2 k d)} \frac{D d}{D n_{o}}-\frac{k_{i}}{k} \frac{D U_{c i}}{D n_{o}}
$$

When wave-current interactions are excluded, the wave orthogonal direction for steady-state conditions is given by:

$$
C_{g} \frac{D \alpha}{D R}=-\frac{C k}{\sinh (2 k d)} \frac{D d}{D n_{o}}
$$

where:

$D=$ total derivative,

$R=$ coordinate in the direction of the wave ray,

$n_{o}=$ coordinate normal to the wave orthogonal.

The governing equation for steady-state conservation of spectral wave action along a wave ray accounting for wave-current interaction is (Jonsson 1990), 


$$
\left(C_{g a}\right)_{i} \frac{\partial}{\partial x_{i}} \frac{C_{a} C_{g a} \cos (\mu-\alpha) E\left(\omega_{a}, \alpha\right)}{\omega_{r}}=\sum \frac{S}{\omega_{r}},
$$

with a similar version for no wave-current interaction (full-plane mode or zero current in half-plane mode),

$$
\left(C_{g}\right)_{i} \frac{\partial}{\partial x_{i}} \frac{C C_{g} \cos (\alpha) E(\omega, \alpha)}{\omega}=\sum \frac{S}{\omega},
$$

where:

$$
\begin{aligned}
& E=\text { wave energy density divided by both } \rho_{w} \text { and } g \text { where } \rho_{w} \text { is the } \\
& \quad \text { density of water, } \\
& S=\text { energy source and sink terms. }
\end{aligned}
$$

\section{Refraction and shoaling}

Refraction and shoaling are implemented in STWAVE by applying the conservation of wave action along backward traced wave rays. Wave rays are traced in a piecewise manner, from the previous grid column or row. The two-dimensional (2-D) wave spectra are set as input along the first grid column (the offshore boundary) in half-plane mode or along all grid boundaries in full-plane mode. The spectrum is calculated by back tracing a wave ray for each frequency and direction component of the spectrum. The wave ray direction, $\mu$, is determined by Equation 7 for a half-plane simulation with wave-current interaction, and only wave ray directions propagating toward the shore $(-87.5$ to $+87.5 \mathrm{deg})$ are included. As previously mentioned, energy propagating toward the offshore is neglected in half-plane mode. For a full-plane simulation, the wave ray direction is the same as the wave orthogonal as wave-current interactions are neglected.

The wave ray is traced back to the previous grid column or row (whichever is encountered first), and the length of the wave ray segment $D R$ is calculated. Derivatives of depth and current components (if applicable) normal to the wave orthogonal are estimated (based on the orthogonal direction) and substituted into Equation 8 for half-plane or Equation 9 for full-plane to calculate the wave orthogonal direction at the previous column. The wavenumber, wave and group celerities, and wave ray angle in the previous column or row are then calculated. 
The energy is calculated as a weighted average of energy between two adjacent grid points in the column and direction bins. The energy density is corrected by a factor of the ratio of the standard angle band width (5-deg for the half-plane and user-specified in the full-plane) to the width of the backtraced band to account for the distortion of the bins through refraction. The shoaled and refracted wave energy is then calculated from the conservation of wave action along a ray using Equation 10 and 11 for half-plane and fullplane, respectively.

\section{Source and sink terms}

Surf-zone wave breaking

The wave-breaking criterion applied in STWAVE is a function of wavelength and water depth:

$$
H_{\text {momax }}=0.1 L \tanh (k d),
$$

where:

$$
\begin{aligned}
\mathrm{H}_{\mathrm{mo} \text {,max }} & =\text { maximum energy-based zero-moment wave height } \\
\mathrm{L} & =\text { wavelength. }
\end{aligned}
$$

This criterion is powerful because it includes both the impacts of depth- and steepness-limited breaking. At a coastal entrance, where waves steepen because of the wave-current interaction, wave breaking is enhanced because of the increased wave steepness. Laboratory experiments conducted by Smith et al. (1997) of irregular wave breaking on ebb currents found that a breaking relationship in the form of the Miche criterion (1951) was simple, robust, and accurate (see also Battjes 1982 and Battjes and Janssen 1978). Equation 12 is applied in STWAVE as the maximum limit on the zeromoment wave height. The energy in the spectrum is reduced at each frequency and direction in proportion to the amount of pre-breaking energy in each frequency and direction band. Nonlinear transfers of energy to high frequencies that occur during breaking are not represented in the model. Model grid cells where the wave is limited by Equations 12 are flagged as actively breaking cells. 


\section{Wind Input}

Waves grow through the transfer of momentum from the wind field to the wave field. The flux of energy, $F_{\text {in }}$, into the wave field is implemented into STWAVE by the following equation (Resio 1988):

$$
F_{i n}=0.85 \lambda \frac{\rho_{a}}{\rho_{w}} C_{m} \frac{u_{*}^{2}}{g},
$$

where:

$$
\begin{aligned}
\lambda= & \text { partitioning coefficient that represents the percentage of total } \\
& \text { atmosphere to water momentum transfer that goes directly to } \\
& \text { the wave field (a value of } 0.75 \text { is typical) } \\
\rho_{a}= & \text { density of air, } \\
\rho_{w}= & \text { density of water, } \\
C_{m}= & \text { mean wave celerity, } \\
u^{*}= & \text { frictional velocity (equal to the product of the wind speed } \mathrm{U}_{\mathrm{mag}} \\
& \text { and the square root of the drag coefficient } C_{D}= \\
& \left.0.0012+0.000025 \mathrm{U}_{\mathrm{mag}}\right) .
\end{aligned}
$$

In deep water, STWAVE provides a total energy growth rate that is consistent with that reported in Hasselmann et al. (1973).

The energy gain to the spectrum is calculated by multiplying the energy flux by the equivalent time for the wave to travel across a grid cell,

$$
\Delta t=\frac{\Delta x}{\beta \bar{C}_{g} \cos \left(\alpha_{m}\right)},
$$

where:

$$
\begin{aligned}
\Delta t & =\text { equivalent travel time } \\
\Delta x & =\text { grid spacing, } \\
\beta & =\text { factor equal to } 0.9 \text { for wind seas } \\
\bar{C}_{g} & =\text { average group celerity of the spectrum, } \\
\alpha_{m} & =\text { mean wave direction relative to the grid. }
\end{aligned}
$$


For half-plane mode, only winds blowing towards the shore ( $+x$-direction) are included, and wave damping by offshore winds and growth of offshoretraveling waves are neglected.

\section{Wave-wave interaction and whitecapping}

As energy is fed into the waves from the wind, it is redistributed through nonlinear wave-wave interactions. Energy is transferred from the peak of the spectrum to both lower frequencies (decreasing the peak frequency or increasing the peak period) and to higher frequencies (where it is dissipated).

In STWAVE, the frequency of the spectral peak is allowed to increase with fetch (or, equivalently, propagation time across a fetch). The equation for this rate of change of $f_{p}$ integrated over a single time-step, $\Delta \mathbf{t}$, is given by Equation 15,

$$
\left(f_{p}\right)_{j+1}=\left[\left(f_{p}\right)_{j}^{7 / 3}-\frac{9}{5} \zeta\left(\frac{u_{*}}{g}\right)^{4 / 3} \Delta t\right]^{-3 / 7}
$$

where the $j$ and $j+1$ subscripts refer to the grid column indices within STWAVE and $\zeta$ is a dimensionless constant (Resio and Perrie 1989). The energy gained by the spectrum is distributed amongst frequencies lower than the peak frequency in a manner that retains the self-similar shape of the spectrum.

Wave energy is dissipated through energy transferred to high frequencies, wave breaking (whitecapping), and turbulent/viscous effects. This dissipation occurs most notably in an actively growing wave field. There is a dynamic balance between energy entering the wave field due to wind input and energy leaving the wave field because of nonlinear fluxes to higher frequencies (Resio 1987; Resio 1988). The energy flux to higher frequencies is represented in STWAVE as:

$$
\Gamma_{E}=\frac{\varepsilon g^{1 / 2} E_{t o t}^{3} k_{p}^{9 / 2}}{\tanh ^{3 / 4}\left(k_{p} d\right)}
$$

where: 


$$
\begin{aligned}
\Gamma_{E} & =\text { energy flux } \\
\varepsilon & =\text { coefficient equal to } 30 \\
E_{t o t} & =\text { total energy in the spectrum divided by } \rho_{w} \text { and } g, \\
k_{p} & =\text { wave number associated with peak of the spectrum. }
\end{aligned}
$$

The energy loss from the spectrum is calculated by multiplying the energy flux by the equivalent time for the wave to travel across a grid cell (Equation 14) with $\beta=1.0$ for the swell portion of the spectrum and 0.9 for the sea portion of the spectrum. This dissipation is only applied in STWAVE if wind input is included.

\section{Bottom friction}

STWAVE includes two formulations for bottom friction. The first is the JONSWAP formulation (Hasselmann et al. 1973; Padilla-Hernandez 2001), where the spectral energy loss due to bottom friction is formulated as,

$$
S_{b f}=-\frac{1}{g} c_{f} \frac{\sigma^{2}}{\sinh ^{2}(k d)} E(f, \alpha) .
$$

where:

$$
f=\text { wave frequency. }
$$

The value of the friction coefficient $c_{f}$ can be set as a constant over the domain or specified individually for each STWAVE cell. For the JONSWAP bottom friction formulation, $c_{f}$ is specified as $\Gamma / g$, where the recommended values of $\Gamma$ for sand beds are in the range of 0.038 to $0.067 \mathrm{~m}^{2} / \mathrm{s}^{3}$ (or $c_{f}=$ 0.004 to 0.007 ) based on experiments in the North Sea. Equation 17 has a weak inverse dependence on water depth as a result of the increase in bottom wave orbital velocity as the relative depth, $k d$, decreases.

A Manning's $n$ formulation is also available in STWAVE (Holthuijsen 2007),

$$
S_{b f}=-\frac{1}{g}\left(\frac{g n^{2}}{d^{1 / 3}}\right) \frac{\sigma^{2}}{\sinh ^{2}(k d)} E(f, \alpha) u_{r m s},
$$

where the value of $n$ is specified as input to STWAVE (either spatially constant or variable) and $u_{r m s}$ is the root-mean-square bottom velocity. With the Manning's formulation, bottom friction dissipation has an 
additional inverse dependence on water depth. Estimates of Manning's $n$ coefficients are available in most fluid mechanics reference books (e.g., 0.01 to 0.05 for smooth to rocky/weedy channels).

Bottom friction in STWAVE has been used to represent dissipation over coral reefs in Hawaii and wetlands in southern Louisiana.

\section{Radiation stress gradients}

Gradients in radiation stress are calculated in STWAVE to provide wave forcing to external circulation models, such as ADCIRC, to drive nearshore currents and water level changes (i.e., wave setup and setdown). Wavedriven currents are generally the dominant forcing for sediment transport in the surf-zone. Radiation stress tensors are calculated based on linear wave theory:

$$
\begin{gathered}
S_{x x}=\rho_{w} g \iint E(f, \alpha)\left[0.5\left(1+\frac{2 k d}{\sinh (2 k d)}\right)\left(\cos ^{2} \alpha+1\right)-0.5\right] d f d \alpha, \\
S_{x y}=\rho_{w} g \iint \frac{E(f, \alpha)}{2}\left[0.5\left(1+\frac{2 k d}{\sinh (2 k d)}\right) \sin 2 \alpha\right] d f d \alpha, \\
S_{y y}=\rho_{w} g \iint E(f, \alpha)\left[0.5\left(1+\frac{2 k d}{\sinh (2 k d)}\right)\left(\sin ^{2} \alpha+1\right)-0.5\right] d f d \alpha .
\end{gathered}
$$

The gradients in radiation stress are calculated as follows:

$$
\begin{gathered}
\tau_{x}=-\frac{\partial S_{x x}}{\partial x}-\frac{\partial S_{x y}}{\partial y}, \\
\tau_{y}=-\frac{\partial S_{x y}}{\partial x}-\frac{\partial S_{y y}}{\partial y} .
\end{gathered}
$$

Values of $\tau_{x} / \rho_{w}$ and $\tau_{y} / \rho_{w}$ can be output from STWAVE for use in circulation modeling.

\section{Numerical discretization}

STWAVE is a finite-difference numerical model, formulated on a Cartesian grid. Grid cells are required to be square $(D X=D Y)$ for half-plane simulations, but DX and DY do not need to be the same for full-plane 
simulations. STWAVE operates in a local coordinate system, with the $x$-axis oriented in the cross-shore direction and the $y$-axis oriented alongshore, forming a right-handed coordinate system. A schematic of the grid orientation is provided in Figure 3. Typically, the $y$-axis is aligned with the bottom contours so the offshore boundary is parallel with the shoreline. Wave angles are defined in a mathematical sense, measured counterclockwise from the $x$-axis. Lateral boundaries in the model can be specified as land or water by specifying the cell depth as positive (water) or negative (land). While land boundaries will reduce wave growth near the boundaries as they "prevent" propagation from landward directions, water-defined boundaries allow a zero-gradient type of boundary condition. This zerogradient boundary condition allows energy consistent with that of neighboring cells to propagate into or out of the domain along the lateral boundary.

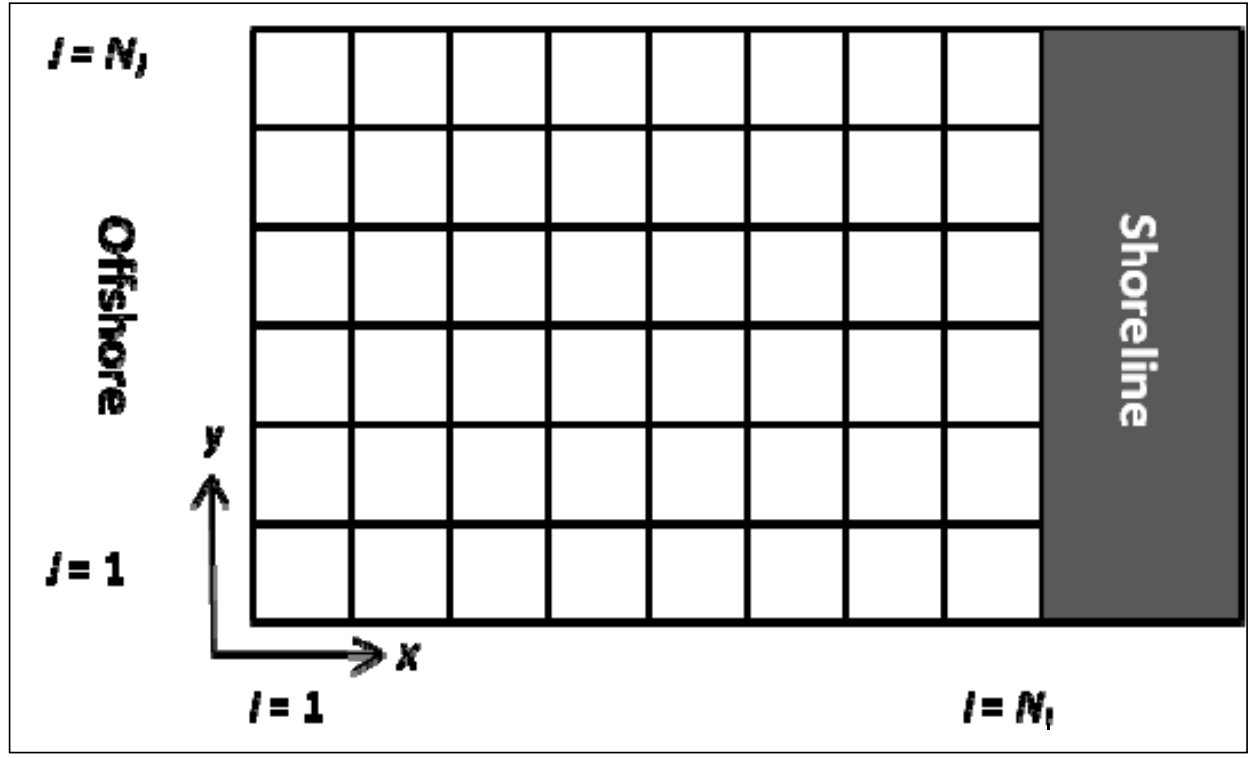

Figure 3. A schematic of a STWAVE grid.

\section{Units}

STWAVE is formulated in metric units. Water heights, water depth, and tide/surge elevation adjustments are in meters, winds are in meters/second, wave periods are in seconds, and energy densities are in $\mathrm{m}^{2} / \mathrm{Hz} / \mathrm{radian}$. Wave and wind directions are input and output in units of degrees which are measured counterclockwise from the grid $x$-axis, but are converted to radians for model computations. 


\section{STWAVE Files}

The primary input file required for a STWAVE simulation is the simulation file ( ${ }^{*}$.sim). It is within this file that the model controls and input/output options are defined. Optional input files include bathymetry (DEP), spatially varying surge or tidal water level adjustments (SURGE), incident wave spectra (SPEC), spatially varying wind (WIND), spatially varying friction coefficients (FRIC), and current fields (CURR).

Depending on which options are selected in the *.sim file, STWAVE may generate two to eight output files. The primary output files for STWAVE are the wave field (WAVE) and peak wave period (TP) files. The wave field file contains the zero-moment wave height $H_{m o}$ in meters, the peak period $T_{p}$ in seconds, and the mean wave direction relative to the STWAVE grid $\alpha_{m}$ in degrees for all grid cells for all snap IDD's, e.g., individual wave instances. Additional output files are wave spectra at selected grid locations (OBSE), wave breaking indices and dissipation (BREAK), radiation stress gradients (RADS), wave parameters at selected grid locations (SELH), wave information at interpolated station locations (STATION), and nesting spectra (NEST). Figure 4 shows a diagram of input and output files used in a STWAVE simulation with additional file information provided in Table 2.

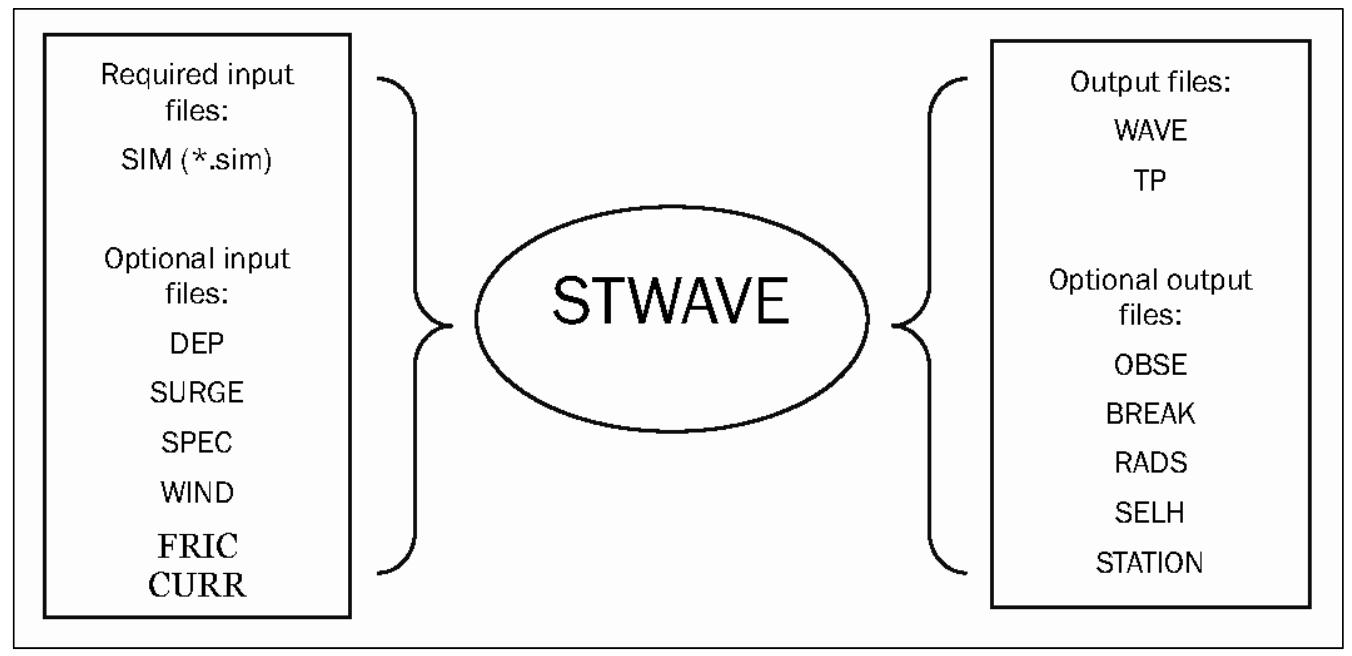

Figure 4. STWAVE input and output files. 
Table 2. STWAVE simulation files.

\begin{tabular}{|c|c|c|c|c|}
\hline Variable & Example filename & Input/output & Type & Description \\
\hline SIM & projname.sim & Input - required & Simulation file & Model parameters \\
\hline DEP & projname.dep & Input - optional & $\begin{array}{l}\text { Global spatial data set } \\
\text { Non-time-dependent }\end{array}$ & $\begin{array}{l}\text { Bathymetry values }(\mathrm{m}) \text { for each grid cell } \\
\text { Water depths are defined as positive numbers and } \\
\text { land elevations as negative numbers }\end{array}$ \\
\hline SURGE & projname.surge.in & Input - optional & $\begin{array}{l}\text { Global spatial data set } \\
\text { Time-dependent }\end{array}$ & $\begin{array}{l}\text { Water level adjustment }(\mathrm{m}) \text { for each grid cell } \\
\text { relative to bathymetry datum } \\
\text { Positive values increase water depth and negative } \\
\text { values decrease water depth } \\
\text { Must be specified for every snap IDD }\end{array}$ \\
\hline SPEC & projname.eng & Input - optional & Spectral file & $\begin{array}{l}\text { Incident 2-D wave energy spectra }\left(\mathrm{m}^{2} / \mathrm{Hz} / \mathrm{rad}\right) \\
\text { Must be specified for every snap IDD }\end{array}$ \\
\hline WIND & projname.wind.in & Input - optional & $\begin{array}{l}\text { Global spatial data set } \\
\text { Time-dependent }\end{array}$ & $\begin{array}{l}\text { Wind speed ( } \mathrm{m} / \mathrm{s} \text { ) and direction (deg) for each grid } \\
\text { cell } \\
\text { Wind direction is considered relative to the STWAVE } \\
\text { coordinate system and is measured } \\
\text { counterclockwise from the } x \text {-axis (same convention } \\
\text { used for wave direction) } \\
\text { Must be specified for every snap IDD }\end{array}$ \\
\hline FRIC & projname.fric.dat & Input - optional & $\begin{array}{l}\text { Global spatial data set } \\
\text { Non-time-dependent }\end{array}$ & Friction coefficient $\left(c_{f}\right.$ or $n$ ) for each grid cell \\
\hline CURR & projanme.curr.in & Input - optional & $\begin{array}{l}\text { Global spatial data set } \\
\text { Time-dependent }\end{array}$ & $\begin{array}{l}\text { Current vector specified as } x \text { - and } y \text { - components } \\
\text { for each grid cell ( } u, v \text { pair in } \mathrm{m} / \mathrm{s} \text { ) } \\
\text { One current field can be used for all model runs or } \\
\text { one may be specified for every snap IDD }\end{array}$ \\
\hline WAVE & projname.wave.out & Output - required & $\begin{array}{l}\text { Global spatial data set } \\
\text { Time-dependent }\end{array}$ & $\begin{array}{l}\text { Wave height in meters }\left(H_{m o}\right) \text {, peak period in } \\
\text { seconds }\left(T_{p}\right) \text {, and mean wave direction relative to } \\
\text { the STWAVE grid in degrees }\left(\alpha_{m}\right) \text { for each grid cell }\end{array}$ \\
\hline TP & projname.tp.out & Output - required & $\begin{array}{l}\text { Global spatial data set } \\
\text { Time-dependent }\end{array}$ & Peak wave period (s) for each grid cell \\
\hline OBSE & projname.obse.out & Output - optional & Spectral file & $\begin{array}{l}\text { Transformed energy spectra at selected }(\mathrm{I}, J) \text { grid } \\
\text { cell locations }\left(\mathrm{m}^{2} / \mathrm{Hz} / \mathrm{rad}\right)\end{array}$ \\
\hline BREAK & projname.brk & Output - optional & $\begin{array}{l}\text { Global spatial data set } \\
\text { Time-dependent }\end{array}$ & $\begin{array}{l}\text { Wave breaking indices or dissipation }\left(\mathrm{m}^{2} / \mathrm{s}\right) \text { for } \\
\text { each cell } \\
\text { Index of } 1 \text { for actively breaking cells and index of } 0 \\
\text { for nonbreaking cells }\end{array}$ \\
\hline RADS & projname.rads.out & Output - optional & $\begin{array}{l}\text { Global spatial data set } \\
\text { Time-dependent }\end{array}$ & $\begin{array}{l}\text { Radiation stress gradients }\left(\mathrm{m}^{2} / \mathrm{s}^{2}\right) \text { for each cell. } \\
\text { Used by circulation models to force wave-driven } \\
\text { currents and water level changes. Stress in these } \\
\text { units is obtained by dividing stress in units of } \mathrm{N} / \mathrm{m}^{2} \\
\text { by the reference density of water }\left(1,000 \mathrm{~kg} / \mathrm{m}^{3}\right) \text {. }\end{array}$ \\
\hline SELH & projname.selh.out & Output - optional & Local spatial data set & $H_{m o}, T_{p}$, and $\alpha_{m}$ for selected $(\mathrm{I}, J)$ grid cell locations \\
\hline STATION & projname.stat.out & Output - optional & Local spatial data set & $H_{m o}, T_{p}$, and $\alpha_{m}$ at interpolated $(x, y)$ coordinate points \\
\hline NEST & projname.nest.out & Output - optional & Spectral file & $\begin{array}{l}\text { Transformed energy spectra saved at selected }(I, J) \\
\text { grid cell locations for nesting application }\end{array}$ \\
\hline
\end{tabular}




\section{Model Controls}

\section{Model parameters}

The simulation file ( ${ }^{*}$.sim) specifies options for running STWAVE and identifies special output points as well as spatially constant input parameters like friction. The simulation file is a simple text ASCII file that is separated into a series of FORTRAN namelists. Depending on the model controls provided in the * ${ }^{*}$ sim file, some of these namelists are required while others are optional. The namelist are required to appear in a certain order in relation to each other. The order of all possible namelist is given in Table 3 along with a brief description of each. The start of a namelist is signified by using the ampersand symbol " $\&$ " followed by the namelist's name. Then the variables assigned to that namelist are listed along with an assigned value. The end of the namelist is signified with the slash symbol "/". Comments to enhance user readability can be inserted between namelist by using pound symbols "\#" in column 1 of the *.sim file with the comment followed on the same line. STWAVE *.sim files used in conjuncttion with SMS (Surfacewater Modeling System) version 11.0+ must have the following text on line 1: “\# STWAVE_SIM_FILE”, without the quotes. The SMS system will automatically format an STWAVE *.sim file in the correct manner for the user through a series of GUI controls related to STWAVE.

Descriptions of the standard model inputs, which are defined in the std_parms namelist, are provided here and include the following:

IPLANE $=$ Switch to run either the half-plane $($ IPLANE $=0$ ) or full-plane (IPLANE $=1$ ) mode of STWAVE.

IPRP $=$ Switch for including propagation only $(I P R P=1)$ or both propagation and source terms (IPRP $=0$ ). Surf-zone wave breaking is included for both options, but wind-wave generation, wave-wave interactions, and whitecapping are included only for IPRP $=0$. Propagation only is usually sufficient for shorter wave propagation distances (on the order of kilometers). Source terms should be included for longer wave propagation distances or cases where only locally generated waves exist. 
Table 3. Ordered listing of all STWAVE *.sim file FORTRAN namelists.

\begin{tabular}{|c|c|c|}
\hline Order & STWAVE Namelist & Description \\
\hline 1 & std_parms & Standard model controls \\
\hline 2 & run_parms & Runtime parameters, ex. number of snaps \\
\hline 3 & spatial_grid_parms & Parameters related to the computational spatial grid \\
\hline 4 & input_files & Names and types of input files \\
\hline 5 & output_files & Names and types of output files \\
\hline 6 & time_parms & Time variables (Optional) \\
\hline 7 & const_spec & Constant boundary input spectrum information (Optional) \\
\hline 8 & depth_func & Analytic depth function (Optional) \\
\hline 9 & const_fric & Spatially/temporally constant friction value (Optional) \\
\hline 10 & snap_idds & Labels for each snap (Optional) \\
\hline 11 & select_pts & List of special output (I,J) grid locations (Optional) \\
\hline 12 & nest_pts & List of output $(\mathrm{I}, J)$ grid points for nesting (Optional) \\
\hline 13 & station_locations & List of special output $(x, y)$ location coordinates (Optional) \\
\hline 14 & const_wind & Spatially constant but time varying winds (Optional) \\
\hline 15 & const_surge & Spatially constant but time varying surge levels (Optional) \\
\hline 16 & const_tma_spec & Spatially constant but time varying TMA spectrum values (Optional) \\
\hline
\end{tabular}

ICUR $=$ Switch for including (ICUR $=1$ or 2$)$ or excluding $(I C U R=0)$ wave-current interaction. Currently, wave-current interaction is only available for half-plane simulations. A current field must be specified for each snap IDD if ICUR $=1$. ICUR $=2$ specifies a single current field for all snap IDD's, and is useful for climatic studies where peak ebb or flood current fields are used in conjunction with multiple typical or extreme incident wave conditions.

IBREAK = Switch for identifying (IBREAK $=1$ or 2$)$ or not identifying (IBREAK $=0$ ) actively breaking wave cells. Cells in which the waves are actively dissipating wave energy are identified by binary indices if IBREAK $=1$ while IBREAK $=2$ prints out the dissipation. The value of IBREAK simply determines if an output file is written to indicate which cells are breaking and has no impact on the simulated wave fields or the breaking calculation.

IRS $=$ Switch for calculating $($ IRS $=1)$ or not calculating $(I R S=0)$ radiation stress gradients. The radiation stress gradients are not 
used by STWAVE, but can be used as input for circulation models (ex., ADCIRC) to force wave-drive currents and water levels.

NSELCT $=$ Number of optional $(\mathrm{I}, \mathrm{J})$ grid cell output points. The 2-D transformed wave spectra are saved to the OBSE file while wave height, period, and direction are written to the SELH file for these selected points. Wave height, period, and direction are saved to all grids points in the WAVE file, but this summary file is useful to check results at critical locations, compare results with measurement, or to isolate locations of interest.

NNEST = Number of optional (I,J) grid cell output points to save spectra for nesting applications. Grid nesting is used to decrease computational time whereby a coarse offshore grid is used to drive multiple nearshore simulations. Wave spectra from the coarse grid are saved at select points that coincide with the offshore boundary of the nearshore grid. Then a separate STWAVE model is initiated to interpolate the coarse grid spectra onto the nearshore grid and model the nearshore wave transformations. Further information on grid nesting is provided by Smith and Smith (2002).

NSTATIONS $=$ Number of optional $(x, y)$ interpolated output points. These interpolated points are defined using $x$ - and $y$-coordinates of the same coordinate system as the grid origin and orientation, not $(\mathrm{I}, \mathrm{J})$ grid cell locations. Wave height, period, and direction for these points are written to the STATION file. Currently, the NSTATIONS option is only a place holder and will be functional in future STWAVE versions.

IBND = Switch for single point entry $($ IBND $=0)$, linear interpolation $(\mathrm{IBND}=1)$, or morphic interpolation (IBND $=2$ ) of spectra on boundaries. IBND $=0$ indicates that a single input spectrum is applied along the entire grid boundary and, thus, should be established along an offshore depth contour where the wave spectrum is fairly homogenous (no large shoals or canyons offshore of the boundary). IBND $=1$ or 2 is used anytime multiple input spectra are applied along the grid boundary, as is usually the case with nesting from a coarser or larger domain model to a finer resolved grid. 
For IBND $=1$, the interpolation method is linear. The energy density for each wave spectrum frequency-direction bin is bilinearly interpolated from the same bins of the adjacent spectra. If points along the boundary are sufficiently dense to define the variation in spectra, linear interpolation gives good results.

For IBND $=2$, the interpolation method is morphic. Morphic interpolation was developed to preserve the shape of the direction distribution when spectra are widely spaced (wave directions vary by $10-15+$ deg from grid point to grid point) or bathymetry is complex. The morphic technique is applicable only for single peaked wave spectra, and is appropriate for climatic wave transformation studies where a parametric spectral shape is applied based on wave parameters. Further information regarding these interpolation techniques can be found in Smith and Smith (2002).

IFRIC $=$ Switch for including (IFRIC $=1,2,3$, and 4$)$ or excluding (IFRIC $=0$ ) bottom friction. Two formulations are included in STWAVE, a JONSWAP (IFRIC $=1$ or 2 ) and Manning formulation (IFRIC $=3$ or 4). For the JONSWAP formulation, $c_{f}$ is specified. For the Manning formulation, Manning's $n$ is the input value. Spatially constant friction (IFRIC $=1$ or 3 ) requires the simulation file to contain a single value of the friction coefficient while spatially variable friction (IFRIC $=2$ or 4 ) requires an input file, FRIC, that specifies the friction coefficient for every grid cell. The preferred method of specifying $c_{f}$ or $n$ is through calibration with measurements.

ISURGE $=$ Switch for spatially constant $($ ISURGE $=0$ ) or spatially variable (ISURGE $=1$ ) water level correction over the grid. This depth correction over the grid is used primarily to account for tidal offsets or storm surges. A surge file (SURGE) specifying the adjustment for every grid cell is required only if ISURGE $=1$. For ISURGE $=0$, the water level correction is specified in the simulation file.

IWIND $=$ Switch for spatially constant (IWIND $=0$ ) or spatially variable (IWIND $=1$ ) wind over the grid. The WIND file specifying the wind speed and direction for each grid cell is required only if IWIND $=1$; for IWIND $=0$, the wind speed and direction are defined in the simulation file. The wind enters into the model simulations only if IPRP $=0$. 
IDEP_OPT = Switch for depth to be provided by a bathymetry file (IDEP_OPT $=0$ ) or to be defined as a plane sloping bottom (IDEP_OPT = 1). The DEP file is required only if IDEP_OPT = o and specifies the bathymetry for each grid cell; otherwise, for IDEP_OPT $=1$, offshore water depth and constant bed slope are specified in the simulation file.

I_BC(ISIDE) $=$ Switch for boundary condition defined as a zero spectrum (I_BC $=0$ ), constant TMA spectrum (I_BC $=1$ ), constant spectrum read from an ENG file (I_BC $=2$ ), or 1-D transformed spectrum (I_BC = 3). One of these boundary conditions must be selected for each side of the grid, this allows for consistency in the input files for both half-plane and full-plane mode. I_BC = $\mathrm{O}$ is set for land or an open boundary. For I_BC = 1, significant wave height, peak wave period, and mean wave direction are defined in the simulation file. For I_BC $=2$, the wave spectra is specified in an input spectra file for every snap IDD. Waves are transformed along the lateral boundary for I_BC $=3$ assuming the bathymetry is 1-D (adjacent boundaries must be I_BC $=0,1$ or 2 ). Only I_BC $=0$ or 2 is available in half-plane mode with I_BC $=2$ likely defined along the offshore boundary and I_BC $=0$ defined along the lateral boundaries.

Summary definitions of these and the remaining model options are provided in Table 4 through Table 19 with an example of a simulation file provided in Appendix A.

Examples of IDD_SPEC_TYPE options are provided in "IDD_SPEC_TYPE examples," and further explanation of the full-plane iterative procedure can be found in "Iterative criteria and parallel execution." 
Table 4. Model parameters: Standard inputs - std_parms namelist.

\begin{tabular}{|c|c|c|}
\hline Parameter & Definition & Comments \\
\hline IPLANE & $\begin{array}{l}=0 \text { for half-plane mode } \\
=1 \text { for full-plane mode }\end{array}$ & \\
\hline IPRP & $\begin{array}{l}=0 \text { for propagation and wind-wave generation } \\
=1 \text { for propagation only }\end{array}$ & \\
\hline ICUR & $\begin{array}{l}=0 \text { for no wave-current interaction } \\
=1 \text { for wave-current interaction where a current } \\
\text { field is specified for each IDD (number of current } \\
\text { fields must equal the number of snap IDD's) } \\
=2 \text { for wave-current interaction where a single } \\
\text { current file is specified for all snaps (one current } \\
\text { field for all snap IDD's) }\end{array}$ & $\begin{array}{l}\text { Wave-current interaction available only for } \\
\text { half-plane simulations } \\
\text { For ICUR }=1 \text { or } 2 \text {, specify input file in } \\
\text { input_files namelist (CURR) }\end{array}$ \\
\hline IBREAK & $\begin{array}{l}=0 \text { for no breaking indices } \\
=1 \text { to write } 0 \text { for nonbreaking and } 1 \text { for breaking } \\
\text { in each grid cell } \\
=2 \text { to print dissipation in each grid cell }\end{array}$ & $\begin{array}{l}\text { Wave breaking locations saved to an output } \\
\text { breaking file (BREAK) } \\
\text { Specify name in output_files namelist }\end{array}$ \\
\hline IRS & $\begin{array}{l}=0 \text { for no wave radiation stress calculations } \\
=1 \text { to calculate and write radiation stress } \\
\text { gradients }\end{array}$ & $\begin{array}{l}\text { Radiation stresses can serve as input to a } \\
\text { circulation model to force wave-driven } \\
\text { currents and water levels } \\
\text { Saved to an output radiation stress file (RADS) } \\
\text { Specify name in output_files namelist }\end{array}$ \\
\hline NSELCT & $\#$ = number of optional $(\mathrm{I}, \mathrm{J})$ grid cell output points & $\begin{array}{l}\text { For each output point, } H_{m o}, T_{p} \text {, and } \alpha_{m} \text { are } \\
\text { saved to a selected wave points output file } \\
\text { (SELH), spectra are saved to the spectral } \\
\text { output file (OBSE) } \\
\text { Specify (I,J) locations in select_pts namelist } \\
\text { Specify name in output_files namelist }\end{array}$ \\
\hline NNEST & $\begin{array}{l}\#=\text { number of optional }(I, J) \text { grid cell output points } \\
\text { for nesting spectra }\end{array}$ & $\begin{array}{l}\text { Saved to nested output file (NEST) } \\
\text { Specify }(I, J) \text { locations in nest_pts namelist } \\
\text { Specify name in output_files namelist }\end{array}$ \\
\hline NSTATIONS & $\begin{array}{l}\#=\text { number of optional interpolated }(x, y) \text { output } \\
\text { locations }\end{array}$ & $\begin{array}{l}\text { These will be interpolated points, not }(\mathrm{I}, J) \text { grid } \\
\text { locations, and saved to the output station file } \\
\text { (STATION) } \\
\text { Specify }(x, y) \text { location in station_locations } \\
\text { namelist } \\
\text { Specify name in output_files namelist }\end{array}$ \\
\hline IBND & $\begin{array}{l}=0 \text { for single point input of spectra on boundary } \\
=1 \text { linear interpolation of spectra on boundaries } \\
=2 \text { for morphic interpolation of spectra on } \\
\text { boundaries }\end{array}$ & \\
\hline IFRIC & $\begin{array}{l}=0 \text { for no bottom friction } \\
=1 \text { for constant JONSWAP bottom friction over grid } \\
=2 \text { for spatially variable JONSWAP bottom friction } \\
\text { over grid } \\
=3 \text { for constant Manning bottom friction over grid } \\
=4 \text { for spatially variable Manning bottom friction } \\
\text { over grid }\end{array}$ & $\begin{array}{l}\text { For IFRIC }=1 \text { or } 2 \text {, input value of } c_{f} \\
\text { For IFRIC }=3 \text { or } 4 \text {, input Manning's } n \\
\text { For IFRIC }=1 \text { or } 3 \text {, coefficient will be entered } \\
\text { under the const_fric namelist } \\
\text { For IFRIC }=2 \text { or } 4 \text {, specify input file in } \\
\text { input_file namelist (FRIC) }\end{array}$ \\
\hline ISURGE & $\begin{array}{l}=0 \text { for constant depth correction over grid } \\
=1 \text { for spatially variable depth correction over grid }\end{array}$ & $\begin{array}{l}\text { For ISURGE = 0, enter correction under the } \\
\text { const_surge namelist }\end{array}$ \\
\hline
\end{tabular}




\begin{tabular}{|c|c|c|}
\hline Parameter & Definition & Comments \\
\hline & & $\begin{array}{l}\text { For ISURGE = 1, specify input file in input_files } \\
\text { namelist (SURGE) }\end{array}$ \\
\hline IWIND & $\begin{array}{l}=0 \text { for constant wind over grid } \\
=1 \text { for spatially variable wind over grid }\end{array}$ & $\begin{array}{l}\text { For IWIND =0, enter additional parameters } \\
\text { under the const_wind namelist } \\
\text { For IWIND = 1, specify input file in input_files } \\
\text { namelist (WIND) }\end{array}$ \\
\hline IDEP_OPT & $\begin{array}{l}=0 \text { for depth field to be read from a bathymetry } \\
\text { file } \\
=1 \text { for plane sloping bottom }\end{array}$ & $\begin{array}{l}\text { For IDEP_OPT = 0, specify input file in } \\
\text { input_files namelist (DEP) } \\
\text { For IDEP_OPT = 1, enter additional } \\
\text { parameters under the depth_fun namelist; } \\
\text { saves grid in fort.915 file }\end{array}$ \\
\hline I_BC1 & \multirow{5}{*}{$\begin{array}{l}=0-\text { constant spectrum set equal to zero } \\
=1-\text { constant TMA spectrum with } \mathrm{H}, \mathrm{T} \text {, and wave } \\
\text { direction specified } \\
=2-\text { constant spectrum read in from an input } \\
\text { spectral energy file } \\
=3-1-\mathrm{D} \text { transformed spectrum }\end{array}$} & \multirow{5}{*}{$\begin{array}{l}\text { For I_BC = } 0 \text { for all grid boundaries, waves will } \\
\text { be locally generated in the modeling domain; } \\
\text { additional parameters are required under the } \\
\text { const_spec namelist } \\
\text { For I_BC(ISIDE) = 1, enter additional } \\
\text { parameters under the const_spec and } \\
\text { const_tma_spec namelist; only available in } \\
\text { full-plane } \\
\text { For I_BC(ISIDE) }=2 \text {, specify input file in } \\
\text { input_files namelist (SPEC) } \\
\text { For I_BC(ISIDE) = 3, the adjacent boundaries } \\
\text { must be } 0,1 \text { or } 2 \text {; only available in full-plane }\end{array}$} \\
\hline I_BC2 & & \\
\hline I_BC3 & & \\
\hline & & \\
\hline I_BC4 & & \\
\hline
\end{tabular}

Table 5. Model parameters: Run time parameters - run_parms namelist.

\begin{tabular}{|c|c|c|}
\hline Parameter & Definition & Comments \\
\hline IDD_SPEC_TYPE & $\begin{array}{l}=0-\text { increment integer snap IDD's } \\
=1-\text { specified integer snap IDD's } \\
= \pm 2-\text { year date format } \\
= \pm 3-\text { local time reference } \\
=4-\text { specified character snap IDD's }\end{array}$ & $\begin{array}{l}=0 \text { - results in IDD's from } 1 \text { to } \\
\text { NUMSTEPS } \\
=1 \text { - allows for non-equally spaced } \\
\text { intervals or numerical values without } \\
\text { reference to time; enter information } \\
\text { under the snap_idds namelist } \\
=2 \text { - intended for regular evenly } \\
\text { spaced time intervals; enter } \\
\text { information under time_parms } \\
\text { namelist } \\
=-2 \text { - intended for non-regularly } \\
\text { spaced time data; must be enclosed } \\
\text { in single quotes; enter information } \\
\text { under time_parms and snap_idds } \\
\text { namelists } \\
=3 \text { - intended for regular evenly } \\
\text { spaced local time intervals; enter } \\
\text { information under time_parms } \\
\text { namelist } \\
=-3 \text { - intended for non-regularly } \\
\text { spaced local time data; must be } \\
\text { enclosed in single quotes; enter } \\
\text { information under time_parms and } \\
\text { snap_idds namelists }\end{array}$ \\
\hline
\end{tabular}




\begin{tabular}{|c|c|c|}
\hline Parameter & Definition & Comments \\
\hline & & $\begin{array}{l}\text { = } 4 \text { - allows for alpha numeric } \\
\text { characters ( } 20 \text { characters max); must } \\
\text { be enclosed in single quotes; enter } \\
\text { information under the snap_idds } \\
\text { namelist }\end{array}$ \\
\hline NUMSTEPS & $\#=$ number of snap IDD's to process & $\begin{array}{l}\text { Required for all IDD_SPEC_TYPE } \\
\text { values except IDD_SPEC_TYPE =2 } \\
\text { Not needed for coupled simulations }\end{array}$ \\
\hline N_GRD_PART_I & $\begin{array}{l}\#=\text { number of grid partitions in the } \mathrm{I}- \\
\text { direction } \\
\text { (grid decomposition and processor } \\
\text { specification) }\end{array}$ & $\begin{array}{l}\text { Only used for parallel simulations } \\
\text { Must be } 1 \text { for half-plane simulations } \\
\text { Must be an integer } \\
\text { Do not fall below } 20 \text { cells per partition }\end{array}$ \\
\hline N_GRD_PART_J & $\begin{array}{l}\#=\text { number of grid partitions in the J- } \\
\text { direction } \\
\text { (grid decomposition and processor } \\
\text { specification) }\end{array}$ & $\begin{array}{l}\text { Only used for parallel simulations } \\
\text { Must be an integer } \\
\text { Do not fall below } 20 \text { cells per partition } \\
\text { N_GRD_PART_I x N_GRID_PART_J = } \\
\text { total number of processors for parallel } \\
\text { simulations }\end{array}$ \\
\hline N_INIT_ITERS & $\begin{array}{l}\#=\text { maximum number of initial iterations to } \\
\text { perform per snap IDD }\end{array}$ & $\begin{array}{l}\text { Only used for full-plane simulations } \\
\text { Must be an integer }\end{array}$ \\
\hline INIT_ITERS_STOP_VALUE & $\begin{array}{l}\#=\text { initial iterations stopping convergence } \\
\text { criteria (relative difference between } \\
\text { iterations) }\end{array}$ & $\begin{array}{l}\text { Only used for full-plane simulations } \\
\text { Real number }\end{array}$ \\
\hline INIT_ITERS_STOP_PERCENT & $\begin{array}{l}\#=\text { initial iterations stopping percentage } \\
\text { criteria (convergent percent of cells - } \\
100.0 \% \text { or less) }\end{array}$ & $\begin{array}{l}\text { Only used for full-plane simulations } \\
\text { Real number }\end{array}$ \\
\hline N_FINAL_ITERS & $\begin{array}{l}\#=\text { maximum number of final iterations to } \\
\text { perform per snap IDD }\end{array}$ & $\begin{array}{l}\text { Only used for full-plane simulations } \\
\text { Must be an integer }\end{array}$ \\
\hline FINAL_ITERS_STOP_VALUE & $\begin{array}{l}\#=\text { final iterations stopping convergence } \\
\text { criteria (relative difference between } \\
\text { iterations) }\end{array}$ & $\begin{array}{l}\text { Only used for full-plane simulations } \\
\text { Real number }\end{array}$ \\
\hline FINAL_ITERS_STOP_PERCENT & $\begin{array}{l}\#=\text { final iterations stopping percentage } \\
\text { criteria (convergent percent of cells - } \\
100.0 \% \text { or less) }\end{array}$ & $\begin{array}{l}\text { Only used for full-plane simulations } \\
\text { Real number }\end{array}$ \\
\hline DEFAULT_INPUT_IO_TYPE & $\begin{array}{l}=1-\text { all input files are of type ASCII } \\
=2-\text { all input files are of type BINARY } \\
\text { (XMDF) }\end{array}$ & \\
\hline DEFAULT_OUTPUT_IO_TYPE & $\begin{array}{l}=0-\text { no output files will be written } \\
=1-\text { all output files are of type ASCII } \\
=2-\text { all output files are of type BINARY } \\
\text { (XMDF) } \\
=3-\text { all output files are saved as both ASCII } \\
\text { and BINARY (XMDF) }\end{array}$ & \\
\hline
\end{tabular}


Table 6. Model parameters: Spatial grid parameters - spatial_grid_parms namelist.

\begin{tabular}{|c|c|c|}
\hline Parameter & Definition & Comments \\
\hline COORD_SYS & $\begin{array}{l}=\text { name of the coordinate system the inputs } \\
\text { are listed in (for metadata purposes only) }\end{array}$ & $\begin{array}{l}\text { 'STATEPLANE' - State Plane } \\
\text { 'LOCAL' - local coordinates } \\
\text { 'UTM' - Universal Transverse } \\
\text { Mercator }\end{array}$ \\
\hline SPZONE & $\begin{array}{l}\#=\text { state plane zone code FIPS number } \\
\#=\text { UTM zone code }\end{array}$ & $\begin{array}{l}\text { Only needed for State Plane and } \\
\text { UTM coordinate system }\end{array}$ \\
\hline XO & $\#=x$-coordinate of the grid origin $(m)$ & Real number \\
\hline YO & $\#=y$-coordinate of the grid origin $(\mathrm{m})$ & Real number \\
\hline AZIMUTH & $\begin{array}{l}\#=\text { the azimuth (rotation) of the grid in } \\
\text { degrees, measured counterclockwise from } \\
\text { East }\end{array}$ & Real number \\
\hline DX & $\#=$ cell spacing $(\mathrm{m})$ in the l-direction & $\begin{array}{l}\text { Real number } \\
\mathrm{DX}=\mathrm{DY} \text { for half-plane simulations }\end{array}$ \\
\hline DY & $\#=$ cell spacing $(\mathrm{m})$ in the J-direction & $\begin{array}{l}\text { Real number } \\
\mathrm{DX}=\mathrm{DY} \text { for half-plane simulations }\end{array}$ \\
\hline N_CELL_I & $\#=$ number of grid cells in the 1 -direction & Must be an integer \\
\hline N_CELL_J & $\#=$ number of grid cells in the J-direction & Must be an integer \\
\hline
\end{tabular}

Table 7. Model parameters: Input file type - input_files namelist.

\begin{tabular}{|c|c|c|}
\hline Parameter & Definition & Comments \\
\hline DEP & Name of input bathymetry file & Required for IDEP_OPT $=0$ \\
\hline SURGE & Name of input water level correction file & Required for ISURGE = 1 \\
\hline SPEC & Name of incident spectral energy file & Required for I_BC(ISIDE) = 2 \\
\hline WIND & Name of input wind file & Required for IWIND = 1 \\
\hline FRIC & Name of input bottom friction file & Required for IFRIC = 2 or 4 \\
\hline CURR & Name of input current file & $\begin{array}{l}\text { Only used for half-plane } \\
\text { simulations } \\
\text { Required for ICUR = } 1 \text { or } 2\end{array}$ \\
\hline IO_TYPE_DEP & $\begin{array}{l}=1-\text { depth input file type is ASCII } \\
=2-\text { depth input file type is BINARY (XMDF) }\end{array}$ & \\
\hline IO_TYPE_SURGE & $\begin{array}{l}=1-\text { surge input file type is ASCII } \\
=2-\text { surge input file type is BINARY (XMDF) }\end{array}$ & \\
\hline IO_TYPE_WIND & $\begin{array}{l}=1-\text { wind input file type is ASCII } \\
=2-\text { wind input file type is BINARY (XMDF) }\end{array}$ & \\
\hline IO_TYPE_SPEC & $\begin{array}{l}=1-\text { spectral input file type is ASCII } \\
=2-\text { spectral input file type is BINARY } \\
\text { (XMDF) }\end{array}$ & \\
\hline IO_TYPE_FRIC & $\begin{array}{l}=1-\text { friction input file type is ASCII } \\
=2-\text { friction input file type is BINARY (XMDF) }\end{array}$ & \\
\hline IO_TYPE_CURR & $\begin{array}{l}=1-\text { current input file type is ASCII } \\
=2-\text { current input file type is BINARY (XMDF) }\end{array}$ & \\
\hline
\end{tabular}


Table 8. Model parameters: Ouput file type - output_files namelist.

\begin{tabular}{|c|c|c|}
\hline Parameter & Definition & Comments \\
\hline WAVE & Name of output wave field file & $\begin{array}{l}\text { Contains } H_{m o}, T_{p} \text {, and } \alpha_{m} \text { for all grid } \\
\text { cells for all snap IDD's }\end{array}$ \\
\hline OBSE & Name of output spectral file & Only for NSELCT > 0 \\
\hline BREAK & Name of output wave breaking file & Only for IBREAK = 1 or 2 \\
\hline RADS & Name of output radiation stress file & Only for IRS = 1 \\
\hline SELH & Name of selected wave points output file & $\begin{array}{l}\text { Only for NSELCT }>0 \\
\text { For each output grid cell, } H_{m o}, T_{p} \text {, and } \\
\alpha_{m} \text { are saved }\end{array}$ \\
\hline STATION & Name of output station file & $\begin{array}{l}\text { Only for NSTATIONS }>0 \\
\text { For each output point, } H_{m o}, T_{p} \text {, and } \alpha_{m} \\
\text { are saved }\end{array}$ \\
\hline NEST & Name of nested output file & Only for NNEST > 0 \\
\hline LOGS & Name of run time log files & ASCII files \\
\hline TP & Name of output peak wave period file & \\
\hline XMDF_SPATIAL & Name of the XMDF spatial output file & $\begin{array}{l}\text { This file only used when IO_TYPE's are } \\
\text { set to } 2 \text { or } 3 \text {. }\end{array}$ \\
\hline IO_TYPE_TP & $\begin{array}{l}=\{0,1,2,3\} \text { (see DEFAULT_OUTPUT_IO_TYPE } \\
\text { description ) }\end{array}$ & $\begin{array}{l}\text { Output file type for the TP file; same } \\
\text { possible values as in } \\
\text { DEFAULT_OUTPUT_IO_TYPE }\end{array}$ \\
\hline IO_TYPE_NEST & $\begin{array}{l}=\{0,1,2,3\} \text { (see DEFAULT_OUTPUT_IO_TYPE } \\
\text { description ) }\end{array}$ & $\begin{array}{l}\text { Output file type for the NEST file; same } \\
\text { possible values as in } \\
\text { DEFAULT_OUTPUT_IO_TYPE }\end{array}$ \\
\hline IO_TYPE_SELH & $\begin{array}{l}=\{0,1,2,3\} \text { (see DEFAULT_OUTPUT_IO_TYPE } \\
\text { description ) }\end{array}$ & $\begin{array}{l}\text { Output file type for the SELH file; same } \\
\text { possible values as in } \\
\text { DEFAULT_OUTPUT_IO_TYPE }\end{array}$ \\
\hline IO_TYPE_RADS & $\begin{array}{l}=\{0,1,2,3\} \text { (see DEFAULT_OUTPUT_IO_TYPE } \\
\text { description ) }\end{array}$ & $\begin{array}{l}\text { Output file type for the RADS file; same } \\
\text { possible values as in } \\
\text { DEFAULT_OUTPUT_IO_TYPE }\end{array}$ \\
\hline IO_TYPE_BREAK & $\begin{array}{l}=\{0,1,2,3\} \text { (see DEFAULT_OUTPUT_IO_TYPE } \\
\text { description ) }\end{array}$ & $\begin{array}{l}\text { Output file type for the BREAK file; } \\
\text { same possible values as in } \\
\text { DEFAULT_OUTPUT_IO_TYPE }\end{array}$ \\
\hline IO_TYPE_OBSE & $\begin{array}{l}=\{0,1,2,3\} \text { (see DEFAULT_OUTPUT_IO_TYPE } \\
\text { description ) }\end{array}$ & $\begin{array}{l}\text { Output file type for the OBSE file; same } \\
\text { possible values as in } \\
\text { DEFAULT_OUTPUT_IO_TYPE }\end{array}$ \\
\hline IO_TYPE_WAVE & $\begin{array}{l}=\{0,1,2,3\} \text { (see DEFAULT_OUTPUT_IO_TYPE } \\
\text { description ) }\end{array}$ & $\begin{array}{l}\text { Output file type for the WAVE file; same } \\
\text { possible values as in } \\
\text { DEFAULT_OUTPUT_IO_TYPE }\end{array}$ \\
\hline IO_TYPE_STATION & $\begin{array}{l}=\{0,1,2,3\} \text { (see DEFAULT_OUTPUT_IO_TYPE } \\
\text { description ) }\end{array}$ & $\begin{array}{l}\text { Output file type for the STATION file; } \\
\text { same possible values as in } \\
\text { DEFAULT_OUTPUT_IO_TYPE }\end{array}$ \\
\hline
\end{tabular}


Table 9. Model parameters: Time related parameters - time_parms namelist.

\begin{tabular}{|c|c|c|}
\hline Parameter & Definition & Comments \\
\hline I_TIME_INC & \# = time increment between snap IDD's & $\begin{array}{l}\text { Required when IDD_SPEC_TYPE }= \pm 2 \\
\text { or } \pm 3 \\
\text { For non-regularly spaced data, enter } 1 \\
\text { Must be an integer }\end{array}$ \\
\hline I_TIME_INC_UNITS & $\begin{array}{l}=\text { units corresponding to time increment } \\
\text { 'ss' = seconds } \\
\text { 'mm' = minutes } \\
\text { 'hh' = hours } \\
\text { 'DD'= days }\end{array}$ & $\begin{array}{l}\text { Required when IDD_SPEC_TYPE }= \pm 2 \\
\text { or } \pm 3 \\
\text { Character data }\end{array}$ \\
\hline IYEAR_START & $=$ the four digit year in which the simulation starts & Required when IDD_SPEC_TYPE $=2$ \\
\hline IMON_START & $\begin{array}{l}=\text { the two digit month in which the simulation } \\
\text { starts }\end{array}$ & Required when IDD_SPEC_TYPE = 2 \\
\hline IDAY_START & $=$ the two digit day in which the simulation starts & Required when IDD_SPEC_TYPE $=2$ \\
\hline IHR_START & $=$ the two digit hour in which the simulation starts & Required when IDD_SPEC_TYPE = 2 \\
\hline IMIN_START & $\begin{array}{l}=\text { the two digit minute in which the simulation } \\
\text { starts }\end{array}$ & Required when IDD_SPEC_TYPE $=2$ \\
\hline ISEC_START & $\begin{array}{l}=\text { the two digit second in which the simulation } \\
\text { starts }\end{array}$ & Required when IDD_SPEC_TYPE = 2 \\
\hline IYEAR_END & $=$ the four digit year in which the simulation ends & Required when IDD_SPEC_TYPE = 2 \\
\hline IMON_END & $=$ the two digit month in which the simulation ends & Required when IDD_SPEC_TYPE $=2$ \\
\hline IDAY_END & $=$ the two digit day in which the simulation ends & Required when IDD_SPEC_TYPE $=2$ \\
\hline IHR_END & $=$ the two digit hour in which the simulation ends & Required when IDD_SPEC_TYPE = 2 \\
\hline IMIN_END & $\begin{array}{l}=\text { the two digit minute in which the simulation } \\
\text { ends }\end{array}$ & Required when IDD_SPEC_TYPE = 2 \\
\hline ISEC_END & $\begin{array}{l}=\text { the two digit second in which the simulation } \\
\text { ends }\end{array}$ & Required when IDD_SPEC_TYPE = 2 \\
\hline
\end{tabular}

Table 10. Model parameters: Constant boundary spectra - const_spec namelist.

\begin{tabular}{|l|l|l|}
\hline Parameter & Definition & Comments \\
\hline NFREQ & $\#=$ number of frequency bins & $\begin{array}{l}\text { Required for I_BC }=1 \text { or all grid } \\
\text { boundaries I_BC }=0\end{array}$ \\
\hline NA & $\#=$ number of angle bands & $\begin{array}{l}\text { Defines angular resolution } \\
\text { Required for I_BC }=1 \text { or all grid } \\
\text { boundaries I_BC }=0 \\
\text { NA }=35 \text { for half-plane simulations } \\
\text { NA is typically set to 72 for full-plane } \\
\text { simulations }\end{array}$ \\
\hline FO & $\#=$ lowest frequency (Hz) & $\begin{array}{l}\text { Required for I_BC }=1 \text { or all grid } \\
\text { boundaries I_BC }=0\end{array}$ \\
\hline DF_CONST & $\#=$ constant frequency increment & $\begin{array}{l}\text { Required for I_BC }=1 \text { or all grid } \\
\text { boundaries I_BC }=0\end{array}$ \\
\hline
\end{tabular}


Table 11. Model parameters: Analytic depth profile - depth_fun namelist.

\begin{tabular}{|l|l|l|}
\hline Parameter & Definition & Comments \\
\hline DP_ISIDE & $\begin{array}{l}\{1,2,3,4\}=\text { side of grid on which depth D1 is } \\
\text { defined }\end{array}$ & Required for IDEP_OPT = 1 \\
\hline DP_D1 & $\#=$ water depth $(\mathrm{m})$ on ISIDE & Required for IDEP_OPT = 1 \\
\hline DP_SLOPE & $\begin{array}{l}\#=\text { constant bed slope applied from ISIDE } \\
\text { across the grid }\end{array}$ & Required for IDEP_OPT = 1 \\
\hline
\end{tabular}

Table 12. Model parameters: Constant bottom friction - const_fric namelist.

\begin{tabular}{|l|l|l|}
\hline Parameter & Definition & Comments \\
\hline cf_const & $\begin{array}{l}\#=\text { constant JONSWAP or Manning bottom } \\
\text { friction value }\end{array}$ & Required for IFRIC = 1 or 3 \\
\hline
\end{tabular}

Table 13. Model parameters: Snap IDD's - snap_idds extra namelist.

\begin{tabular}{|l|l|l|}
\hline Parameter & Definition & Comments \\
\hline \multirow{5}{*}{ IDDS (NUMSTEPS) } & \multirow{2}{*}{ time/case event identifier for each snap IDD } & $\begin{array}{l}\text { Required for IDD_SPEC_TYPE }=1,-2, \\
-3, \text { or } 4\end{array}$ \\
& & $\begin{array}{l}\text { IDD_SPEC_TYPE }=1 \text { is for integer } \\
\text { data } \\
\text { IDD_SPEC_TYPE }=-2 \text { or }-3 \text { is for } \\
\text { integer or character data (20 } \\
\text { characters max), both enclosed in } \\
\text { single quotes } \\
\text { IDD_SPEC_TYPE }=4 \text { is for character } \\
\text { data (20 characters max) enclosed in } \\
\text { single quotes } \\
\text { Must appear as single column }\end{array}$ \\
\hline
\end{tabular}

Table 14. Model parameters: Selected points - select_pts extra namelist.

\begin{tabular}{|c|c|c|}
\hline Parameter & Definition & Comments \\
\hline $\begin{array}{l}\text { IOUT(NSELCT), } \\
\text { JOUT(NSELCT) }\end{array}$ & $\begin{array}{l}\#=(I, J) \text { grid cell locations for selected output } \\
\text { points }\end{array}$ & $\begin{array}{l}\text { Required for NSELCT }>0 \\
\text { To save } H_{m o}, T_{p} \text {, and } \alpha_{m} \text { as well as } \\
\text { spectra } \\
\text { Must appear as two column pairs }\end{array}$ \\
\hline
\end{tabular}

Table 15. Model parameters: Nest points - nest_pts extra namelist.

\begin{tabular}{|l|l|l|}
\hline Parameter & Definition & Comments \\
\hline $\begin{array}{l}\text { INEST(NNEST), } \\
\text { JNEST(NNEST) }\end{array}$ & $\begin{array}{l}\#=(\mathrm{I}, \mathrm{J}) \text { grid cell locations to save spectra for } \\
\text { nesting application }\end{array}$ & $\begin{array}{l}\text { Required for NNEST }>0 \\
\text { Must appear as two column pairs }\end{array}$ \\
\hline
\end{tabular}


Table 16. Model parameters: Station points - station_locations extra namelist.

\begin{tabular}{|c|c|c|}
\hline Parameter & Definition & Comments \\
\hline $\begin{array}{l}\text { STAT_XCOOR(NSTATIONS), } \\
\text { STAT_YCOOR(NSTATIONS) }\end{array}$ & $\begin{array}{l}\#=(x, y) \text { coordinates of station output } \\
\text { locations }\end{array}$ & $\begin{array}{l}\text { Required for NSTATIONS }>0 \\
\text { Real numbers } \\
\text { Must appear as two column } \\
\text { pairs }\end{array}$ \\
\hline
\end{tabular}

Table 17. Model parameters: Spatially constant winds - const_wind extra namelist.

\begin{tabular}{|c|c|c|}
\hline Parameter & Definition & Comments \\
\hline $\begin{array}{l}\text { UMAG_CONST_IN(NUMSTEPS), } \\
\text { UDIR_CONST_IN(NUMSTEPS) }\end{array}$ & $\begin{array}{l}\text { \# = magnitude (UMAG_CONST_IN) and } \\
\text { direction (UDIR_CONST_IN) for spatially } \\
\text { constant winds }\end{array}$ & $\begin{array}{l}\text { Required for IWIND =0 } \\
\text { Real numbers } \\
\text { Must appear as two column } \\
\text { pairs }\end{array}$ \\
\hline
\end{tabular}

Table 18. Model parameters: Spatial water level adjustment - const_surge extra namelist.

\begin{tabular}{|l|l|l|}
\hline Parameter & Definition & Comments \\
\hline DADD_CONST_IN(NUMSTEPS) & $\begin{array}{l}\text { \# = spatially constant water level height } \\
\text { adjustment }\end{array}$ & $\begin{array}{l}\text { Required for ISURGE }=0 \\
\text { Real number } \\
\text { Must appear as single column }\end{array}$ \\
\hline
\end{tabular}

Table 19. Model parameters: TMA boundary spectra - const_tma_spec extra namelist.

\begin{tabular}{|c|c|c|}
\hline Parameter & Definition & Comments \\
\hline $\begin{array}{l}\text { H_SPEC_IN(NUMSTEPS,ISIDE), } \\
\text { TP_SPEC_IN(NUMSTEPS,ISIDE), } \\
\text { WVANG_SPEC_IN(NUMSTEPS,ISIDE) }\end{array}$ & $\begin{array}{l}\#=\text { constant boundary spectra } \\
\text { wave height }(\mathrm{m}) \text { - H_SPEC_IN } \\
\text { peak period (s) - TP_SPEC_IN } \\
\text { wave direction (deg) - WVANG_SPEC_IN }\end{array}$ & $\begin{array}{l}\text { Require when I_BC(ISIDE) = } \\
1 \text { where ISIDE = 1, 2, 3, or } 4 \\
\text { (boundary sides of the } \\
\text { domain) } \\
\text { Real numbers } \\
\text { Must appear as three } \\
\text { column triplets }\end{array}$ \\
\hline
\end{tabular}

\section{IDD_SPEC_TYPE examples}

In order to provide for easy setup as well as detailed control, there are seven options for naming snap IDD's (o, 1, $\pm 2, \pm 3$, and 4$)$. The simulation file and results of each selection is shown below to further clarify these options.

\section{IDD_SPEC_TYPE $=0$}
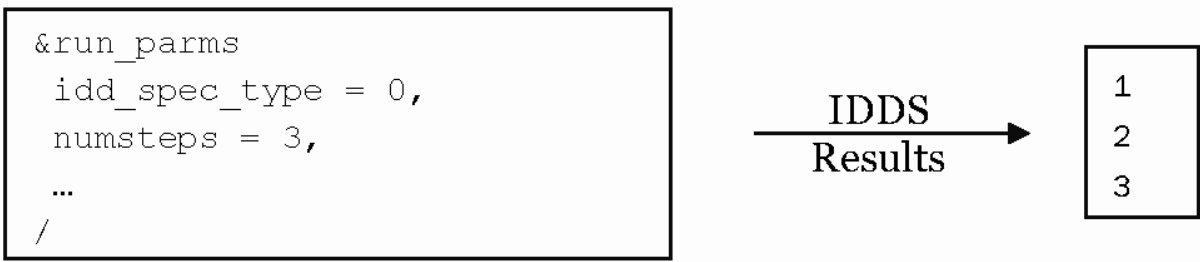
IDD_SPEC_TYPE $=-3$

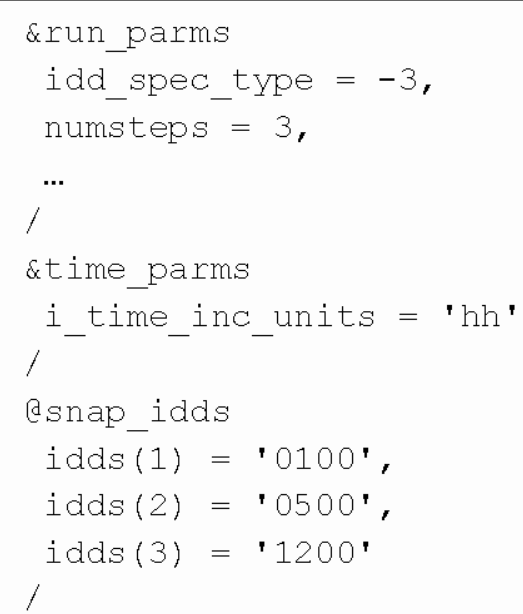

IDD_SPEC_TYPE $=3$

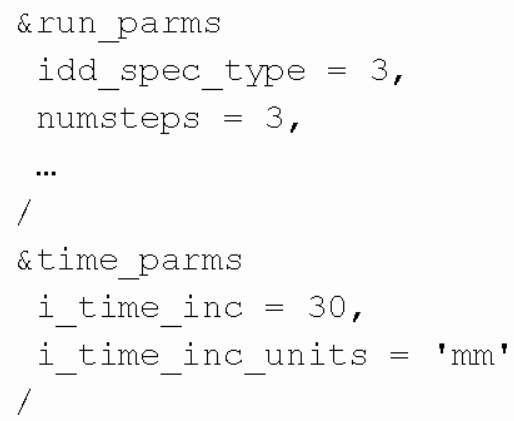

IDD_SPEC_TYPE $=4$

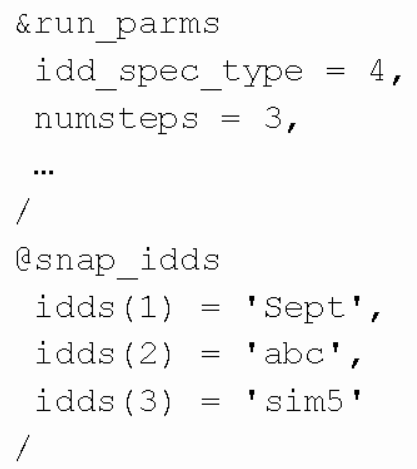

\section{Iterative criteria and parallel execution}

The solution process for the full-plane version of STWAVE is an iterative process that requires a convergent state to signal that a suitable solution 
has been achieved. The process is divided into two states, an initial and a final sweep stage. During the initial iterative sweep, boundary spectra information is simply propagated from the boundary throughout the domain. Once this stage reaches convergence, winds and surges are added to the forcing in the final sweep stage, and this stage iteratively executes until it also reaches a convergent state.

These convergent states are defined by the user in the simulation file under the run_parms namelist. The convergence criteria for the fullplane version of STWAVE are:

N_INIT_ITERS - maximum number of initial iterations to perform per snap IDD

INIT_ITERS_STOP_VALUE - relative difference between initial iterations

INIT_ITERS_STOP_PERCENT - minimum percent of cells that must satisfy stopping criteria for initial iterations

N_FINAL_ITERS - maximum number of final iterations to perform per snap IDD

FINAL_ITERS_STOP_VALUE - relative difference between final iterations

FINAL_ITERS_STOP_PERCENT - minimum percent of cells that must satisfy stopping criteria for final iterations

During a single iteration, energy propagation can only cross one grid partition at a time. As a result, the maximum number of initial/final iterations should be set to a value of at least 5-10 larger than the largest grid partition (e.g., a domain partitioned 4 times in the I-direction and 10 times in J-direction should have the maximum number of iterations be no less than 15). These are fail safe stopping values since it limits the number of iterations calculated but convergence could still be reached before this number. 
The average wave height for each cell is the stopping criteria monitored for convergence. The relative change in average wave height between iterations is checked by the following scheme:

$$
H^{n-1}=\left[\begin{array}{c}
h_{1,1}^{n-1} \\
h_{1,2}^{n-1} \\
\cdots \\
h_{N I, N J}^{n-1}
\end{array}\right],
$$

Average wave height at iteration $(n-1)$

$$
H^{n}=\left[\begin{array}{c}
h_{1,1}^{n} \\
h_{1.2}^{n} \\
\cdots \\
h_{N I, N J}^{n}
\end{array}\right] \text {, }
$$

Average wave height at iteration $(n)$

$$
R=\frac{\left|H^{n}-H^{n-1}\right|}{\operatorname{avg}\left(H^{n}\right)},
$$

Relative change in average wave height between iterations ( $n$ and $n-1$ )

where:

$$
\begin{aligned}
H & =\text { average wave height for an iteration, } \\
h & =\text { individual grid cell wave height } \\
N I & =\text { total grid cells in I-direction, } \\
N J & =\text { total grid cells in J-direction, } \\
R & =\text { relative change in average wave height. }
\end{aligned}
$$

The STOP_PERCENT is defined as the minimum percent of cells that must satisfy the STOP_VALUE for convergence. Thus, when STOP_PERCENT of the cells' R-values are less than the STOP_VALUE, the solution has converged. The relative difference between iterations or STOP_VALUE should be defined as a value between 0.05 and 0.1 with the STOP_PERCENT of grid cells defined close to 100.0 (98.5 - 100.0). The smaller the maximum relative difference (STOP_VALUE), the more final iterations are performed and as a result the more simulation time STWAVE requires.

The parallelized in time feature of STWAVE uses a time decomposition of the snaps whereby each snap is completed on its own processor using a single grid. Essentially what happens is that a distribution of serial executions is performed whereby each snap IDD has its own dedicated processor. For example a job with 50 snaps would require the use of 50 processors with each processor performing only one snap.

The parallelized in space capability of STWAVE uses domain decomposition where the STWAVE domain is divided into smaller grid chunks called partitions. As previously stated, half-plane simulations can only be divided 
in the $\mathrm{J}$-direction while full-plane simulations can be divided in the I- and $\mathrm{J}$ directions. The number of computer processors required for a parallelized STWAVE simulation is dictated by the number of partitions specified in the simulation file under the run_parms namelist,

N_GRID_PART_I - number of grid partitions in the I-direction, = 1 for half-plane

N_GRID_PART_J - number of grid partitions in the J-direction

where the total number of processors used is the product of the partitions,

Number of Processors $=$ N_GRID_PART_I $\times$ N_GRID_PART_J.(24)

For example, if a grid is partitioned into three parts in the I-direction and five parts in the $\mathrm{J}$-direction, then 15 processors are required for the STWAVE simulation. DO NOT use less than 20 cells per partition dimension when deciding on how to divide the grid. Note for the full-plane option, while increasing the number of processors does require more iterations to reach convergence it still requires less wall-clock time to reach a solution.

\section{Sensitivity to final convergence criteria and number of processors}

Full-plane STWAVE operates using an iterative algorithm whereby a set of user-defined iterative controls, such as number of iterations and stopping criteria, are imposed to signal the convergence of a suitable solution. As a result, the performance behavior, running time, and accuracy of the solution are dependent on these parameters. The use of spatially varying wind and surge fields, such as those used for hurricane simulations, typically causes the model to "work harder" at deriving a converged solution and shows more sensitivity to the stopping criteria than spatially constant wind and surge fields. This section provides a detailed analysis whereby the final stopping criteria are varied in order to determine the solution sensitivity to such differences. In addition to stopping criteria, the analyses consider the parallel in space component and address how the solution is affected by decomposing the domain into different numbers of partitions. The tests were performed using different intensity synthetic hurricane simulations, one making landfall in southeastern Louisiana and another along the Texas coast near Port Aransas. 


\section{Louisiana SE grid}

The Louisiana SE grid is comprised of 683 cells in the I-direction and 744 cells in the J-direction with the cell spacing in both directions set at 200.0 $\mathrm{m}$. Note in Figure 5 that the model domain includes both water and land cells, with land appearing in brown. Cells that are dry (land) are not active during a snap. However, due to time varying storm surge values, dry cells can become inundated and are then made active. The model input conditions are those of a synthetic hurricane with wind fields supplied from a planetary boundary layer model (MORPHOS PBL), spectral boundary conditions supplied from a larger scale wave model simulation using the WAM model (Komen et al. 1994), and surge values supplied from ADCIRC. The spatially-averaged characteristics of the Louisiana simulation input over the 97 snaps are shown in Figures 6 through Figure 9. The average wave height is shown in Figure 10. All the parallel test cases were run using the ERDC DSRC high performance computing resources; in particular all parallel simulations were completed using the Cray XT4 computer known as Jade. Jade has 2,146 compute nodes with each node containing a 2.1-GHz AMD Opteron 64-bit quad-core processors and 8 GBytes of dedicated memory (http://www.erdc.hpc.mil/). The nodes are networked together using a Cray SeaStar2 communications engine. The STWAVE source code was compiled using the Portland Group (PGI) 10.3.o FORTRAN compiler and the MPICH-2 implementation for MPI. Due to the high memory requirements for the serial test cases, those simulations were performed on a Linux workstation with dual $2.8 \mathrm{GHz}$ quad-core AMD Opteron processors with $512 \mathrm{~KB}$ of Cache, a total of $24 \mathrm{~GB}$ of system memory and using the 64-bit OpenSuse 11.o Linux operating system. The STWAVE source code was compiled using GNU FORTRAN 4.2.

Table 20 shows the tested combination of grid decompositions and stopping values used in this sensitivity analysis. The grid partition size is dictated by a desire to keep the partitions as square as possible without falling below the 20 cell per partition limit. The final stopping criteria (denoted by EF in the table) consist of the pair of variables FINAL_ITERS_STOP_VALUE and FINAL_ITERS_PERCENT_VALUE. The stop value is the relative difference between iterations, $\mathbf{R}$, and must be in the range of o.0-1.o. The percentage value is between 0.0-100.0 and governs the amount of cells that must be less than or equal to the stop value in order to exit the iteration scheme. 


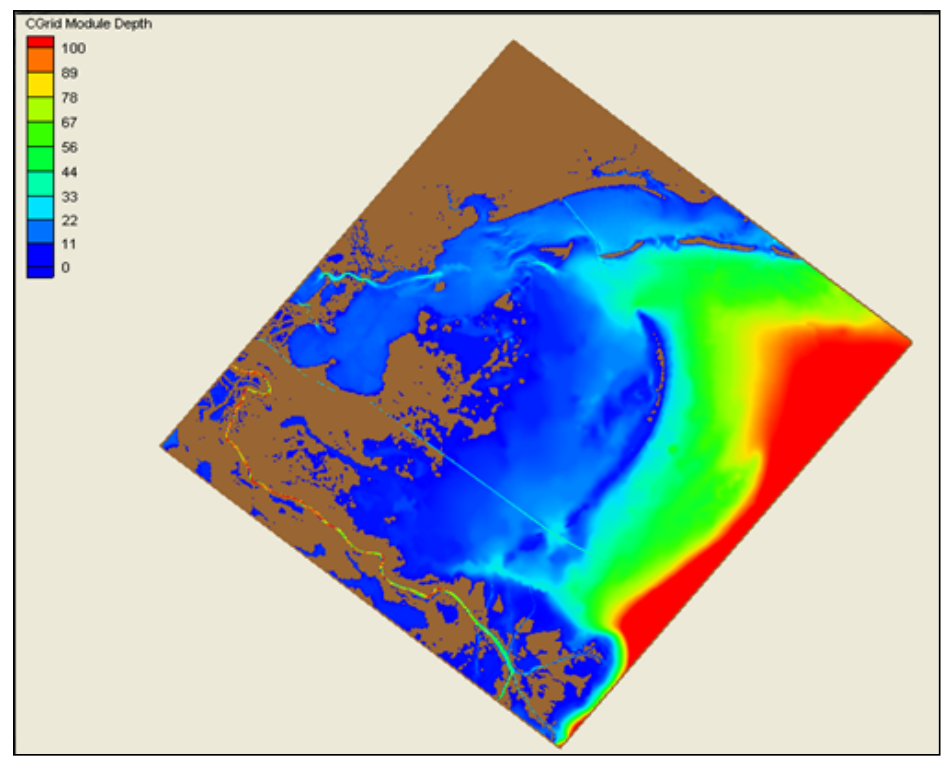

Figure 5. Bathymetry contours for the Louisiana grid.

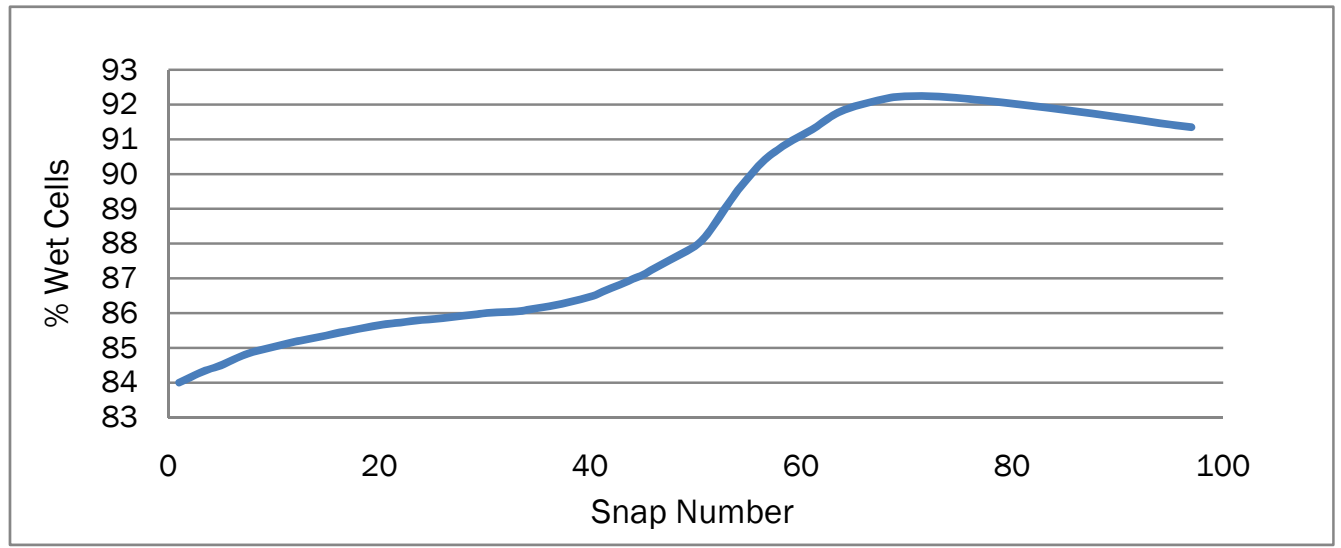

Figure 6. Percentage of wet cells (active) for each snap for the Louisiana grid.

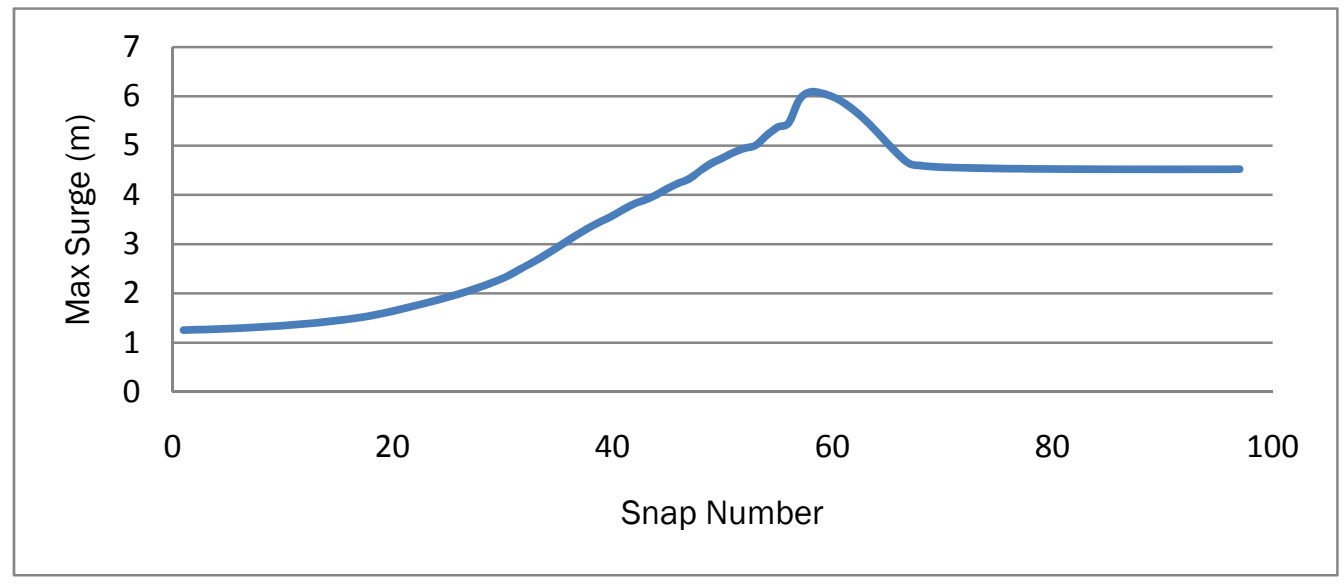

Figure 7. Maximum surge levels (meters) over the grid for each snap in the Louisiana grid. 


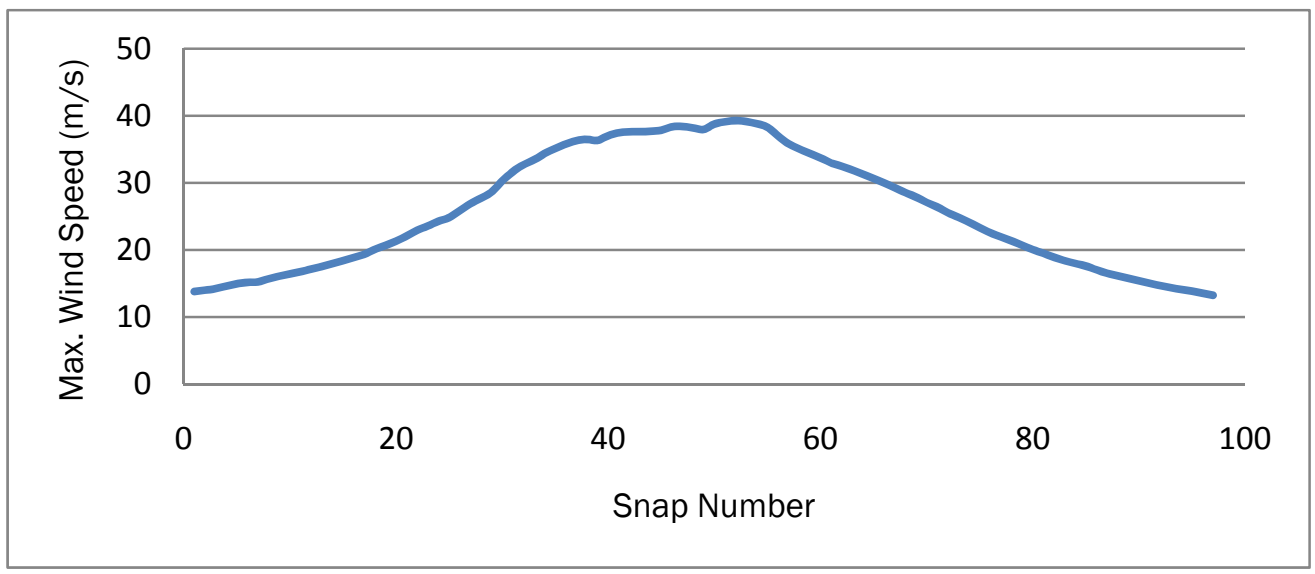

Figure 8. Maximum wind speed (meters/second) over the grid for each snap in the Louisiana grid.

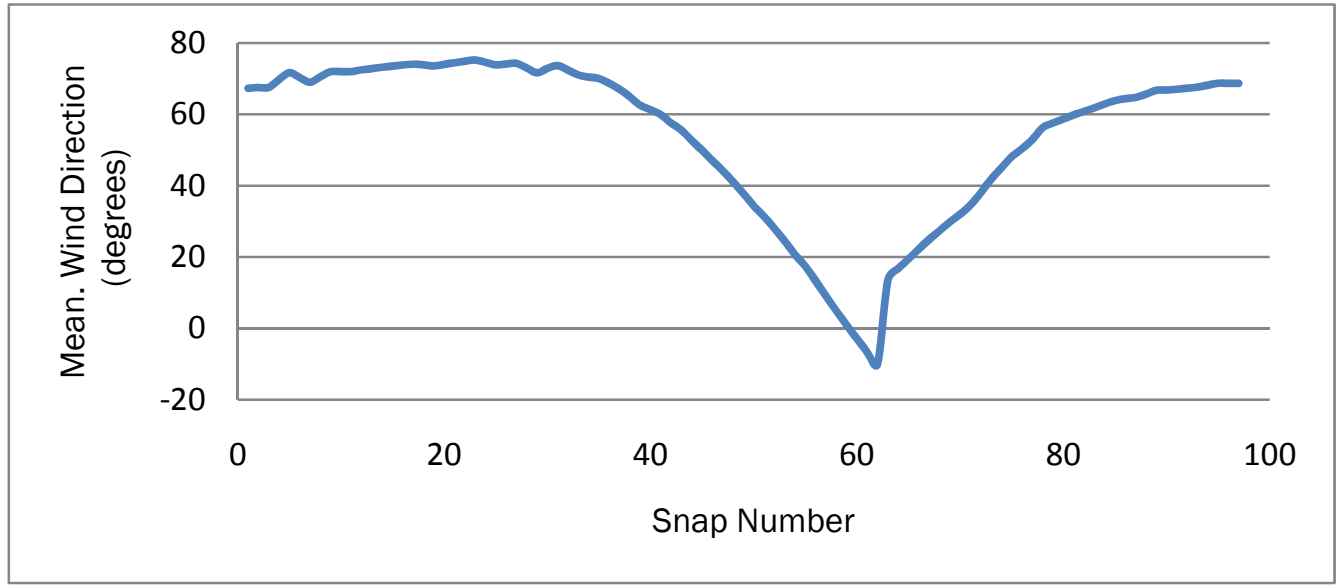

Figure 9. Mean wind direction (degrees) over the grid for each snap in the Louisiana grid.

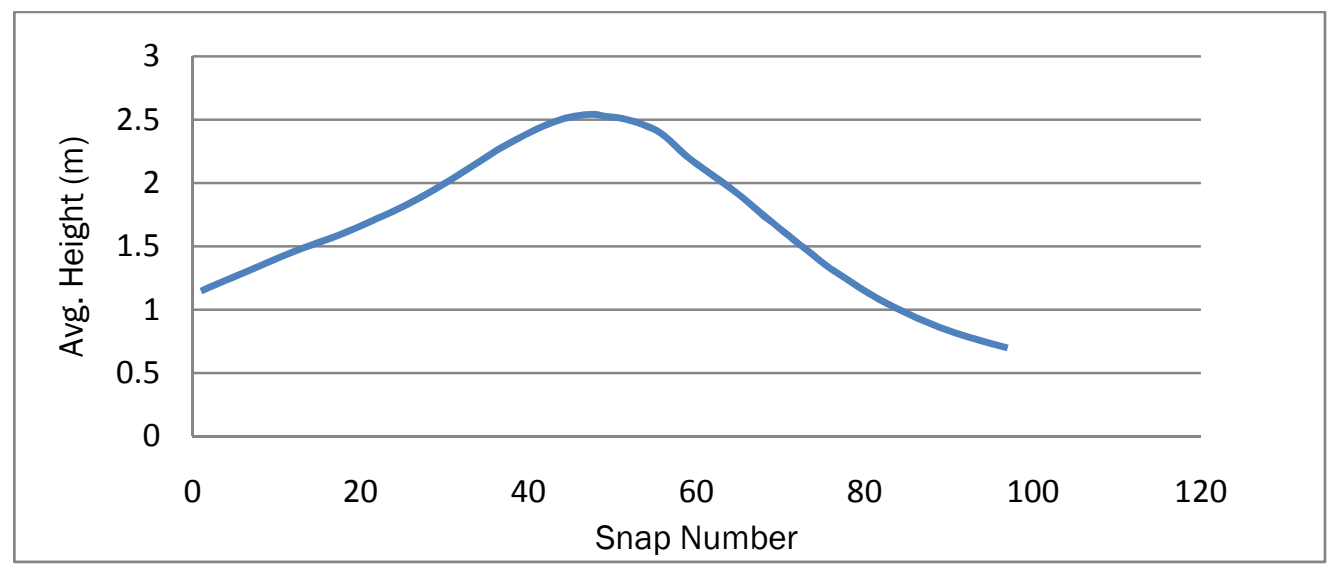

Figure 10. Average wave height for each snap for the Louisiana grid. 
Table 20. Parameters used for sensitivity tests on the Louisiana grid.

\begin{tabular}{|l|l|l|l|}
\hline Run Number & Grid Partitioning $\left(\mathrm{N}_{\mathfrak{I}} \times \mathrm{N}_{\mathrm{J}}\right)$ & No. of Processors & $\mathrm{EF}$ \\
\hline $\mathrm{B}$ & $1 \times 1$ & 1 & $0.1,99.8$ \\
\hline 1 & $11 \times 12$ & 132 & $0.1,99.8$ \\
\hline 2 & $14 \times 15$ & 210 & $0.1,99.8$ \\
\hline 3 & $17 \times 19$ & 323 & $0.1,99.8$ \\
\hline 4 & $22 \times 24$ & 528 & $0.1,99.8$ \\
\hline S2 & $1 \times 1$ & 1 & $0.05,99.8$ \\
\hline 5 & $11 \times 12$ & 132 & $0.05,99.8$ \\
\hline 6 & $14 \times 15$ & 210 & $0.05,99.8$ \\
\hline 7 & $17 \times 19$ & 323 & $0.05,99.8$ \\
\hline 8 & $22 \times 24$ & 528 & $0.05,99.8$ \\
\hline S3 & $1 \times 1$ & 1 & $0.1,99.5$ \\
\hline 9 & $11 \times 12$ & 132 & $0.1,99.5$ \\
\hline 10 & $14 \times 15$ & 210 & $0.1,99.5$ \\
\hline 11 & $17 \times 19$ & 323 & $0.1,99.5$ \\
\hline 12 & $22 \times 24$ & 528 & $0.1,99.5$ \\
\hline
\end{tabular}

As a first analysis, total computational times are compared for all test cases listed in Table 20 in order to determine the effect of grid partitioning and $\mathrm{EF}$ values on execution time. The results for total computation times are illustrated in Figure 11. As the number of processors increases, the overall execution time of STWAVE decreases. This indicates that dividing the STWAVE domain into smaller grid partitions results in a faster overall execution (wall-clock) time - for example, increasing the partitions from $11 \times 12$ to $22 \times 24$ reduced the running time by approximately a third. While a linear speedup is not achieved, the time advantages and lessened per processor memory requirements are substantial.

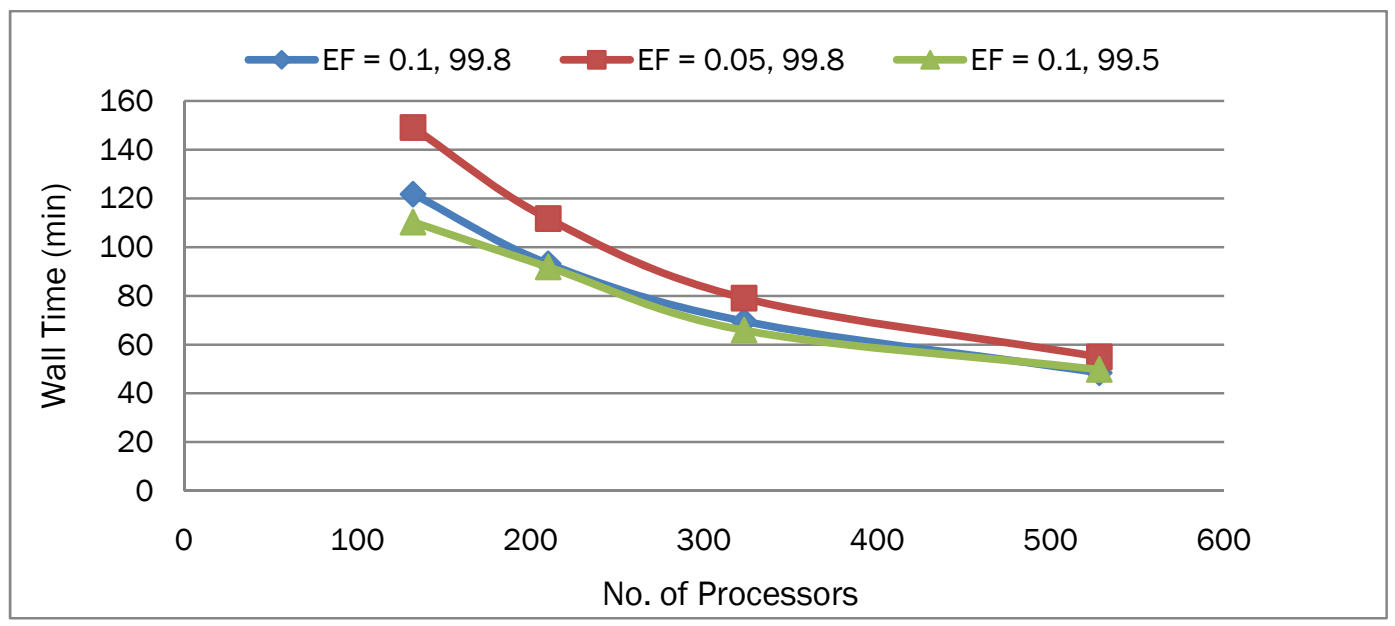

Figure 11. Wall clock time for computing 97 snaps on the Louisiana grid. 
Returning to Figure 11, it is also seen that longer running times are required for stricter stopping criteria. The running times required for a stop percent of 99.8 is slightly longer than for a stop percent of 99.5 for all processors considering the same relative difference. In addition, a smaller relative difference (0.05) has a slower completion time than a higher relative difference (0.10) for the same stop percent. However, the magnitude of difference between wall times decreases as the number of processors increase. The time difference between an EF of $(0.1,99.5)$ and an $\mathrm{EF}$ of $(0.1,99.8)$ is about $15 \mathrm{~min}$ at 132 processors and nearly negligible at 528 processors. Similarly, the time difference between an EF of (0.1, $99.8)$ and $(0.05,99.8)$ is approximately $40 \mathrm{~min}$ at 132 processors and less than 10 min at 528 processors. It should be noted that wall time appears to be more sensitive to relative difference than stop percent, particularly for a smaller number of processors, given that the largest time differences result from tightening the relative difference.

Looking at the individual iteration level by taking average overall iterations performed for the 97 snaps, it is apparent that the completion time per iteration is considerably higher when STWAVE is run in serial mode (one processor) compared with parallel mode (multiple processors). The time per iteration continues to decrease gradually as the number of processors increase, as seen in Figure 12, indicating more processors (i.e., finer grid partitions) accelerate the computations.

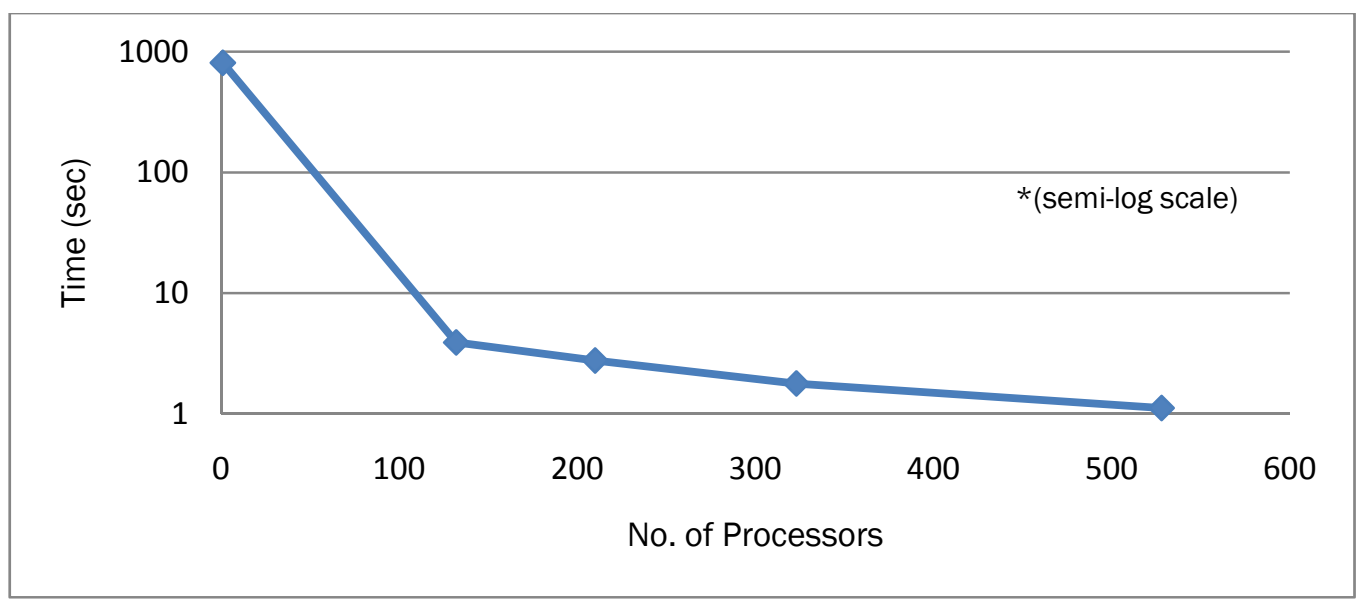

Figure 12. Average time per iteration versus the number of processor for the Louisiana grid.

Another consideration is the required iteration count per snap to satisfy the convergence criteria. For all test cases performed here, the number of iterations performed per snap tends to increase towards the end of the simulation time, e.g., the later snaps. This is mainly due to the number of 
active cells (i.e., wet areas of the domain) increasing as the hurricane makes landfall and the surge propagates inland. This increase in the total number of active cells requires STWAVE to perform more iterations per snap in order to reach the required convergence criteria. The percentage of wet cells as a function of snap number is shown in Figure 6 with the number of iterations per snap for all cases shown in Figure 13.

More iterations and variability in iteration count is observed for the case where the smallest maximum difference (0.05) is used. The variability in iteration count shows the effort of STWAVE to converge on a solution subjected to a smaller difference between cells, and indicates that relative difference has a greater impact on the iteration count than the percentage of cells criteria. The time required to obtain a suitable solution is directly influenced by the iteration count, which explains why the simulations with an $\mathbf{R}$ of 0.05 for FINAL_ITERS_STOP_VALUE had the longest wall clock time. Finally, it is observed that using more grid partitions tends to require more iteration per snap, particularly in conjunction with stricter stopping criteria.

Four representative snap solutions are selected to observe how the solution itself varied with different convergence criteria and grid decomposition. The four snaps selected span the simulation event. One occurs early in the storm, the next one is just before the peak surge, the third is just after the peak surge, and the final one is after the eye of the storm has passed beyond the computational domain. Solutions are compared with a base simulation run on a personal computer in serial mode with $\mathrm{EF}=(0.1,99.8)$. Although output was obtained at all four snaps, significant differences are observed between cases for snap 97, therefore, the comparisons will focus on snap 97 and the changes observed as a result of the test specifications.

Figure 14 shows the wave height variations between different stopping criteria for snap 97 using the serial method. No significant differences among the three solutions are noted, suggesting that changing the stopping criteria for final iterations would not provoke significant changes in wave height when only one processor is used for execution. The only noticeable difference among the serial simulations is the wall time required to achieve them; where, as expected, the slowest and longest wall times correspond to an $\mathrm{EF}=(0.1,99.5)$ and $(0.05,99.8)$, respectively. 
For the parallel simulations, differences between each case as a result of changes in both the number of processors and the stopping criteria are observed. Using a greater maximum relative change of 0.1 for the final iterations and then distributing the calculations amongst several processors results in an underpredicted wave height field when compared with the base simulation. Additionally, using the less stringent $\mathbf{R}=0.1$, in combination with a higher number of processors, causes apparitions of blocks to appear in the wave height solution (wave heights are not continuous across the blocks). The appearance of these blocks indicates that the stopping criteria were not sufficient to produce a reasonable solution. As a result, when the iterations stopped, the final solutions of each individual grid partition did not match completely the values of their neighbors along the grid partition boundaries. This caused discontinuities along the grid partition boundaries in the combined final solution and hence, the appearance of blocks in the contour plots. Comparing Figure 15 and Figure 16, it is notable that the stopping criteria $\mathrm{EF}=(0.05,99.8)$ provides the best solution independent of the number of processors when compared to the serial runs. Specifically, the blocks tend to disappear and the wave height fields more closely match those of the base simulation. No significant disparities between solutions are observed between an EF of 99.8 and 99.5, which equates to a difference of about 1,524 cells, indicating that small changes in the percentage of cells that meet the relative difference does not make a considerable impact on the final solution, at least for the Louisiana grid being analyzed here.

Differences in average wave height solutions as a result of varying convergence criteria are shown in Figure 17. The larger magnitudes and fluctuations are associated with the maximum relative difference $\mathbf{R}$, which clearly indicates the solution is more sensitive to the maximum relative difference rather than the percentage of cells satisfying the stop value. It is important to note that while the solution is affected by convergence criteria, the maximum wave height difference is approximately $5 \mathrm{~cm}$, which is comparatively small considering the average wave heights of the modeled storm were between 1.0 and 2.6 m, as shown in Figure 10. 


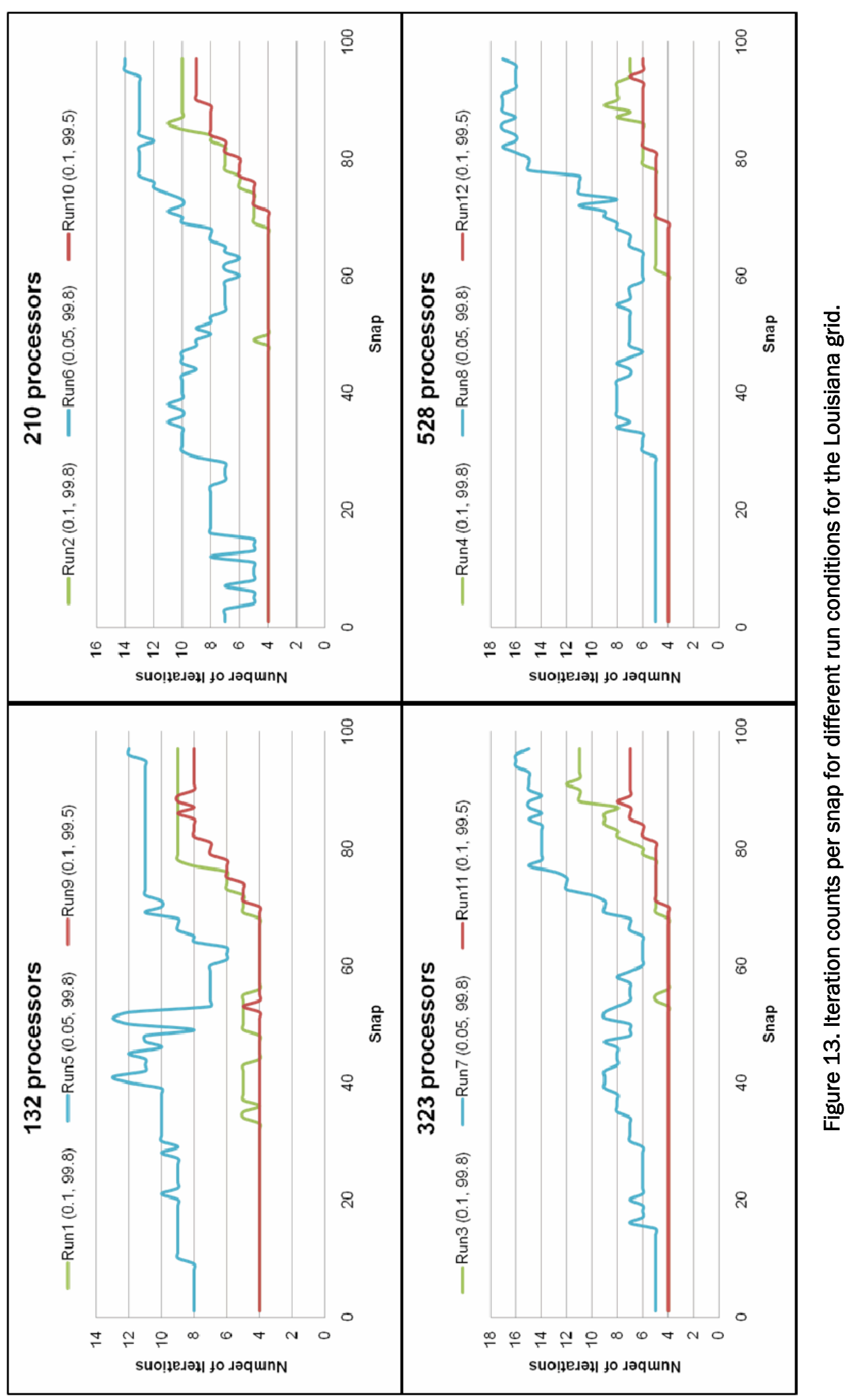



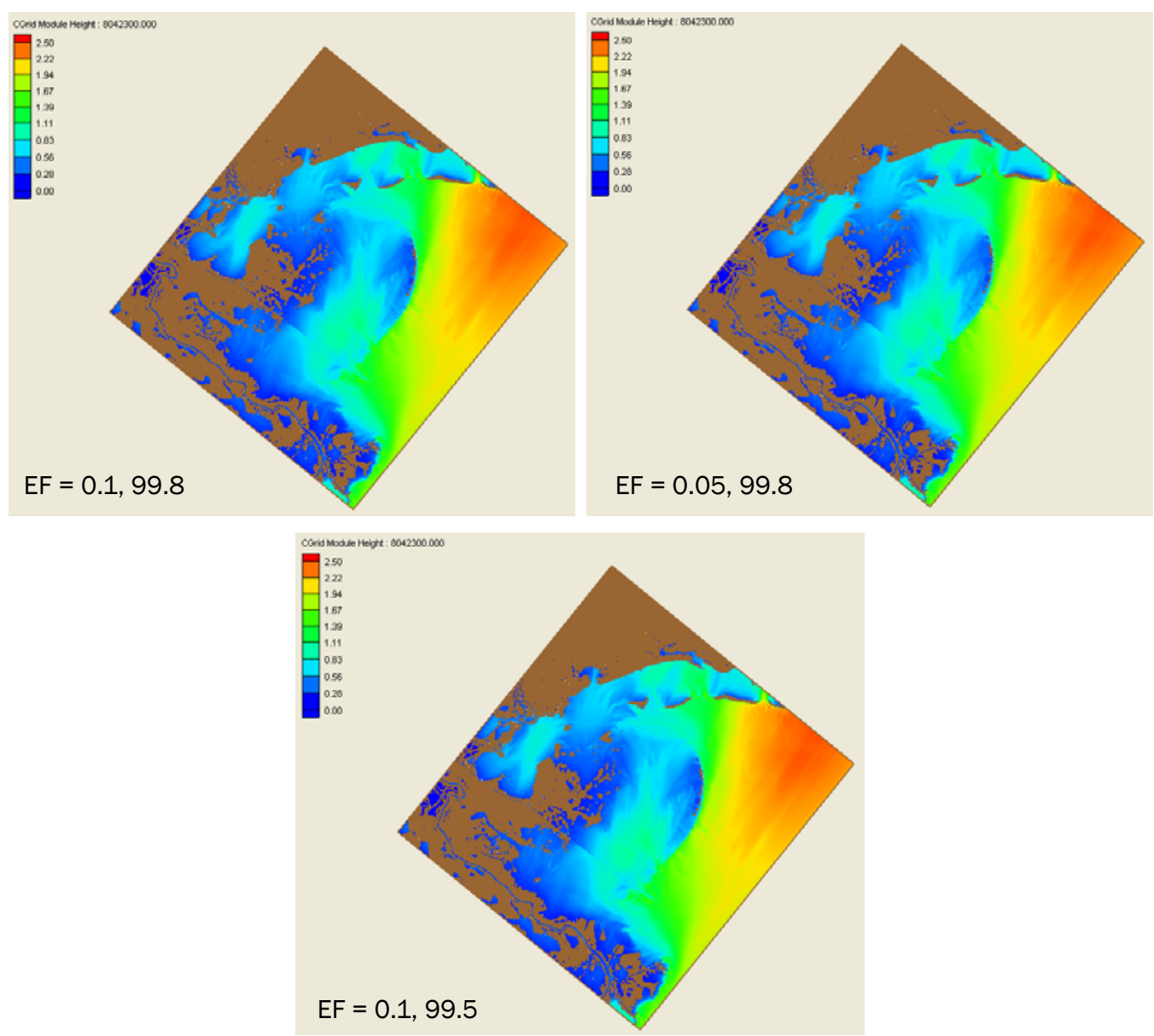

Figure 14. Wave heights (meters) for snap 97 from the serial mode runs for the Louisiana grid.

\section{Texas grid}

The Texas coastline grid consists of 255 cells in the I-direction and 360 cells in the $\mathrm{J}$-direction with a cell-spacing of $200.0 \mathrm{~m}$ in both directions. The topography and bathymetry contours are shown in Figure 18 . The model input conditions are those of a synthetic hurricane with wind fields supplied from a planetary boundary layer model (MORPHOS PBL), spectral boundary conditions supplied from a larger scale WAM simulation, and surge fields supplied from ADCIRC. Spatially averaged values of the input characteristics on the Texas grid are shown in Figure 19 through Figure 22. The tested model control conditions are shown in Table 21. The analyses with the Texas grid is meant to act as a supplement for the Louisiana grid, and mainly addresses wall time and solution sensitivities to the model control parameters. The base case for this grid is the serial case, $\mathrm{EF}=(0.1$, 99.8) simulation. 


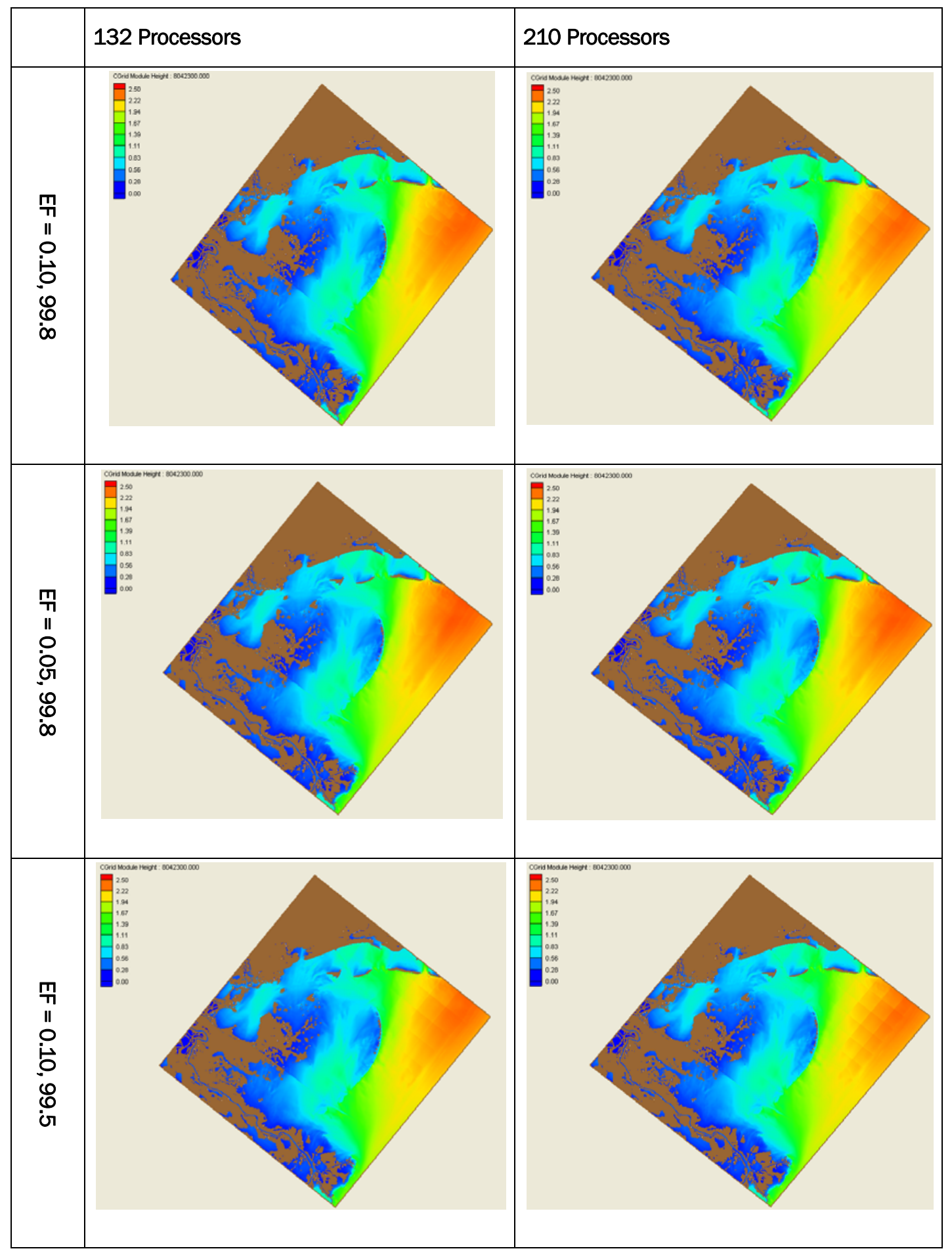

Figure 15. Contours of wave height for snap 97 on the Louisiana grid for different EF values for 132 processors and 210 processors. 


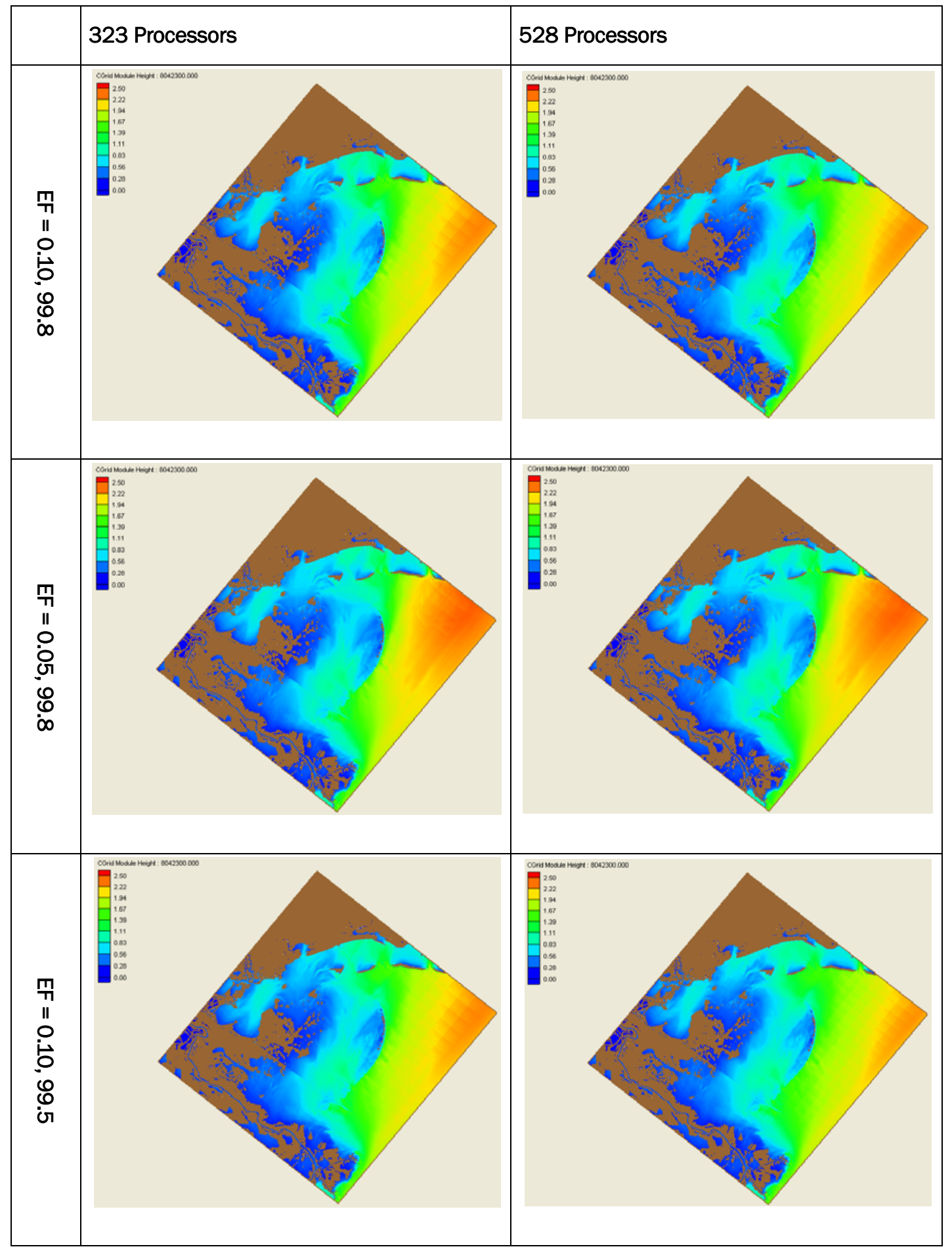

Figure 16. Contours of wave height for snap 97 on the Louisiana grid for different EF values for 323 processors and 528 processors. 


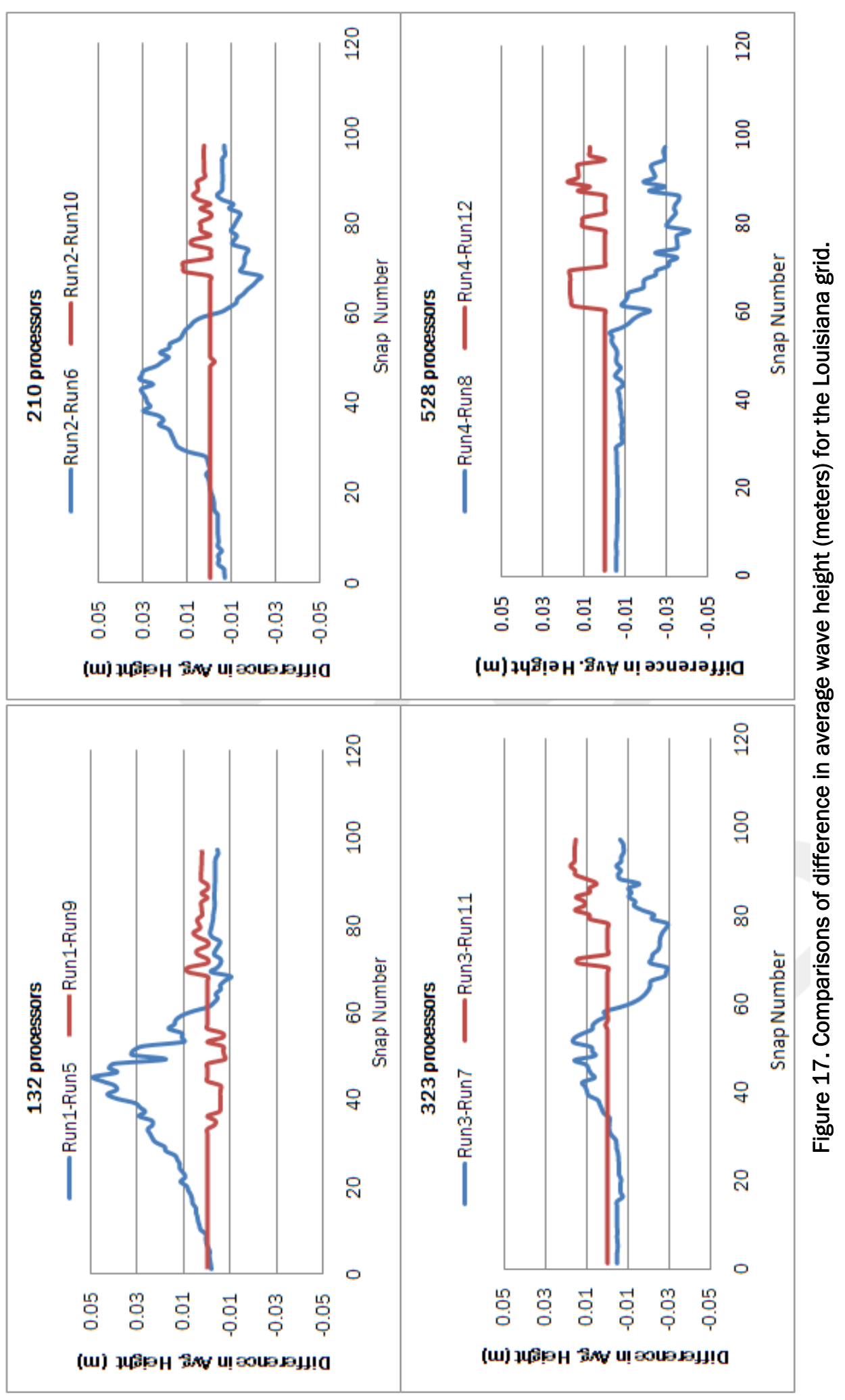




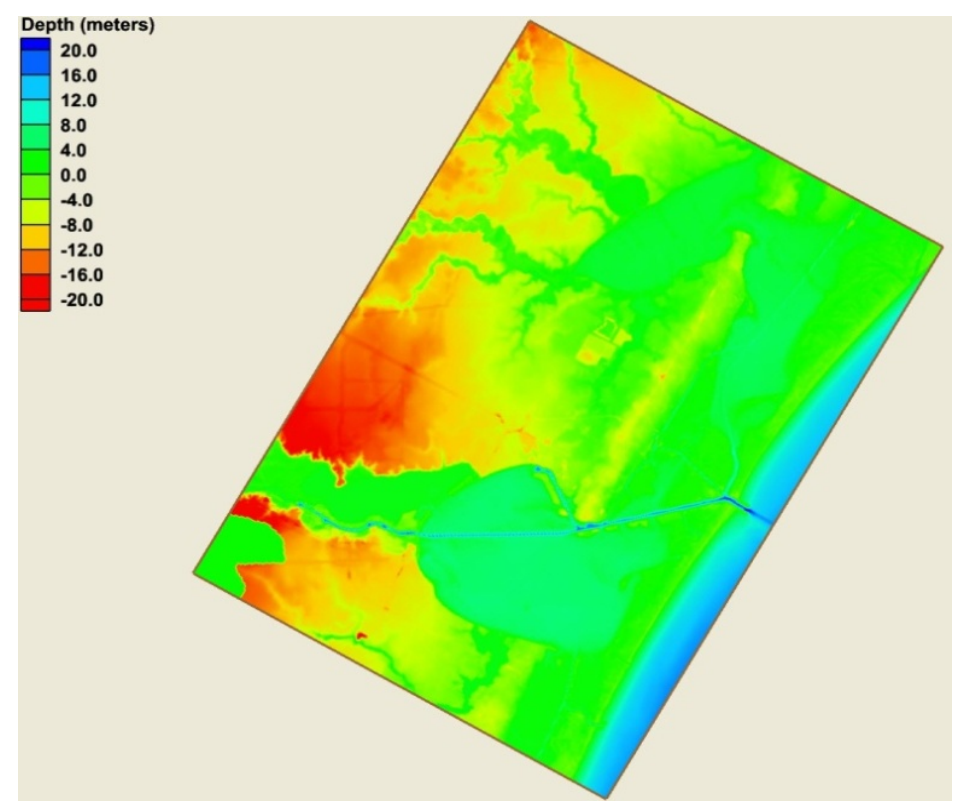

Figure 18. Bathymetry/topography contours for the Texas grid.

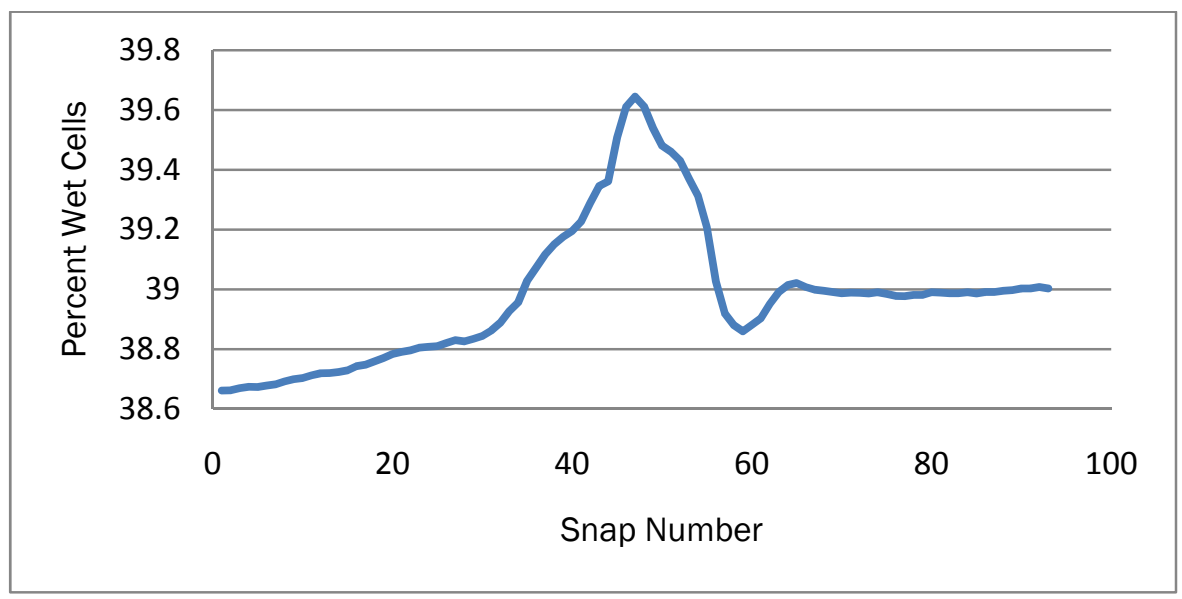

Figure 19. Percent of wet (active) cells for each snap for the Texas case.

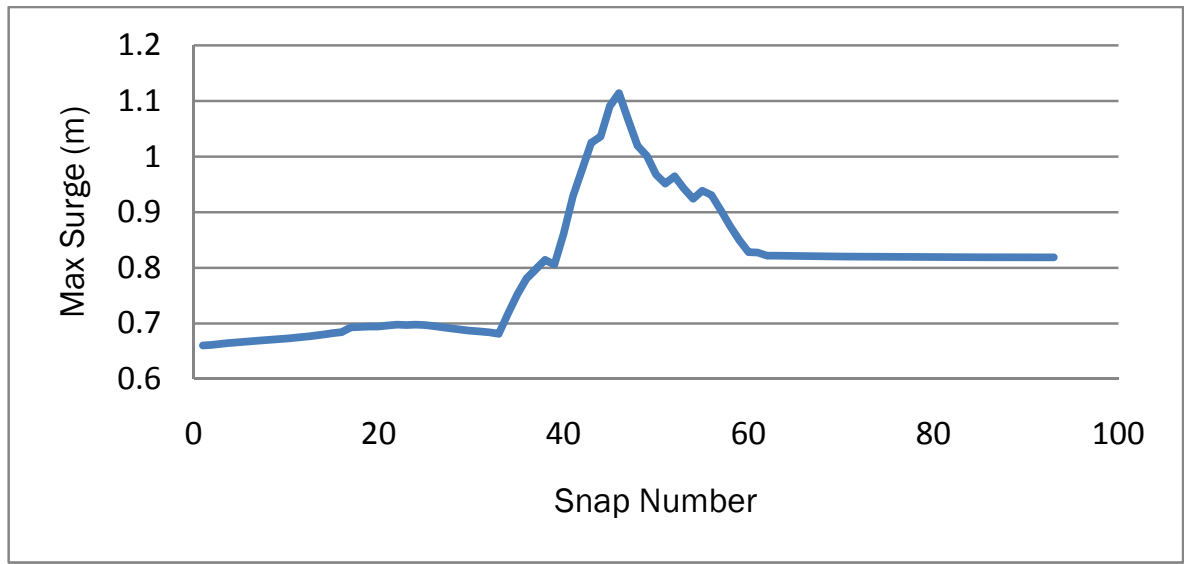

Figure 20. Maximum surge levels (meters) over the grid for each snap in the Texas case. 


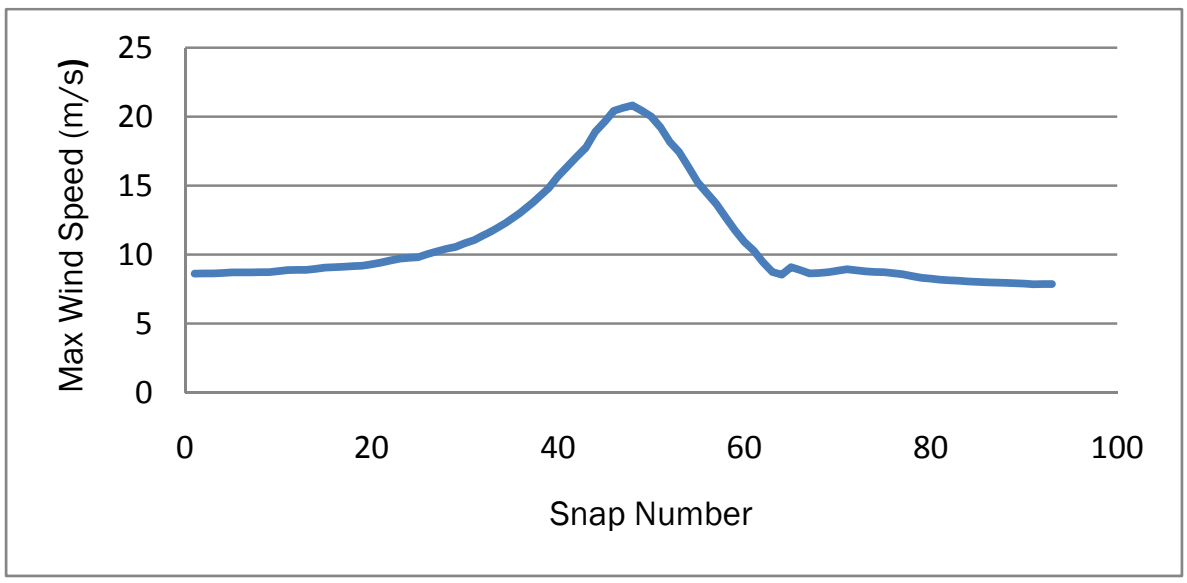

Figure 21. Maximum wind speed (meters/second) over the grid for each snap in the Texas case.

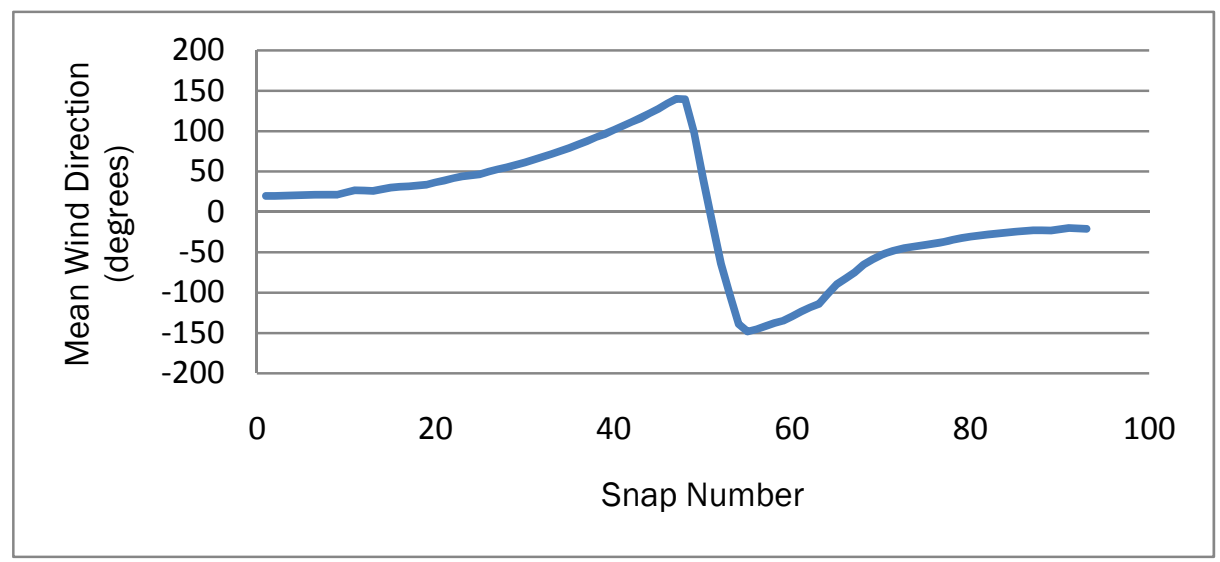

Figure 22. Mean wind direction (degrees) over the grid for each snap in the Texas case.

All the Texas grid simulations, both serial and parallel, were performed using the ERDC DSRC high performance computing resources.

Specifically the SGI Altix ICE machine known as Diamond was used. Diamond contains 1,920 compute nodes (15,360 compute cores). Each compute node contains two 2.8-GHz Intel Xeon 64-bit quad-core Nehalem processors and 24 GBytes of dedicated memory. The nodes are connected to each other in a HyperCube topology DDR 4X InfiniBand network. The STWAVE source code was compiled using the version 11.1.074 Intel Fortran compiler and the MPICH-2 implementation of MPI. 
Table 21. Parameters used for sensitivity tests on the Texas grid.

\begin{tabular}{|c|c|c|c|}
\hline Run Number & Grid Partitioning $\left(N_{I} \times N_{J}\right)$ & No. of Processors & $\mathrm{EF}$ \\
\hline$B$ & $1 \times 1$ & 1 & $0.1,99.8$ \\
\hline 1 & $2 \times 3$ & 6 & $0.1,99.8$ \\
\hline 2 & $4 \times 6$ & 24 & $0.1,99.8$ \\
\hline 3 & $6 \times 9$ & 54 & $0.1,99.8$ \\
\hline 4 & $8 \times 11$ & 88 & $0.1,99.8$ \\
\hline 5 & $12 \times 17$ & 204 & $0.1,99.8$ \\
\hline S2 & $1 \times 1$ & 1 & $0.05,99.8$ \\
\hline 6 & $2 \times 3$ & 6 & $0.05,99.8$ \\
\hline 7 & $4 \times 6$ & 24 & $0.05,99.8$ \\
\hline 8 & $6 \times 9$ & 54 & $0.05,99.8$ \\
\hline 9 & $8 \times 11$ & 88 & $0.05,99.8$ \\
\hline 10 & $12 \times 17$ & 204 & $0.05,99.8$ \\
\hline S3 & $1 \times 1$ & 1 & $0.1,99.5$ \\
\hline 11 & $2 \times 3$ & 6 & $0.1,99.5$ \\
\hline 12 & $4 \times 6$ & 24 & $0.1,99.5$ \\
\hline 13 & $6 \times 9$ & 54 & $0.1,99.5$ \\
\hline 14 & $8 \times 11$ & 88 & $0.1,99.5$ \\
\hline 15 & $12 \times 17$ & 204 & $0.1,99.5$ \\
\hline S4 & $1 \times 1$ & 1 & $0.05,99.5$ \\
\hline 16 & $2 \times 3$ & 6 & $0.05,99.5$ \\
\hline 17 & $4 \times 6$ & 24 & $0.05,99.5$ \\
\hline 18 & $6 \times 9$ & 54 & $0.05,99.5$ \\
\hline 19 & $8 \times 11$ & 88 & $0.05,99.5$ \\
\hline 20 & $12 \times 17$ & 204 & $0.05,99.5$ \\
\hline
\end{tabular}

As in the Louisiana case, the same pattern for total wall clock time versus number of processors is observed for the smaller Texas grid, shown in Figure 23. The total time decreases as the number of processors increases, and stricter final convergence criteria require longer running times using the same number of processors. The greatest increase in run time occurs when the maximum relative difference is reduced from 0.10 to 0.05 for a cell percentage of 99.8. The difference in run time becomes less substantial when more processors are used. 


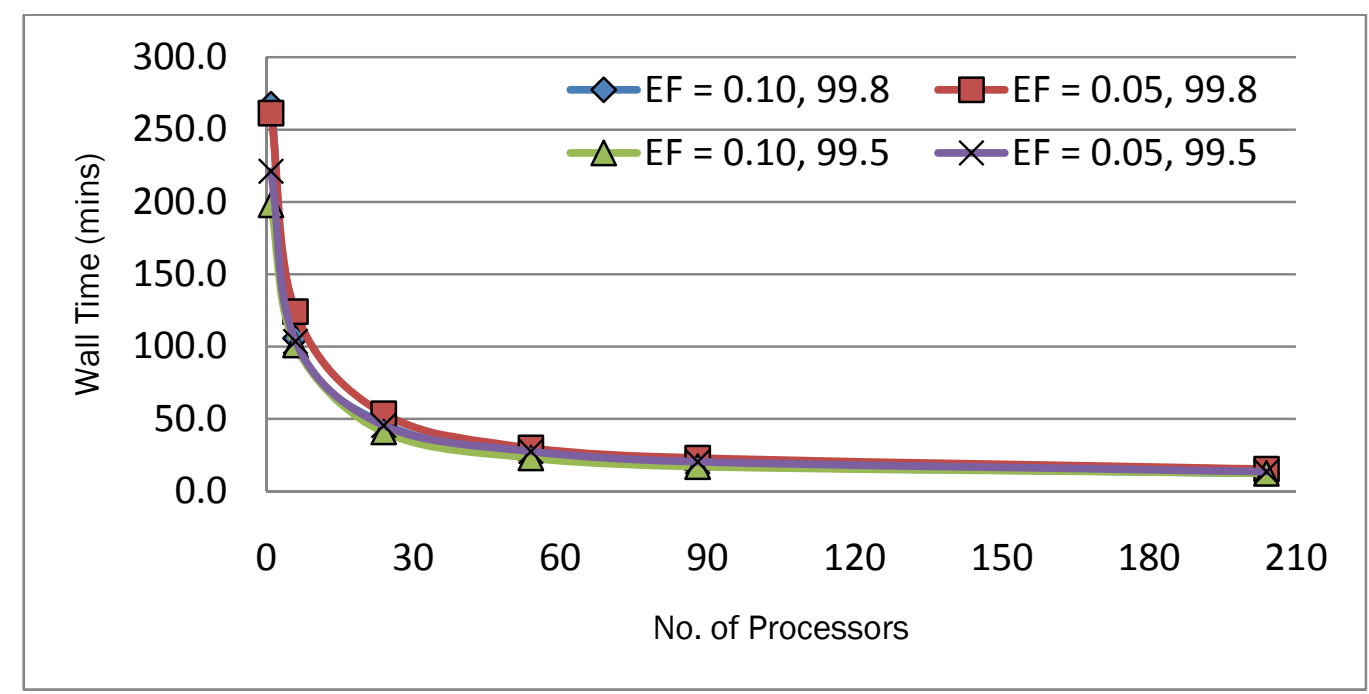

Figure 23. Total wall clock time (minutes) for different run parameters for the Texas grid.

The difference between wave height fields due to convergence criteria and domain decomposition is further addressed by this analysis. The maximum wave height occurred at snap 36 and this snap is considered for investigating the sensitivity due to changes in grid partitioning and convergence criteria. In Figure 24 a contour plot of the wave height field for snap 36 is shown for the base run parameters, $\mathrm{EF}=(0.1,99.8)$. The plots for the other serial cases are nearly indistinguishable from the base and are not shown. In Figure 25 through Figure 27 spatial plots showing the difference in wave height solutions between the serial and parallel simulations of the same convergence criteria are presented. In general, differences between the serial and parallel wave fields increase as the number of processors increase, and there tends to be a persisting underestimation of wave heights within the inland water bodies across all processors. This is clearly seen in the darker blue color of Figure 26 as compared to Figure 25. Similar to the Louisiana grid, partition blocks become noticeable at the greatest processor number (204 processors) for the lower $\mathbf{R}$-value of o.1. These blocks indicate the EF criteria were not sufficient to allow the matching of solutions between grid partitions. 


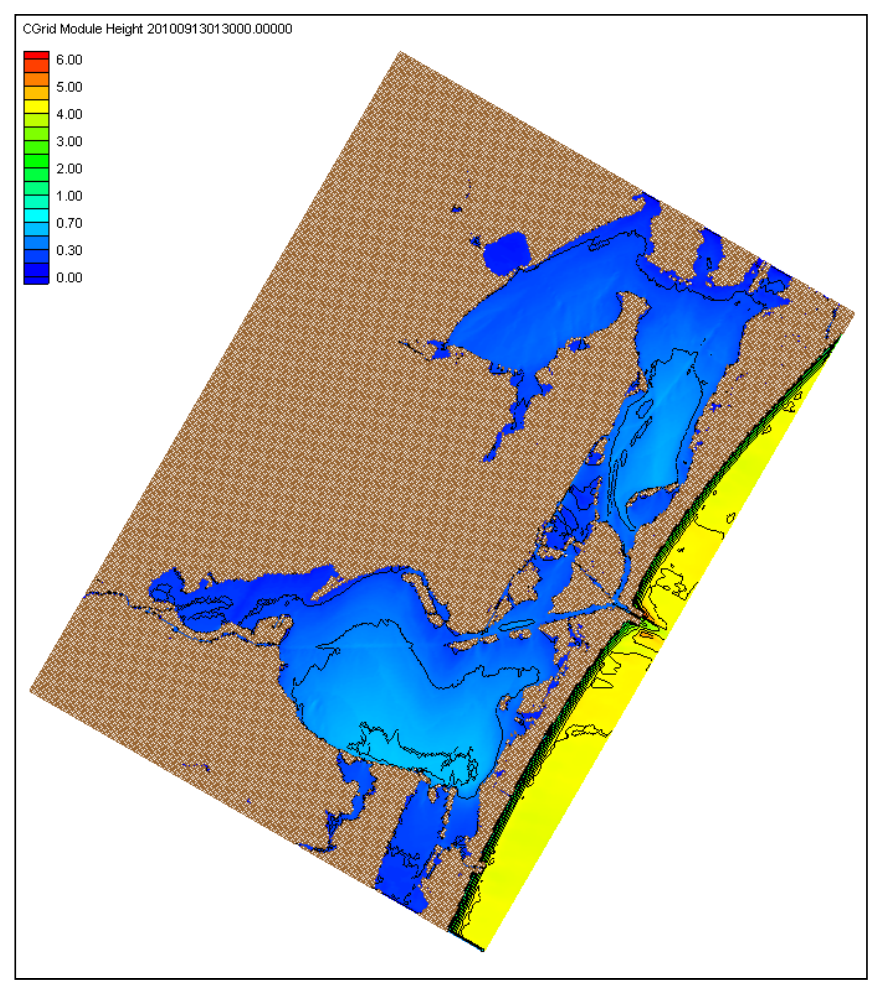

Figure 24. Wave height (meters) for snap 36 of the Texas case, using the serial base case of $\mathrm{EF}=(0.1,99.8)$.

Next, in order to further evaluate convergence criteria, only the serial simulations are considered to eliminate the discrepancies resulting from number of processors. It is observed that tightening the maximum relative difference $\mathbf{R}$ to 0.05 resulted in a slightly higher predicted wave height for a cell percentage of 99.8 and 99.5. However, no differences between the solutions were seen by decreasing the cell percentage from 99.8 to 99.5 , a change of only 275 cells, while maintaining the same $\mathbf{R}$-value. Figure 28 shows this behavior for snap 36. This behavior supports the assertion that the STWAVE solution is more influenced by the maximum relative difference between cells than the percentage of cells satisfying the stopping criteria, at least for the values considered herein. The maximum difference between any solutions was roughly $5 \mathrm{~cm}$, which represents a larger percentage of the average wave height $(0.12-0.36 \mathrm{~m})$ than that seen in the Louisiana grid. A time series plot showing the average wave height over the entire grid for each snap is shown in Figure 29. 


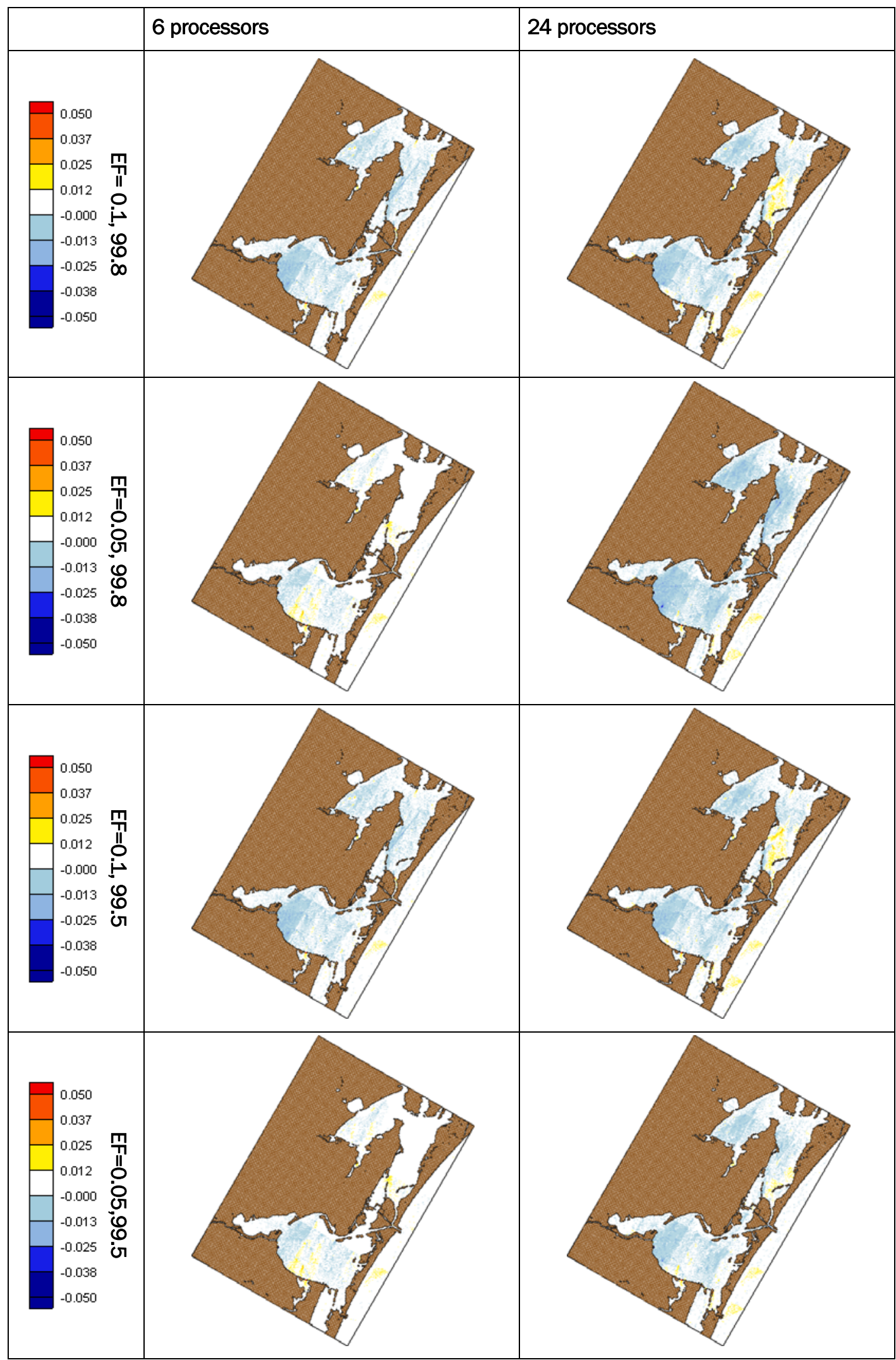

Figure 25. Difference in wave height (meters) for 6 and 24 processors of the same EF criteria. 


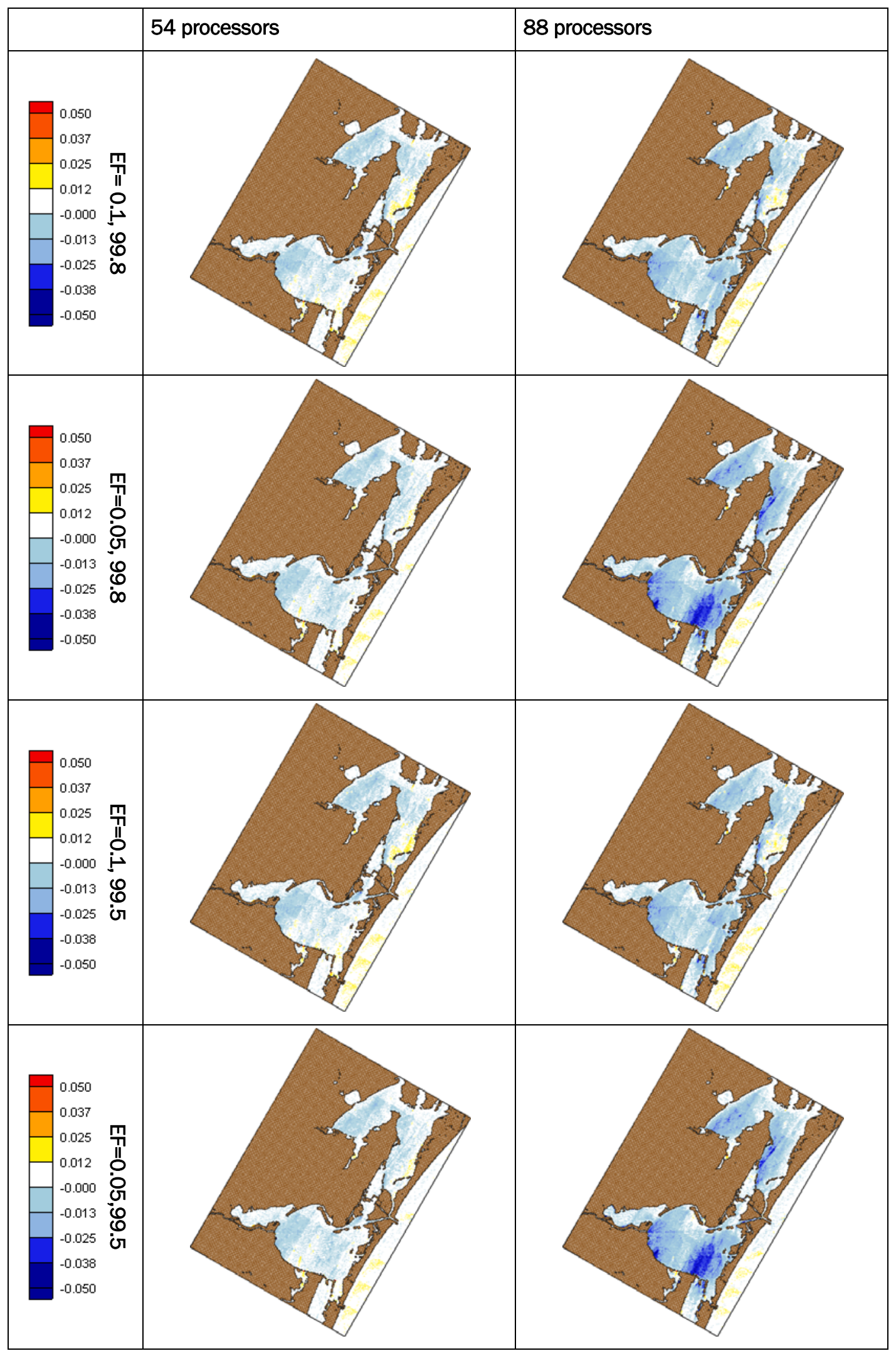

Figure 26. Difference in wave height (meters) for 54 and 88 processors of the same EF criteria. 


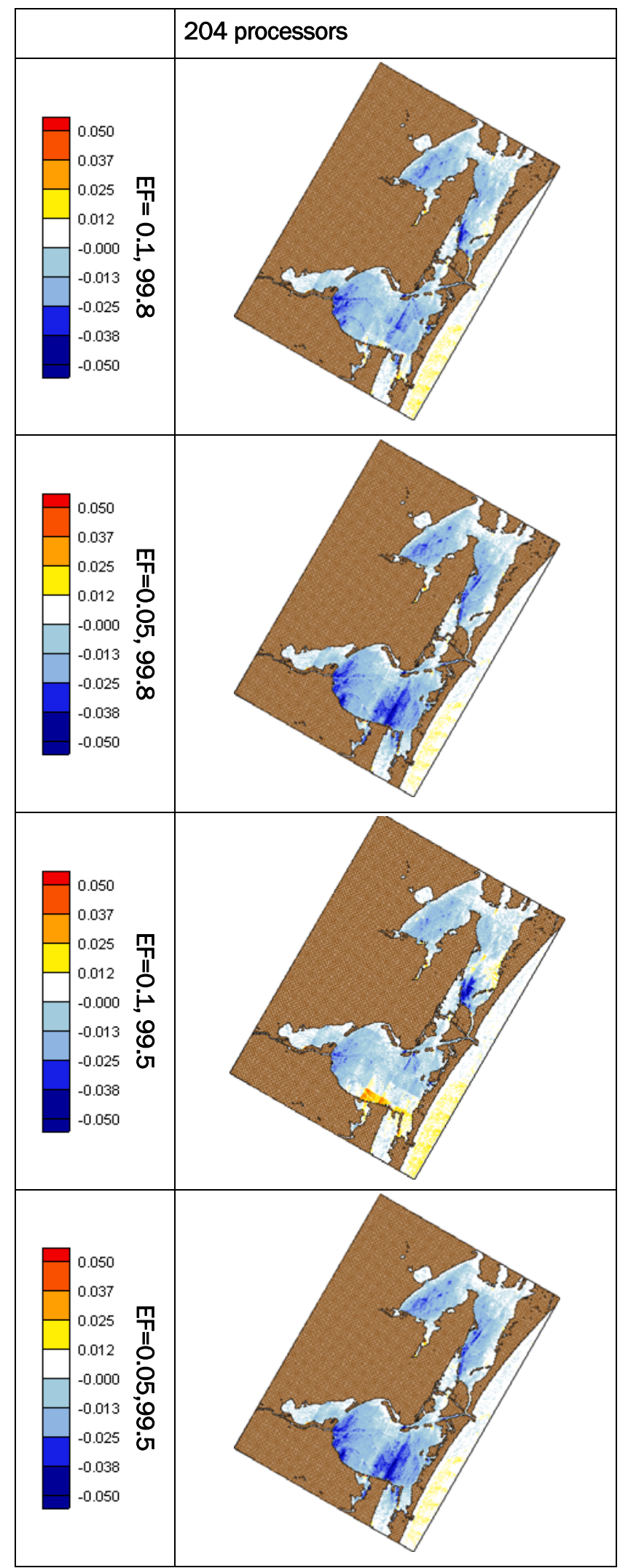

Figure 27. Difference in wave height (meters) for 204 processors of the same EF criteria. 


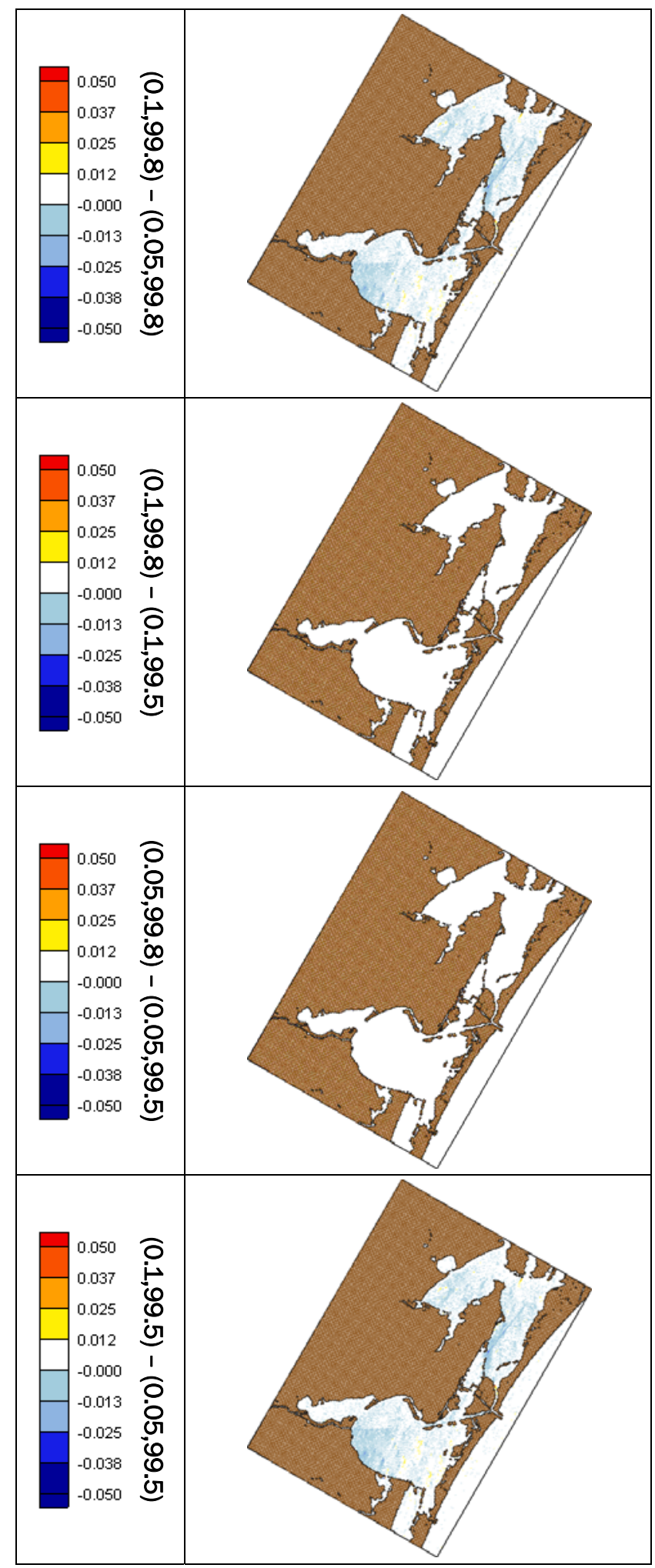

Figure 28. Difference in wave height (meters) versus EF value for serial runs. 


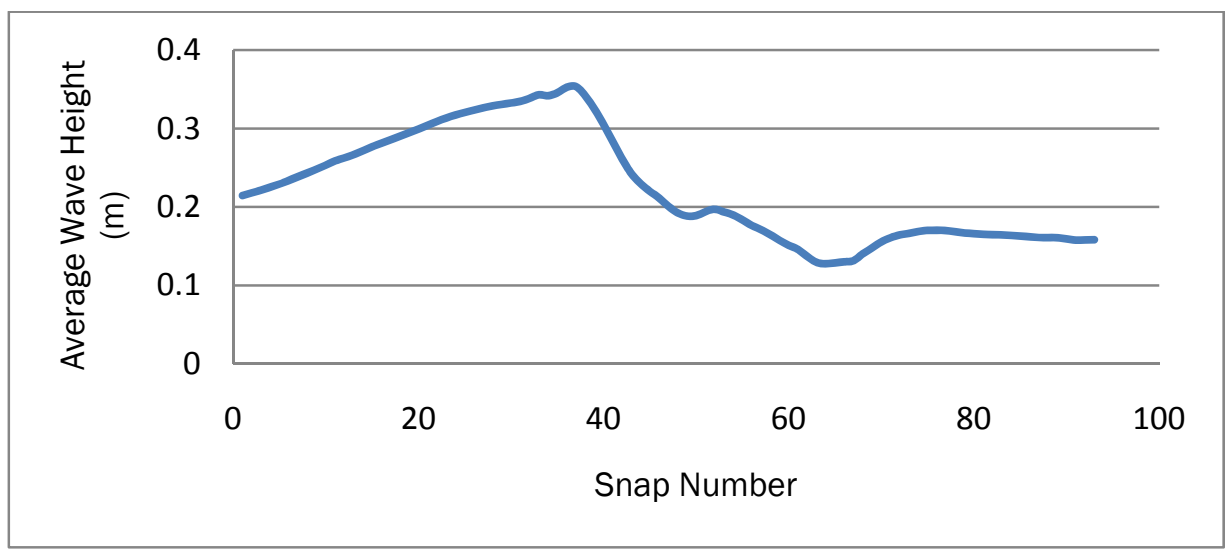

Figure 29. Average wave height (meters) over the grid for each snap in the Texas case.

\section{Recommendations}

Simulating nearshore hurricane waves using STWAVE showed slightly different solutions depending on the number of processors and the convergence criteria when calculating the final iterations. As a result, sufficient convergence criteria must be defined to obtain accurate solutions when a large STWAVE domain is partitioned. The following is a list of the findings of the sensitivity analyses as well as recommendations for defining final convergent criteria:

- Decomposing a STWAVE domain, thereby increasing the number of required processors, results in substantially decreased wall clock run time for STWAVE and allows for larger problems to be solved by distributing memory requirements.

- Stricter convergence criteria increase the running time for STWAVE when considering the same number of processors. However, the difference in wall time tends to decrease as the number of processors increase.

- Wall time appears to be more sensitive to the maximum relative difference parameter (FINAL_ITERS_STOP_VALUE) than the percentage of cells required to obtain the stop value (FINAL_ITERS_PERCENT_VALUE).

- More iteration is required when the maximum relative difference is tightened than the cell percentage. Hence, increasing the relative difference is likely more costly in terms of time than increasing the percentage of cells required to obtain the stop value.

- If the relative difference criterion is insufficient, blocks appear in the wave field and indicate the final solution was not adequately passed between cells. No apparent differences in overall solution quality were 
observed between selecting 99.5 or 99.8 as the cell percentage for parallel runs.

- Differences in the wave field solution occurred as a result of varying convergence criteria and number of processors. However, these differences appear to be on the order of centimeters and most likely are within an acceptable tolerance considering the magnitude of the generated waves.

- If an STWAVE domain is going to be decomposed close to the maximum allowed portioning (i.e., each partition approaches but does not go below 20 cells), results herein indicate an EF of $(0.05,99.8)$ provides the results most closely resembling those of a serial simulation. Running these EF criteria with more computer processors will allow an adequate and timely solution, since the wall times of the stricter criteria and many processors approaches those of the relaxed criteria at a lower number of processors.

- For a domain decomposition resulting in a smaller number of processors, an EF of $(0.05,99.5)$ is likely to suffice. The relative difference is kept the same to facilitate value matching along grid boundaries, while a slightly lower cell percentage was shown to reduce wall time and not significantly impact the solution. 


\section{STWAVE Spatial Data Sets}

STWAVE spatial data sets define a series of values associated with points in space, i.e., (I,J) grid cells or interpolated $(x, y)$ locations within the domain. There are two types of spatial data sets, global and local. Global data sets span the entire computational grid (each grid cell is defined a value) while local data sets consist of values connected with particular (I,J) grid cells or $(x, y)$ locations. Further explanation of these data sets is given here with examples of STWAVE global and local spatial data sets provided in Appendix B. SMS 11.0+ must have the following text on line 1: “\#STWAVE_SPATIAL-DATASET," without the quotes.

Spatial data sets begin with two namelists, datadims and dataset. Descriptions of these FORTRAN namelists are given in Table 22 and Table 23.

Table 22. STWAVE spatial data sets - datadims namelist.

\begin{tabular}{|c|c|c|}
\hline Variable Name & Description & Comments \\
\hline DATATYPE & $\begin{array}{l}=0-\text { global data sets } \\
=1-\text { local }(I, J) \text { grid cell data sets } \\
=2-\text { local station }(x, y) \text { data sets }\end{array}$ & $2-$ is not functional at this time \\
\hline NUMRECS & $\#=$ number of snap IDD's & $\begin{array}{l}=1 \text { for time-independent data } \\
\text { sets }\end{array}$ \\
\hline NUMFLDS & $\#=$ number of fields per snap IDD & \\
\hline $\mathrm{NI}$ & $\begin{array}{l}\#=\text { number of cells in the I-direction for global } \\
\text { data sets } \\
\#=\text { number of output points per snap IDD for } \\
\text { local data sets }\end{array}$ & \\
\hline NJ & $\begin{array}{l}\#=\text { number of cells in the J-direction for global } \\
\text { data sets } \\
\#=1 \text { for local data sets }\end{array}$ & \\
\hline DX & \# = grid spacing $(\mathrm{m})$ in the l-direction & Not provided for local data sets \\
\hline DY & $\#=$ grid spacing $(\mathrm{m})$ in the J-direction & Not provided for local data sets \\
\hline GRIDNAME & $=$ associated STWAVE grid name & Character data \\
\hline
\end{tabular}


Table 23. STWAVE spatial data sets - dataset namelist.

\begin{tabular}{|l|l|l|}
\hline Variable Name & Description & Comments \\
\hline FLDNAME(NUMFLDS) & = name of each field & Character data \\
\hline FLDUNITS(NUMFLDS) & = units for each field & Character data \\
\hline RECINC & $\#$ = increment between snap IDD's & $\begin{array}{l}\text { RECINC = 1 for time-independent } \\
\text { or non-regularly spaced data sets }\end{array}$ \\
\hline RECUNITS & = units corresponding to I_TIME_INC & $\begin{array}{l}\text { Character data } \\
\text { Enter “ “ for integer, alpha } \\
\text { numeric, or snap IDD's spanning } \\
\text { multiple units }\end{array}$ \\
\hline REFTIME & = reference starting time & $\begin{array}{l}\text { Character data } \\
\text { Set as IDDS(1) }\end{array}$ \\
\hline
\end{tabular}

\section{Global spatial data sets}

Global spatial data sets cover the entire scope of the domain by assigning each grid cell a value. Global spatial data sets are either time-dependent (cell values are uniquely assigned for every snap IDD) or timeindependent (every snap uses one set of cell values, provided only once). Time-dependent spatial data sets include spatially varying water level corrections (SURGE), spatially varying winds (WIND), wave fields (WAVE), peak wave periods (TP), breaking indices (BREAK), and radiation stresses (RADS). Bathymetry (DEP) and bottom friction (FRIC) comprise the time-independent global spatial data sets. Current fields (CURR) are time-dependent data sets for ICUR $=1$ and time-independent for ICUR $=2$. For global data sets, the file header appears as follows:

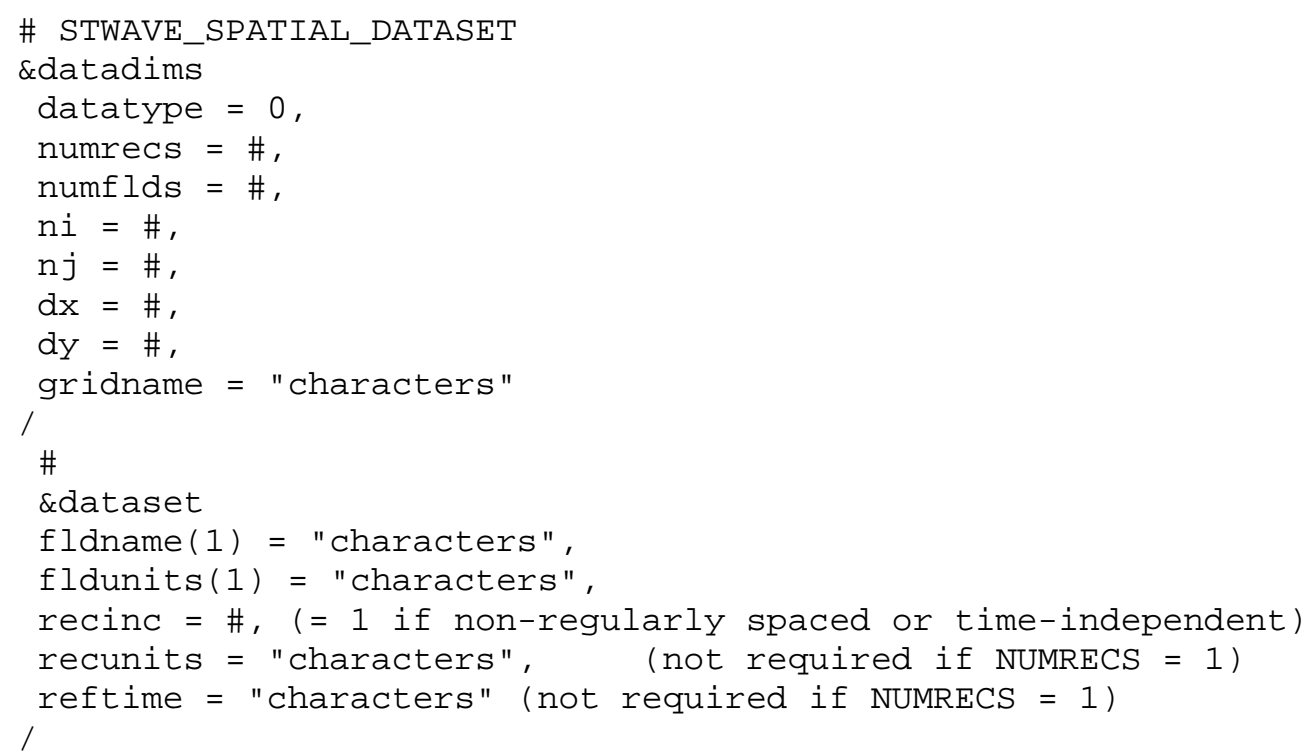


The record data or grid cell values follow the namelists and are listed as the following for a global data set with three fields:

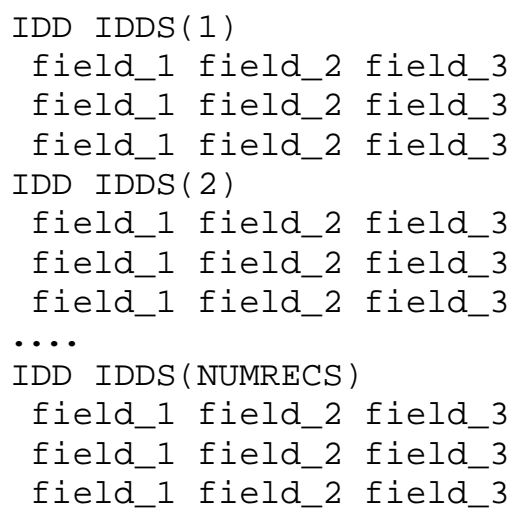

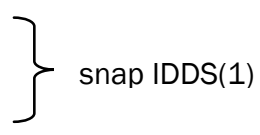
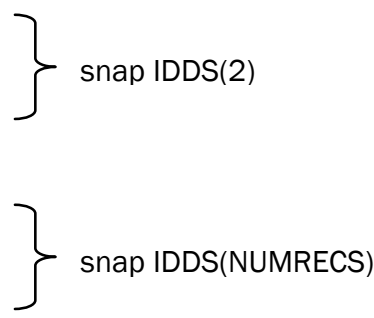

If the record is time-independent, then the number of records is equal to one, NUMRECS $=1$ and only one snap IDDS is listed.

To read these records, the file begins with the value at $(1, \mathrm{NJ})$ and reads in the cross-shore direction ( $\mathrm{I}=1$ to NI). The read is repeated for $\mathrm{J}=\mathrm{NJ}-1$ following the cross-shore direction ( $\mathrm{I}=1$ to NI), and progresses to $\mathrm{J}=1$ as seen in the following FORTRAN algorithm:

do $\mathrm{j}=\mathrm{NJ}, 1,-1$

$\operatorname{read}\left(10,{ }^{*}\right)(\operatorname{data}(i, j), i=1, N I)$

enddo

\section{Local spatial data sets}

Local spatial data sets contain values that are connected to particular selected locations, either (I,J) grid cells or $(x, y)$ coordinates. Only the output files SELH and STATION are available for the local spatial data sets. The local spatial data sets use the same two FORTRAN namelist as the global spatial data sets, with the distinguishing factor being the value of datatype $=\{1$ or 2$\}$.

The main header of the file appears as follows for local spatial data sets:

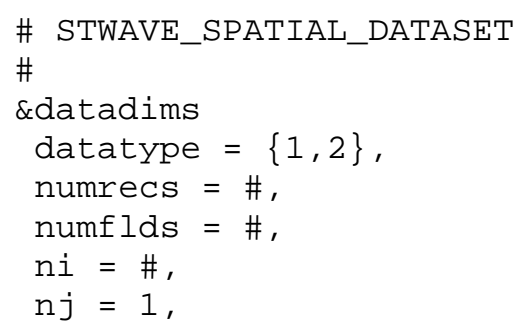




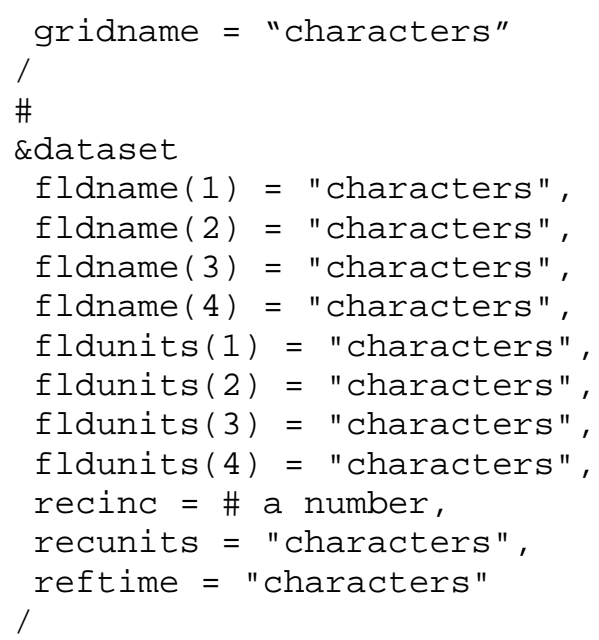

The data in a local spatial data sets are arranged slightly different from global data sets. For local spatial data sets, the snap IDD identifier does not separate the records but instead serves as the first field value, as seen in the next paragraph. The number of times a snap IDD appears depends on the number of selected output points (NI). This arrangement makes it easy to load the data records into a spreadsheet and sort the data on any field with the snap IDDS still attached.
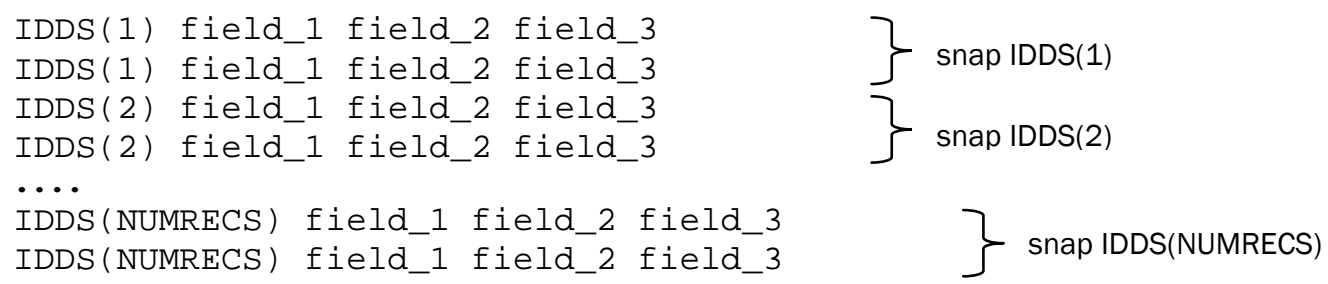


\section{STWAVE Spectral Data Sets}

Incident 2-D wave spectra are specified in energy density as a function of frequency and direction (units of $\mathrm{m}^{2} / \mathrm{Hz} /$ radians). The input spectra can be specified at single or multiple points along a boundary. Generally, it is good practice to establish the offshore boundary of the bathymetry grid along a constant depth contour, particularly when a single input spectrum is applied along the entire offshore boundary. Spectral data sets have one namelist, datadims, which is described in further detail in Table 24. The SPEC, NEST, and OBSE spectral data sets are described in Table 24 with examples provided in Appendix C. SMS 11.0+ must have the following text on line 1: “\#STWAVE_SPETRAL_DATASET,” without the quotes.

Table 24. STWAVE spectral data sets - Datadims namelist.

\begin{tabular}{|c|c|c|}
\hline Variable Name & Description & Comments \\
\hline DATATYPE & $\begin{array}{l}=0-\text { local station }(x, y) \text { locations } \\
=1-\text { grid cell }(I, J) \text { locations }\end{array}$ & Provided only for output files \\
\hline NUMRECS & $\#=$ number of snap IDD's & \\
\hline NUMFREQ & $\#=$ number of frequency bins & $\begin{array}{l}\text { Determines how finely the calculated } \\
\text { spectra are resolved } \\
\text { Large number increases computation time } \\
\text { and a small number reduces model } \\
\text { resolution } \\
20-30 \text { bins typically used }\end{array}$ \\
\hline NUMANGLE & $\#=$ number of angle bands & $\begin{array}{l}\text { Defines angular resolution } \\
=35 \text { required for half-plane simulations ( } 5 \text { - } \\
\text { deg resolution in direction) and } 72 \text { is typical } \\
\text { for full-plane simulations }\end{array}$ \\
\hline NUMPOINTS & $\#=$ number of spatial locations providing data & \\
\hline AZIMUTH & $\#=$ the azimuth (rotation) of the grid in degrees & Real number \\
\hline COORD_SYS & $\begin{array}{l}=\text { name of the coordinate system the inputs are } \\
\text { listed in }\end{array}$ & $\begin{array}{l}\text { 'STATEPLANE' - State Plane } \\
\text { 'LOCAL' - local coordinates } \\
\text { 'UTM' - Universal Transverse Mercator }\end{array}$ \\
\hline SPZONE & $\begin{array}{l}\text { \# = state plane zone code FIPS number } \\
\#=\text { UTM zone }\end{array}$ & $\begin{array}{l}\text { Only needed for State Plane and UTM } \\
\text { coordinate system }\end{array}$ \\
\hline RECUNITS & $=$ units corresponding to I_TIME_INC & $\begin{array}{l}\text { Character data ( } 4 \text { characters max) } \\
\text { Set as I_TIME_INC_UNITS for output files } \\
\text { Not needed for SPEC input }\end{array}$ \\
\hline REFTIME & $=$ reference starting time & $\begin{array}{l}\text { Character data ( } 20 \text { characters max) } \\
\text { Set as IDDS(1) for output files } \\
\text { Not needed for SPEC input }\end{array}$ \\
\hline
\end{tabular}


The main header of the spectral files appear as follows:

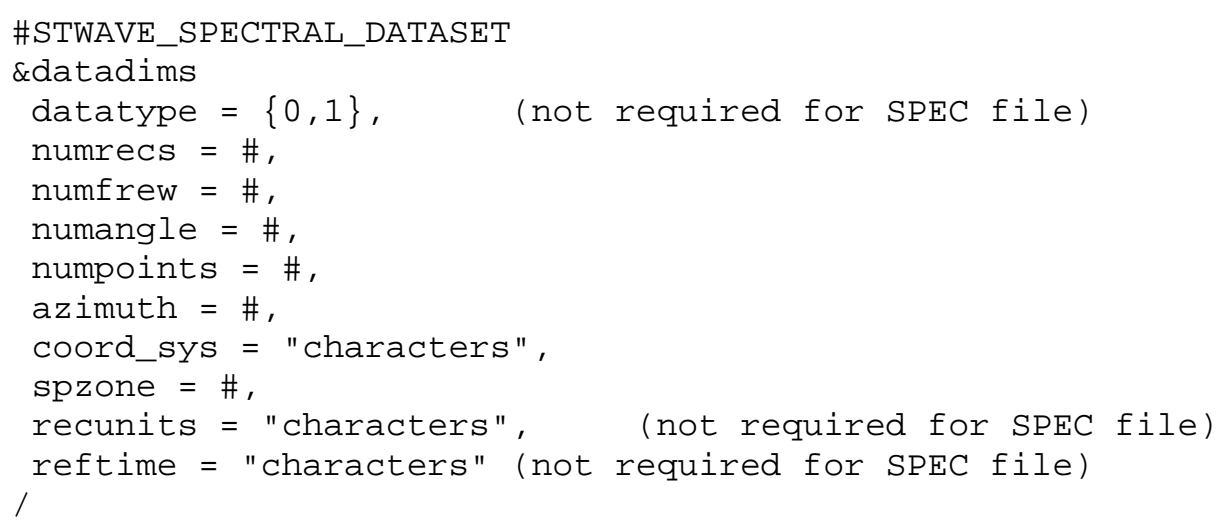

The next section of the SPEC file specifies the frequencies for model spectra (used for the input spectra, internal computations, and output spectra), starting from the lowest frequency. There must be NUMFREQ frequencies specified. These frequencies should span the frequency range where significant wave energy is contained in the spectrum; a good rule is that the minimum frequency is $0.5{ }^{*} f_{P}$ and the maximum frequency is $2^{*} f_{P}$ where $f_{P}$ is the spectral peak. Wave frequencies outside the frequency bin range will not be resolved by the model.

The Frequencies section is read in free format in the following manner:

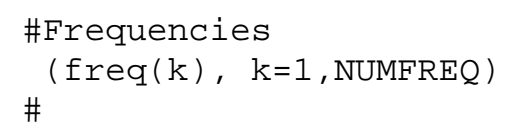

Spectral identifiers are grouped first by snap IDD and then by location.

\section{SPEC files}

Following the Frequencies section is a header line containing the snap IDD, wind information, peak frequency, water elevation adjustment, and the $(x, y)$ point coordinates. This header line is read in free format and is followed by the energy densities in $\mathrm{m}^{2} / \mathrm{Hz} /$ radians. The spectrum is read by reading the energy densities for all the wave directions associated with the lowest frequency, and then reading energy densities for all directions for the next lowest frequency, etc. For half-plane mode, the wave directions begin at $-85^{\circ}$ and increase in $5^{\circ}$ increments to $85^{\circ}$. For full-plane mode, the wave directions begin at $0^{\circ}$ and increase in (360 $/$ NUMANGLE) degree increments to $355^{\circ}$. The spectra are read in the following format: 
loop over IDDS(1-NUMRECS)

loop over point locations $n$ (1-NUMPOINTS)

IDDS, UMAG, UDIR, FM, DADD, $X \operatorname{COOR}(n), \operatorname{YCOOR}(n)$

$((\mathrm{e}(\mathrm{k}, \mathrm{l}, \mathrm{n}), \mathrm{l}=1$, NUMANGLE $), \mathrm{k}=1$, NUMFREQ $)$

end loop over point locations (1-NUMPOINTS)

end loop over IDDS(1_NUMRECS)

where:

UMAG $=$ wind speed in meters/second

UDIR = wind direction relative to STWAVE coordinate system in degrees

$\mathrm{FM}=$ peak spectral frequency in $\mathrm{Hz}$

$\mathrm{DADD}=$ elevation adjustment in meters relative to bathymetry datum

$(\mathrm{XCOOR}, \mathrm{YCOOR})=$ point location

In the half-plane version of the code boundary spectrum input are allowed only on a single side, the seaward side, of the domain. In the full-plane version, boundary spectrum inputs are allowed to be defined on any side, but are currently restricted to a single side. This restriction will be eliminated in future releases.

\section{OBSE and NEST file}

Wave spectra at selected grid cells, specified in the * sim file, are saved to spectral output files. Similar to the SPEC input file, this file begins with a header which is followed by the frequencies. Following the Frequencies section is a header line containing the snap IDD, wind information, water level adjustment, and selected output (I,J) grid location. The energy density values are in $\mathrm{m}^{2} / \mathrm{Hz} /$ radians. The spectra are written starting with the lowest frequency and writing energy density for all wave directions, followed by the energy density for all wave directions for the next lowest frequency, etc. The spectra are written in an order based on the I-cell index, starting from smallest index and proceeding to the largest index. The spectra are written in the following format:

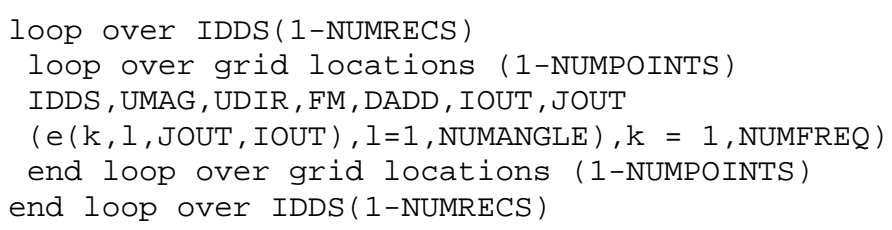

where IOUT $=$ I-grid location and JOUT $=\mathrm{J}$-grid location . 


\section{References}

Battjes, J.A. 1982. A case study of wave height variations due to currents in a tidal entrance. Coast. Engrg. 6: 47-57.

Battjes, J.A. and J.P.F.M. Janssen. 1978. Energy loss and set-up due to breaking of random waves. Proc. 16th Coast. Engrg. Conf. ASCE. 569-587.

Hasselmann, K., T.P. Barnett, E. Bouws, H. Carlson, D.E. Cartwright, K. Enke, J.A. Ewing, H. Gienapp, D.E. Hasselmann, P. Kruseman, A. Meerburg, P. Muller, D.J. Olbers, K. Richter, W. Sell, and H. Walden. 1973. Measurements of wind-wave growth and swell decay during the Joint North Sea Wave Project (JONSWAP). Deut. Hydrogr. Z., Suppl. A, 8(12): 1-95.

Holthuijsen, L.H. 2007. Waves in ocean and coastal waters. Cambridge: Cambridge University Press. 387 pp.

Jonsson, I.G. 1990. Wave-current interactions. The sea. Chapter 3, Vol. 9, Part A, B. LeMehaute and D.M. Hanes, ed., New York: John Wiley \& Sons, Inc.

Komen, G., L. Cavaleri, M. Donelan, K. Hasselmann, S. Hasselmann, and P.A.E.M. Janssen, 1994: Dynamics and Modeling of Ocean Waves. Cambridge University Press, $560 \mathrm{pp}$.

Mei, C.C. 1989. The applied dynamics of ocean surface waves. Singapore: World Scientific Publishing.

Miche, M. 1951. Le pouvoir reflechissant des ouvrages maritimes exposes a l'action de la houle. Annals des Ponts et Chaussess. 121e Annee: 285-319 (translated by Lincoln and Chevron, University of California, Berkeley, Wave Research Laboratory, Series 3, Issue 363, June 1954).

Padilla-Hernandez, R. and J. Monbaliu. 2001. Energy balance of wind waves as a function of the bottom friction formulation. Coast. Engrg. 43: 131-148.

Resio, D.T. 1987. Shallow-water waves. I: Theory. J. Wtrway., Port, Coast., and Oc. Engrg. ASCE. 113(3): 264-281.

Resio, D.T. 1988. Shallow-water waves. II: Data comparisons. J. Wtrway., Port, Coast., and Oc. Engrg. ASCE. 114(1): 50-65.

Resio, D.T. and W. Perrie. 1989. Implications of an $f^{-4}$ equilibrium range for windgenerated waves. J. Phys. Oceanography. 19: 193-204.

Smith, J.M. 2001. Modeling nearshore transformation with STWAVE. ERDC/CHL CHETN I-64. Vicksburg, MS: U.S. Army Engineer Research and Development Center. http://chl.erdc.usace.army.mil/chetn.

Smith, J.M. 2007. Full-plane STWAVE with bottom friction: II. Model overview. CHETN-I-75. Vicksburg, MS: U.S. Army Engineer Research and Development Center. http://chl.erdc.usace.army.mil/chetn. 
Smith, J.M., D.T. Resio, and C.L. Vincent. 1997. Current-induced breaking at an idealized inlet. Proc. Coastal Dynamics '97. ASCE. 993-1002.

Smith, J.M., A.R. Sherlock, and D.T. Resio. 2001. STWAVE: Steady-state wave model user's manual for STWAVE, Version 3.o. ERDC/CHL SR-01-01, Vicksburg, MS: U.S. Army Engineer Research and Development Center.

Smith, J.M. and S.J. Smith. 2002. Grid nesting with STWAVE. ERDC/CHL CHETN I-66. Vicksburg, MS: U.S. Army Engineer Research and Development Center. http://chl.erdc.usace.army.mil/chetn. 


\section{Appendix A: Example STWAVE_SIM_FILE}

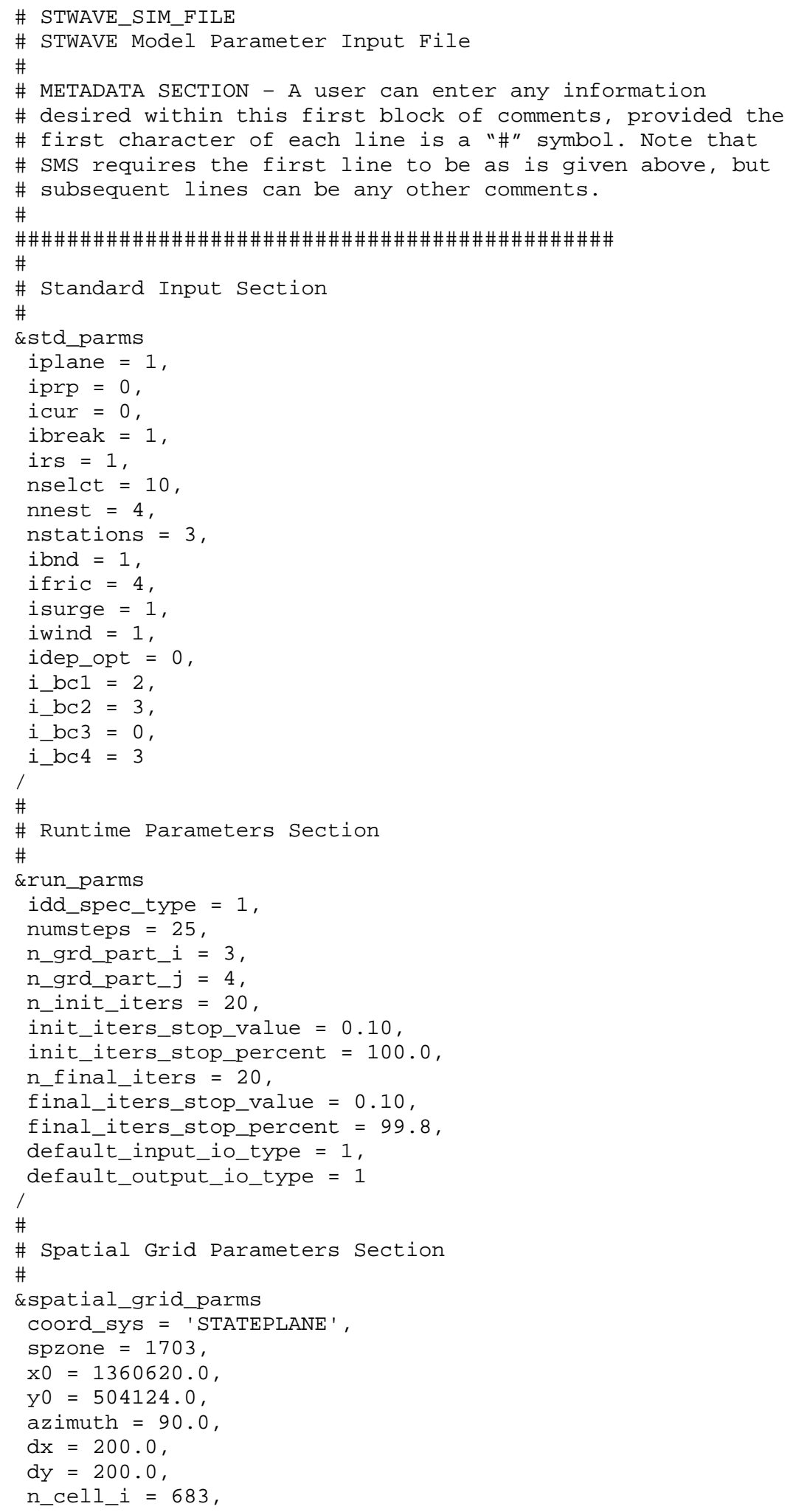




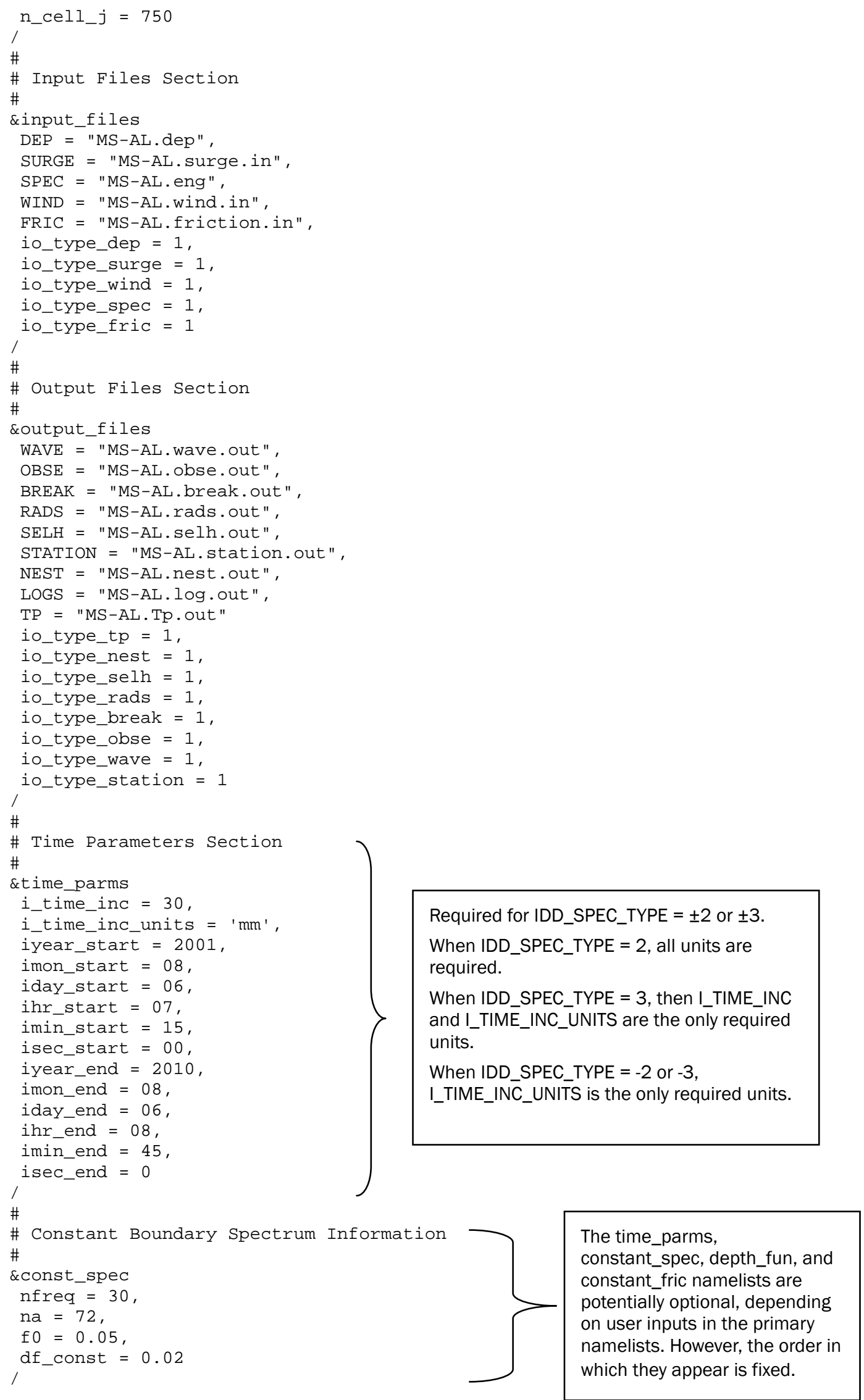


\#

\# Analytic Depth Profile

\#

\&depth_fun

dp_iside $=1$,

dp_d1 = 20.0,

dp_slope $=0.10$

/

\#

\# Constant Bottom Friction Value

The following bold "extra" namelists are

potentially optional, depending on user inputs in

the primary namelists. However, the order in

which they appear is fixed. Notice the "extra"

namelists start with an “@” instead of an “\&”.

\&const_fric

cf_const $=0.01$

l

\#

\# Snap IDDs

\#

@snap_idds

$\operatorname{idds}(1)=9120800$,

idds $(2)=9310125$,

$\operatorname{idds}(3)=9310205$,

$\ldots$.

idds (numsteps)

I

\#

\# Select Point Data

\#

@select_pts

iout $(1)=10$, jout $(1)=74$,

iout $(2)=125$, jout $(2)=201$,

...

iout (nselct), jout(nselct)

I

\#

\# Nest Point Data

\#

@nest_pts

inest $(1)=78$, jnest $(1)=176$,

inest $(2)=94$, jnest $(2)=67$,

....

inest (nnest), jnest(nnest)

/

\#

\# Station Location Data

\#

@station_locations

stat_xcoor $(1)=1361620.0$, stat_ycoor $(1)=502124.0$, stat_xcoor $(2)=1362820.0$, stat_ycoor $(2)=502324.0$,

$\ldots$

$$
\text { stat }
$$

\#

\# Spatially Constant Winds

\#

@const_wind

umag_const_in(1) $=2.9$, udir_const_in(1) $=0.0$,

umag_const_in $(2)=3.1$, udir_const_in(2) $=12.0$,

umag_const_in $(3)=3.2$, udir_const_in $(3)=15.6$,

....

/

umag_const_in(numsteps), udir_const_in(numsteps)

Must appear as two column pairs.

\# Spatially Constant Water Level Adjustment

\#

@const_surge

dadd_const_in $(1)=0.2$,

dadd_const_in $(2)=0.8$,

Must appear as a single entry per row (i.e. one column).

Must appear as two column pairs. 


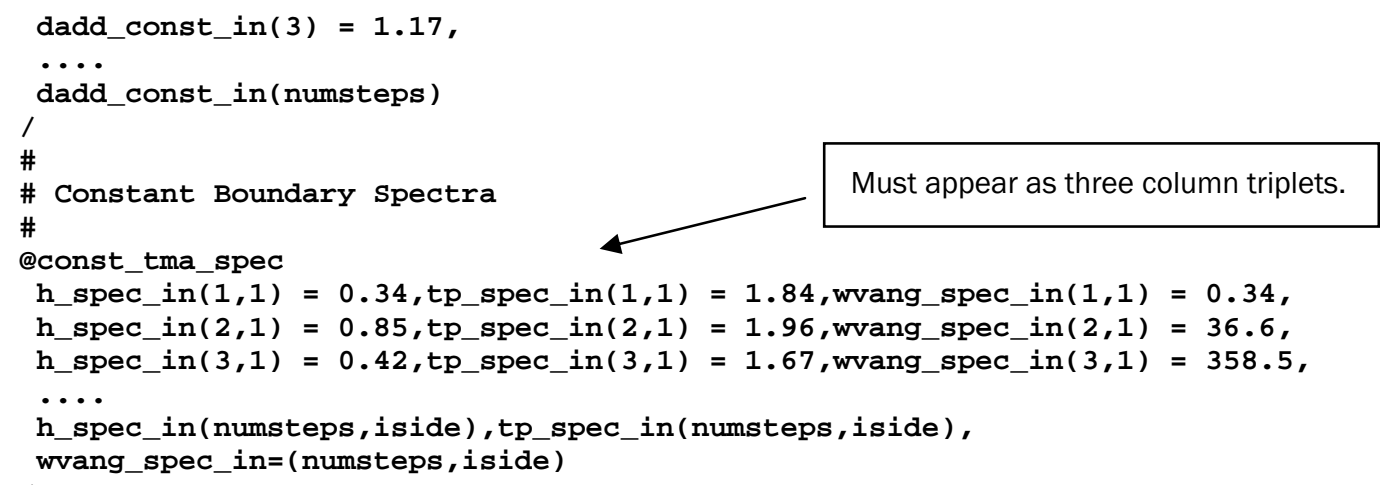




\section{Appendix B: Example STWAVE Spatial Files}

\section{Global Input: DEP File}

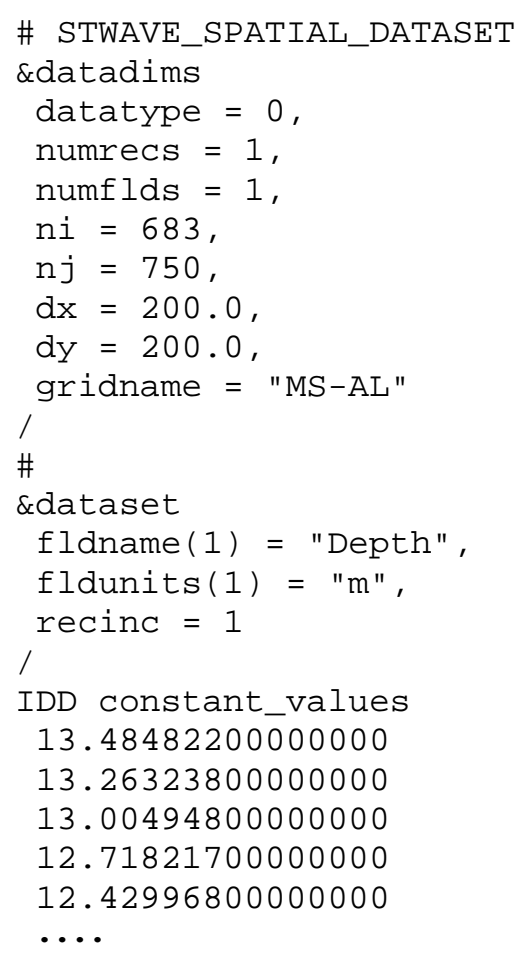




\section{Global Input: SURGE File}

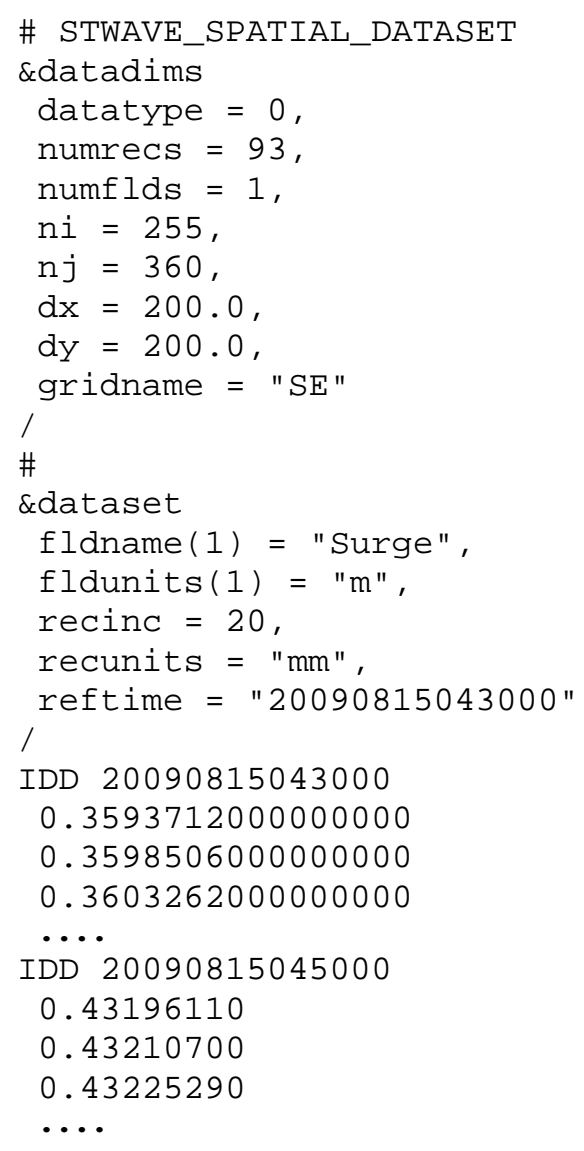




\section{Global Input: WIND File}

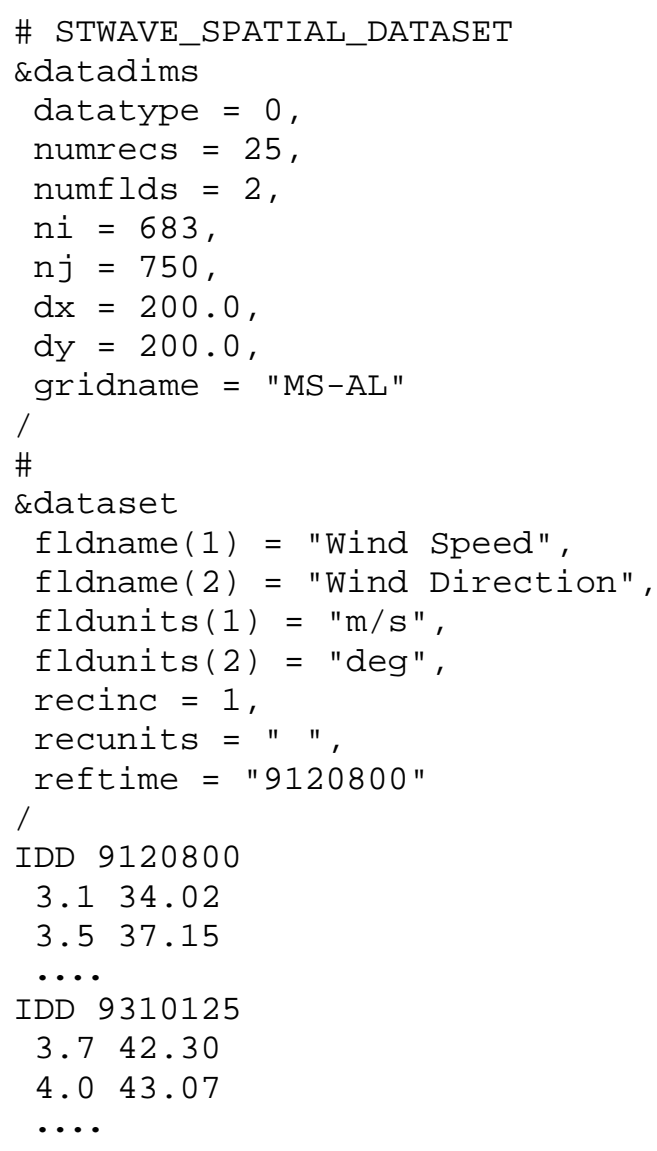




\section{Global Input: FRIC File}

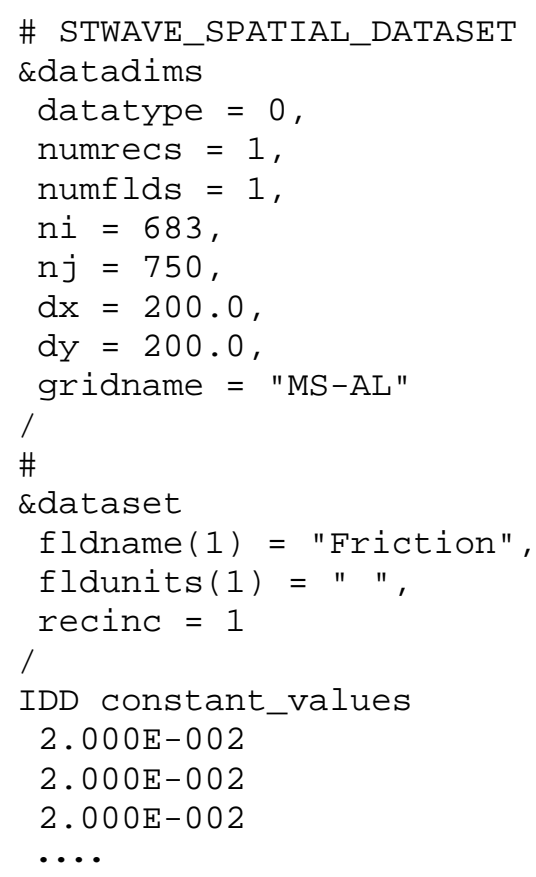




\section{Global Input: CURR File}

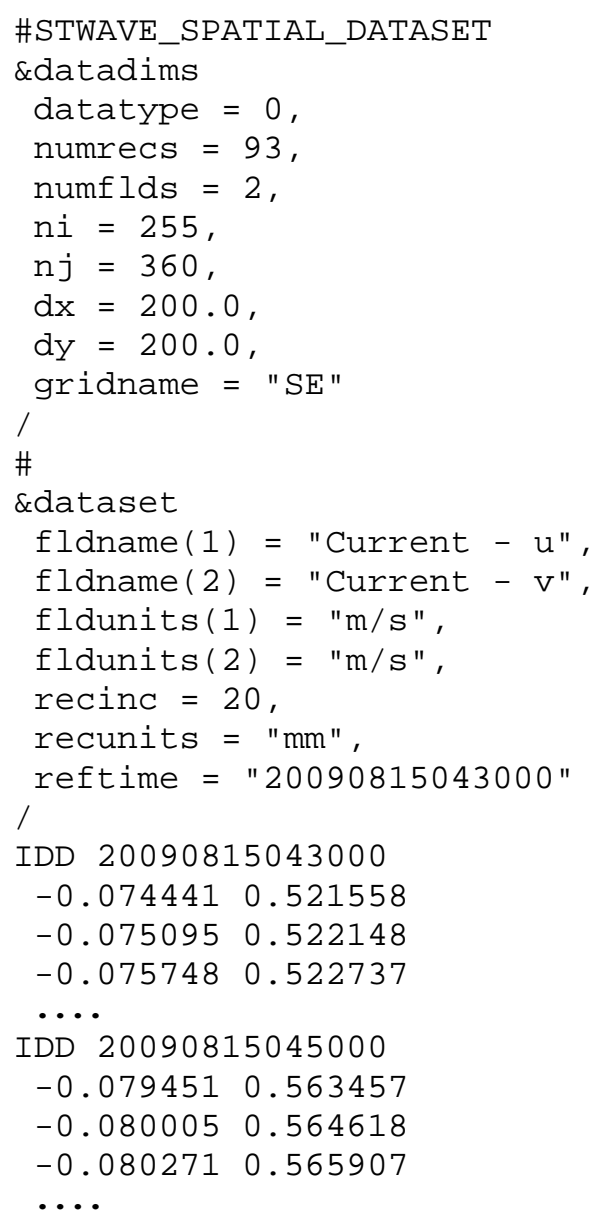




\section{Global Output: WAVE File}

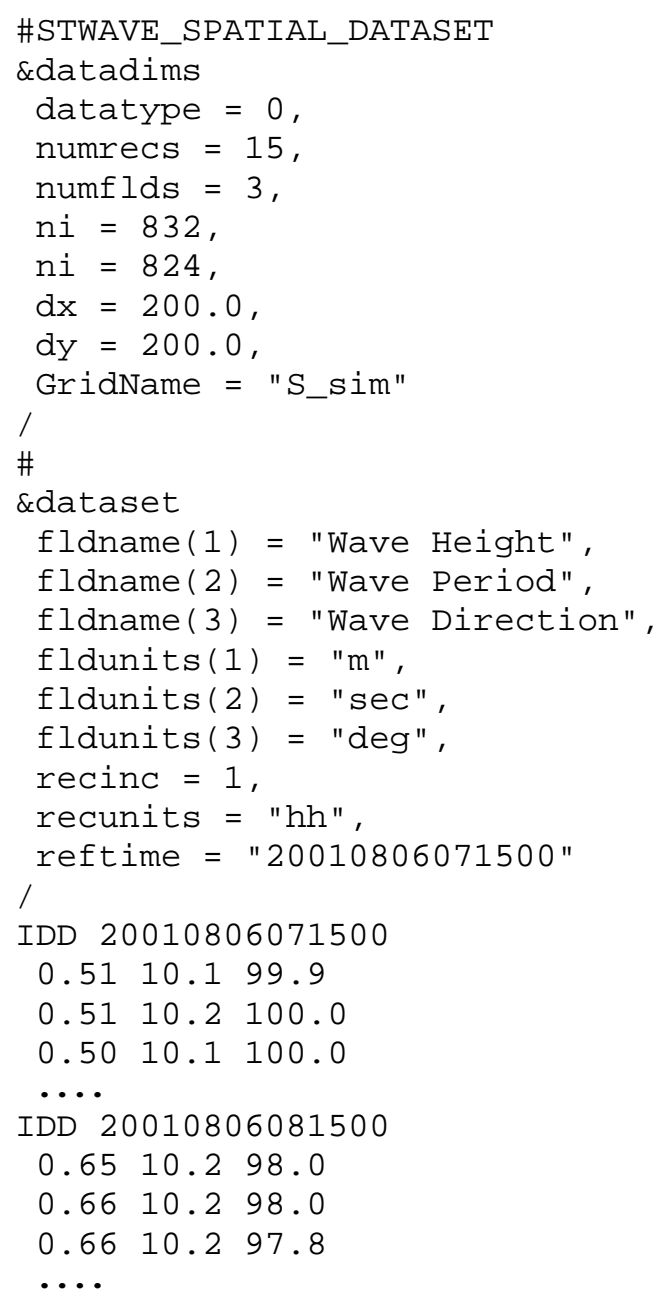




\section{Global Output: BREAK File}

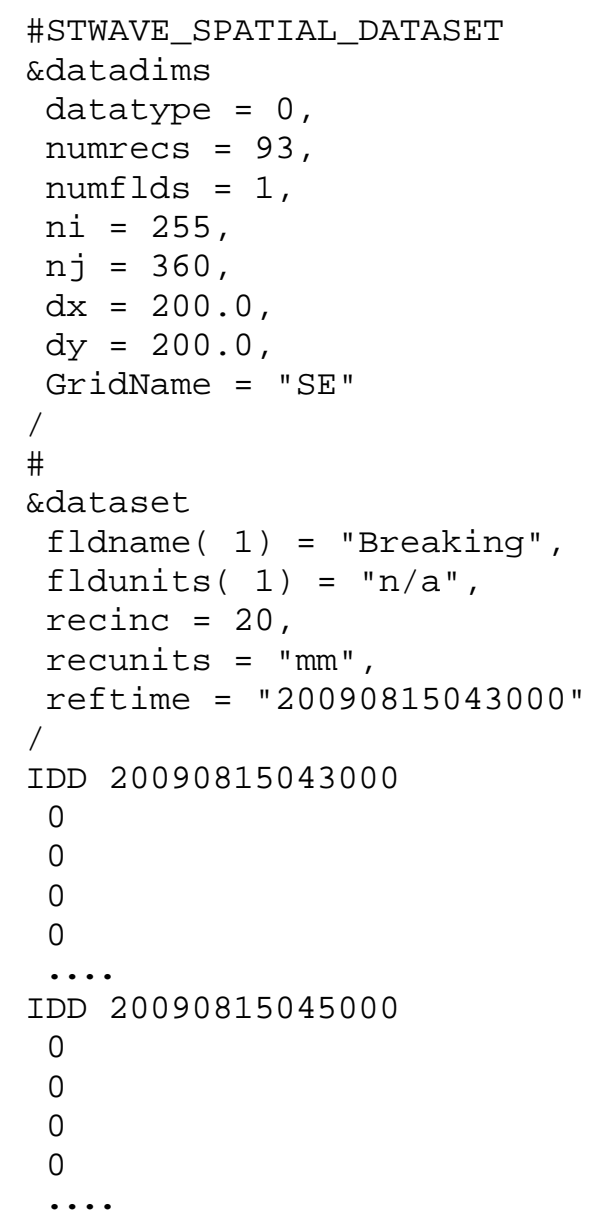




\section{Global Output: RADS File}

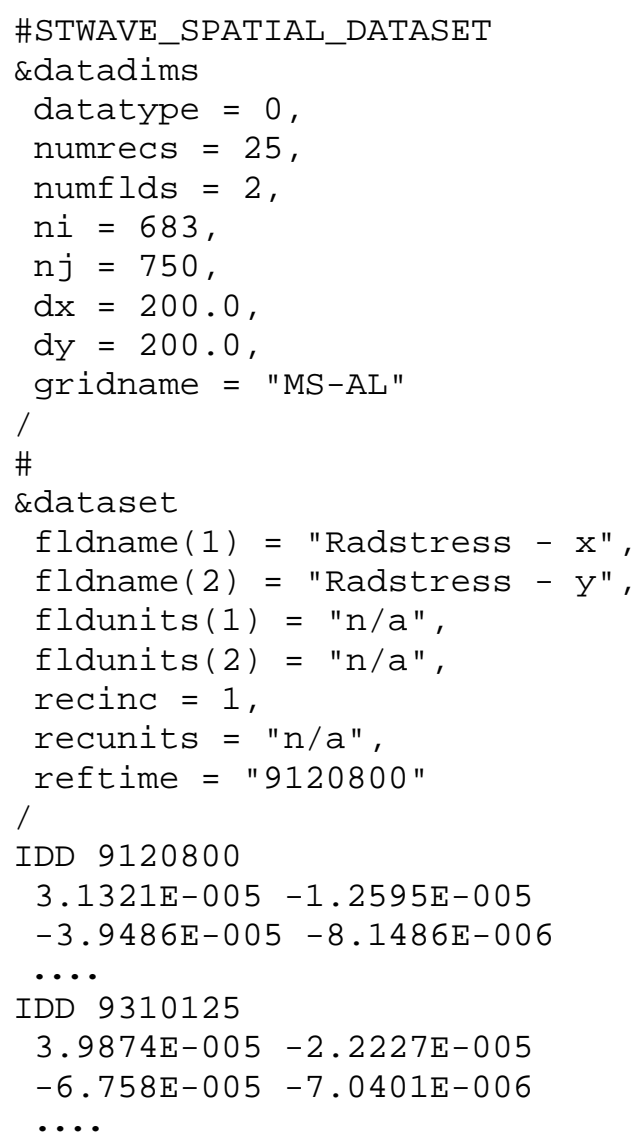




\section{Local Selected Points (I,J) : SELH File}

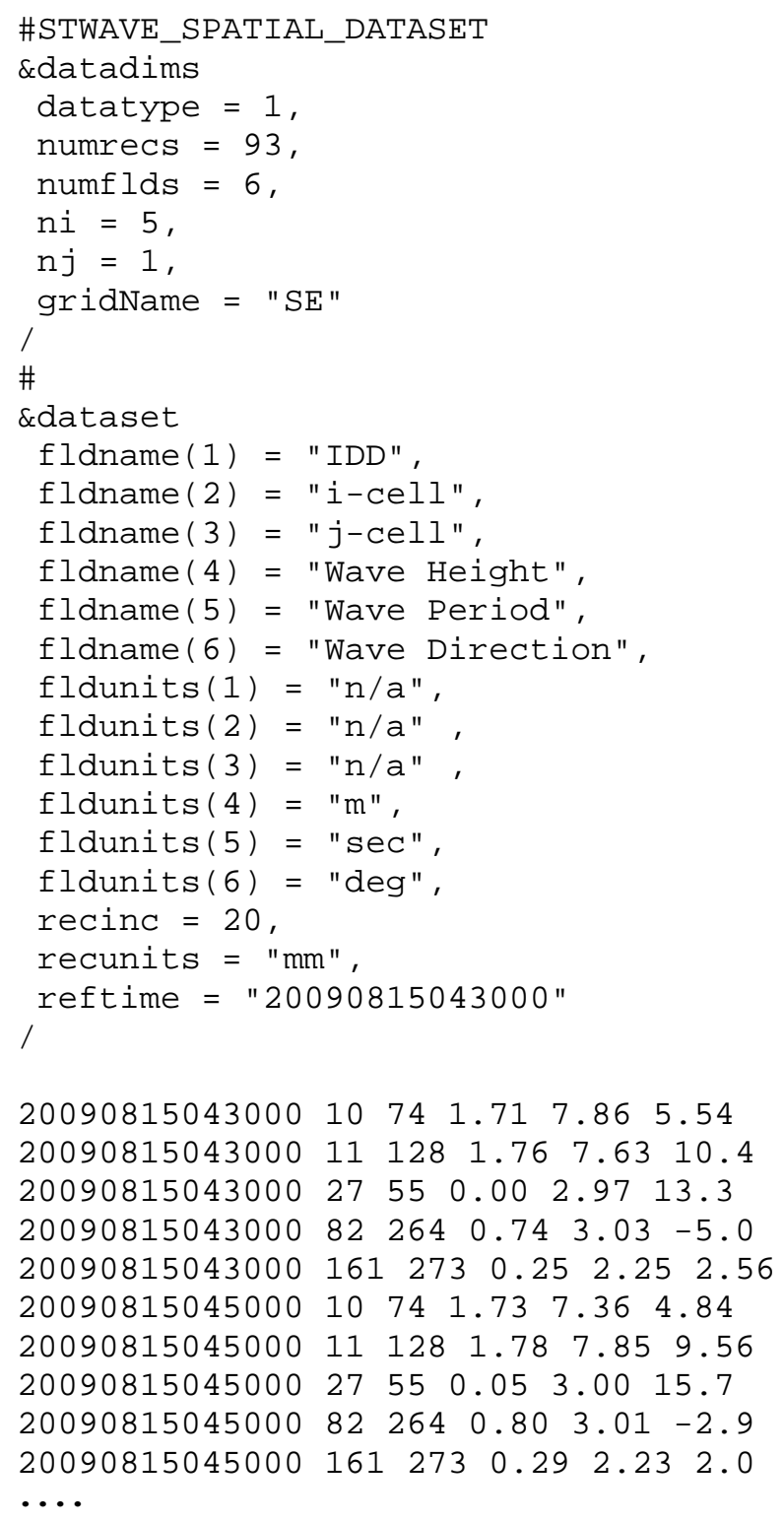




\section{Local Stations $(x, y)$ : STATION File}

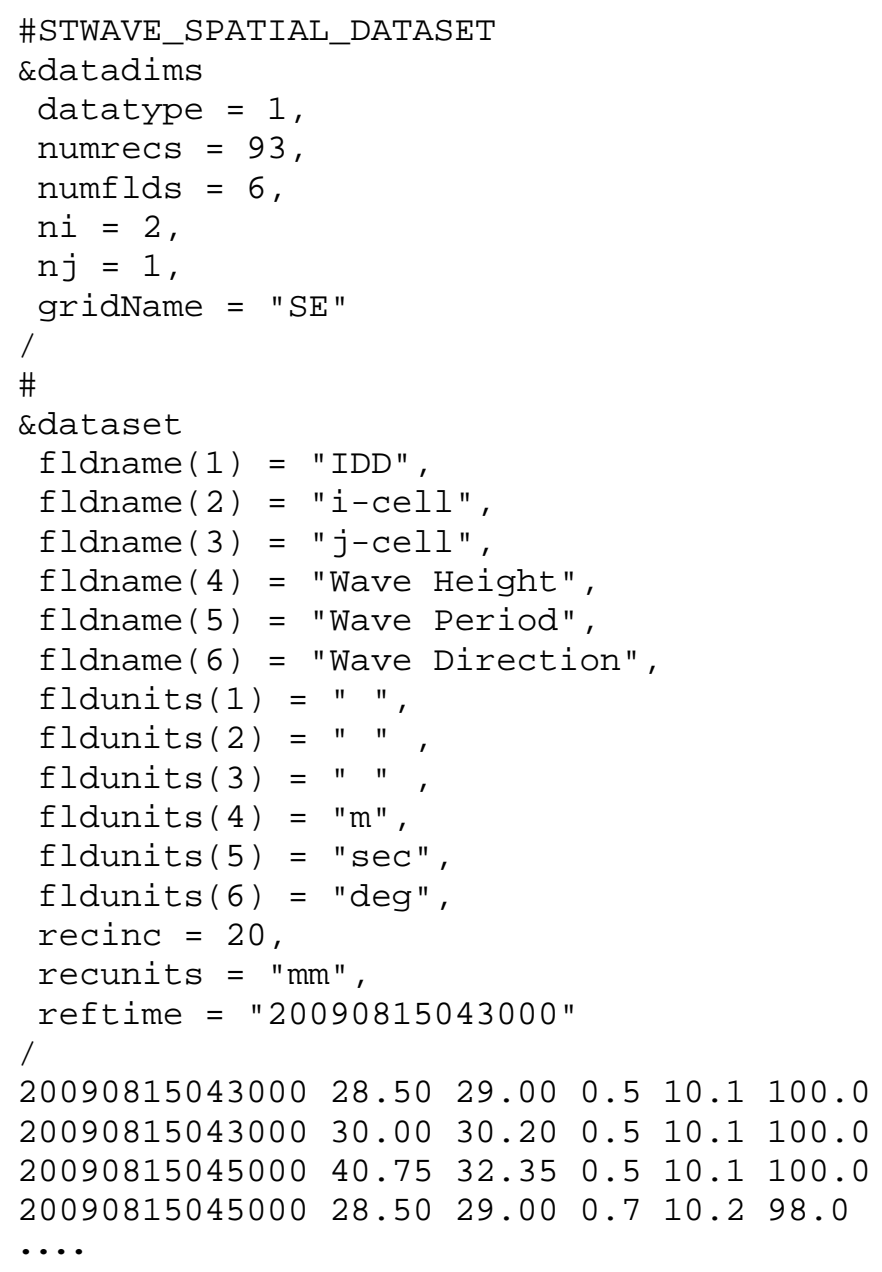




\section{Appendix C: Example STWAVE Spectral Files}

\section{SPEC File}

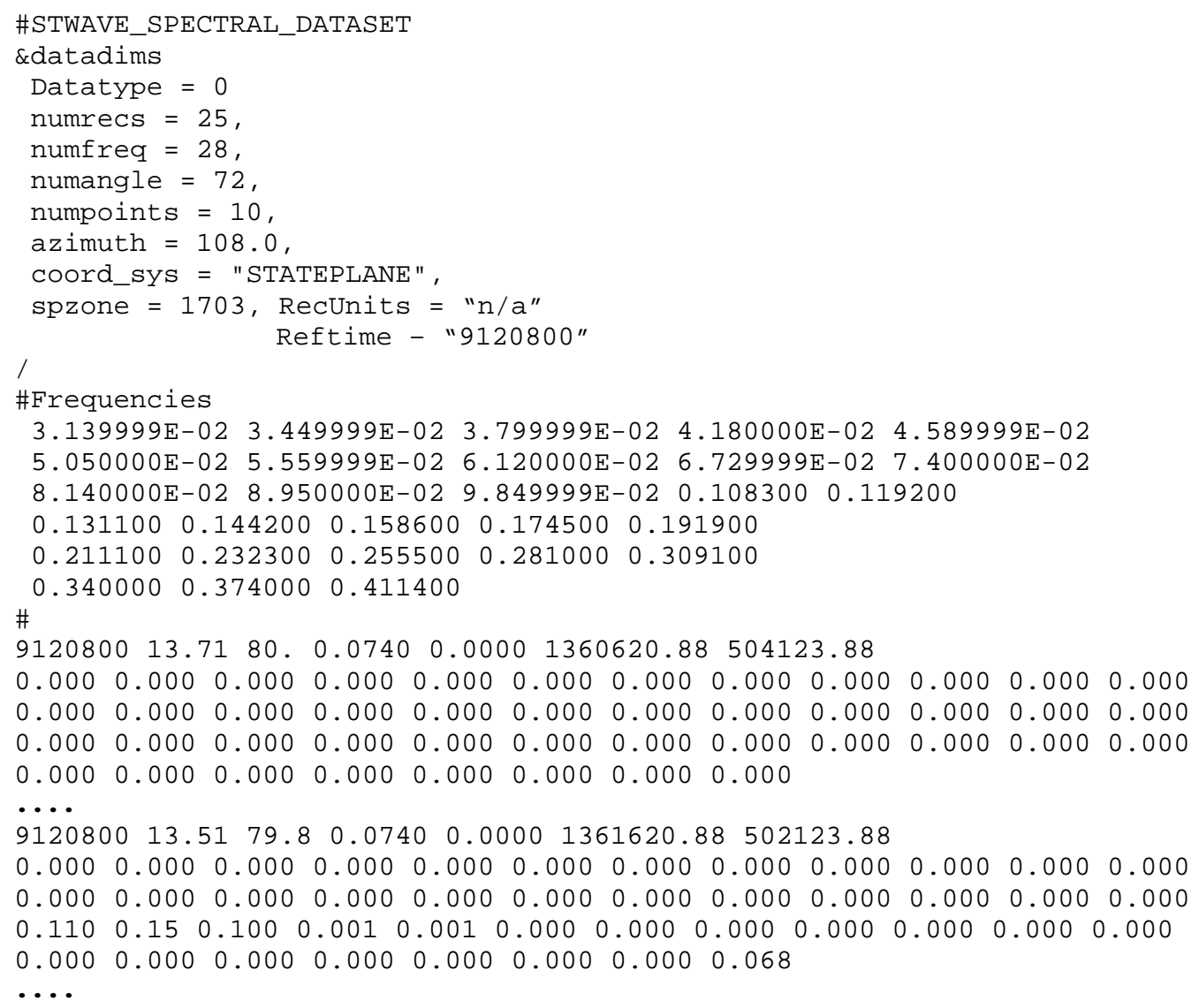




\section{OBSE and NEST File}

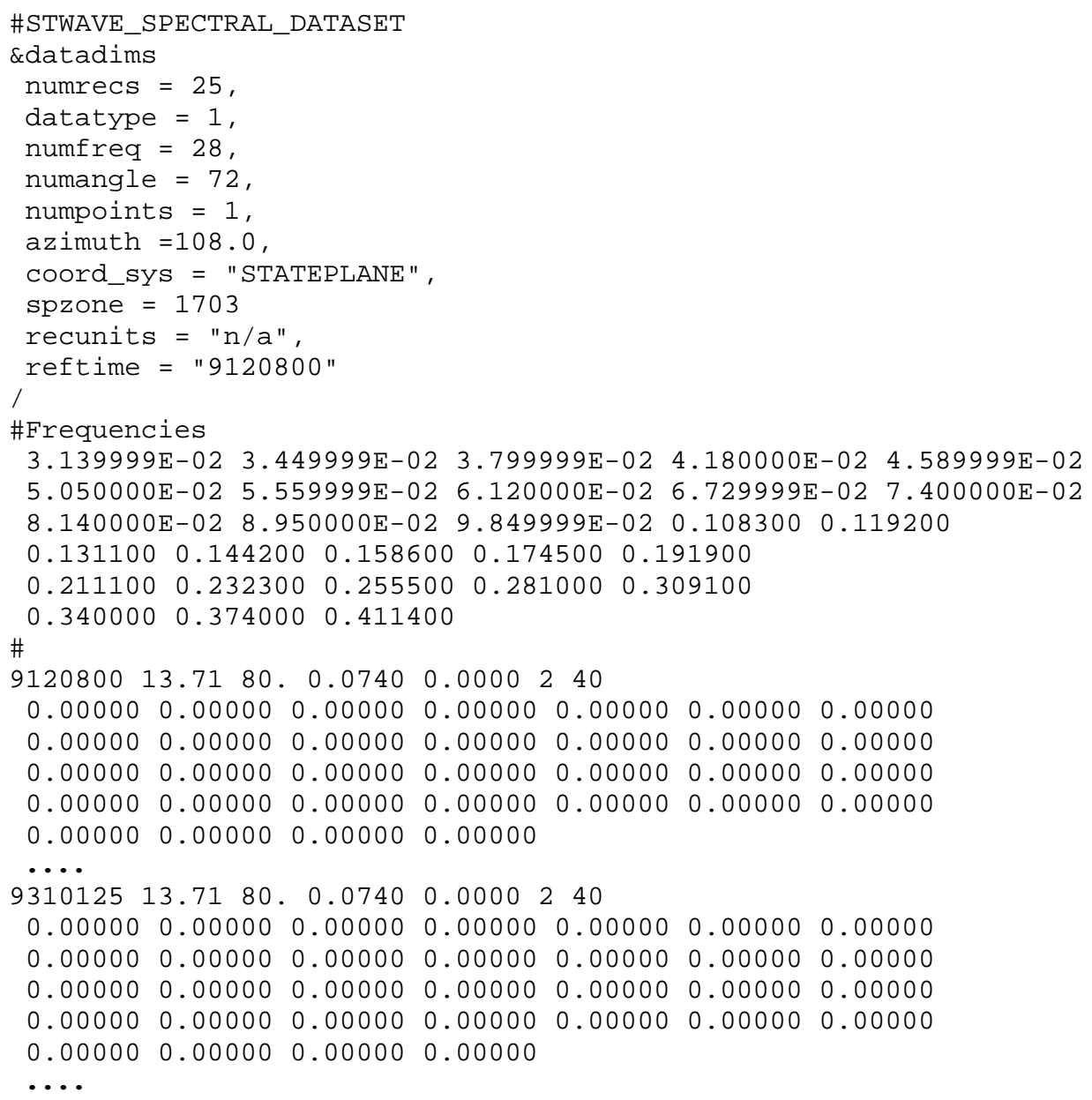




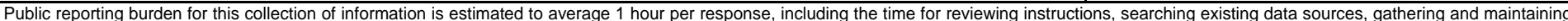

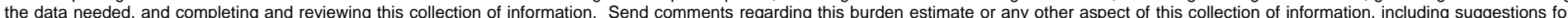

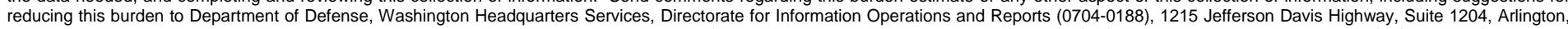

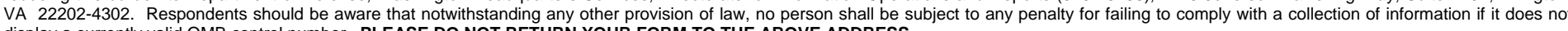
display a currently valid OMB control number. PLEASE DO NOT RETURN YOUR FORM TO THE ABOVE ADDRESS.

\begin{tabular}{l|c}
$\begin{array}{l}\text { 1. REPORT DATE (DD-MM-YYYY) } \\
\text { September } 2011\end{array}$ & $\begin{array}{c}\text { 2. REPORT TYPE } \\
\text { Final report }\end{array}$ \\
\hline
\end{tabular}

\section{TITLE AND SUBTITLE}

STWAVE: Steady-State Spectral Wave Model User’s Manual for STWAVE, Version 6.0

\section{AUTHOR(S)}

Thomas C. Massey, Mary E. Anderson, Jane McKee Smith, Julieta Gomez, and Rusty Jones

3. DATES COVERED (From - To)

5a. CONTRACT NUMBER

5b. GRANT NUMBER

5c. PROGRAM ELEMENT NUMBER

5d. PROJECT NUMBER

5e. TASK NUMBER

5f. WORK UNIT NUMBER

447JC7

8. PERFORMING ORGANIZATION REPORT NUMBER

ERDC/CHL SR-11-1

U.S. Army Engineer Research and Development Center

Coastal and Hydraulics Laboratory

3909 Halls Ferry Road

Vicksburg, MS 39180-6199

9. SPONSORING I MONITORING AGENCY NAME(S) AND ADDRESS(ES)

10. SPONSOR/MONITOR'S ACRONYM(S)

Headquarters, U.S. Army Corps of Engineers

Washington, DC 20314-1000

11. SPONSOR/MONITOR'S REPORT NUMBER(S)

\section{DISTRIBUTION / AVAILABILITY STATEMENT}

Approved for public release. Distribution is unlimited.

\section{SUPPLEMENTARY NOTES}

\section{ABSTRACT}

Estimating nearshore wave transformation and wind-wave growth is a critical component of many coastal engineering projects, e.g., predicting shoreline change, designing and maintaining coastal structures, and simulating coastal storm events. Performing physical model studies or gathering field data is not always a feasible option, and, as a result, the use of numerical models for simulating these complex coastal hydrodynamics has become a universal practice. STWAVE (STeady-state spectral WAVE), a nearshore spectral wave model, was originally developed by the U.S. Army Engineer Research and Development Center (ERDC), Coastal and Hydraulics Laboratory (CHL) to accurately simulate nearshore wave propagation and transformation including refraction, shoaling, breaking, and wind-wave generation. Recently, the CHL has further enhanced STWAVE to include both half-plane and full-plane capabilities within a single executable; improved and streamlined file formats; and made it Earth System Modeling Framework (ESMF) compliant which allows for easier coupling to other models. STWAVE now runs in serial mode as well as parallel in time or space on both personal computing (PC) and high-performance computing (HPC) systems. This report describes STWAVE version 6.0 capabilities, features, theory, and implementation. In depth descriptions of model parameters and examples of the new file formats are also provided.

\begin{tabular}{|l|c|c|c|c|c|}
\hline $\begin{array}{l}\text { 15. SUBJECT TERMS } \\
\text { STWAVE } \\
\text { Spectral }\end{array}$ & $\begin{array}{l}\text { Steady-state } \\
\text { Storm surge } \\
\text { Waves }\end{array}$ \\
\hline 16. SECURITY CLASSIFICATION OF: & & $\begin{array}{l}\text { 17. LIMITATION } \\
\text { OF ABSTRACT }\end{array}$ & $\begin{array}{l}\text { 18. NUMBER } \\
\text { OF PAGES }\end{array}$ & $\begin{array}{l}\text { 19a. NAME OF RESPONSIBLE } \\
\text { PERSON }\end{array}$ \\
\cline { 1 - 2 } $\begin{array}{l}\text { a. REPORT } \\
\text { UNCLASSIFIED }\end{array}$ & b. ABSTRACT & c. THIS PAGE & & $\begin{array}{l}\text { 19b. TELEPHONE NUMBER (include } \\
\text { area code) }\end{array}$ \\
& UNCLASSIFIED & & 89 & \\
\end{tabular}

